\title{
Falldefinitionen des Robert Koch-Instituts zur Übermittlung von Erkrankungs- oder Todesfällen und Nachweisen von Krankheitserregern
}

\author{
Ausgabe 2007 \\ gemäß $\int 4$ Abs. 2 des Gesetzes zur Verhütung und Bekämpfung \\ von Infektionskrankheiten beim Menschen \\ (Infektionsschutzgesetz - IfSG)
}




\section{Inhaltsverzeichnis}

Allgemeiner Teil

Abkürzungen

Hinweise zur Anwendung der Falldefinitionen

Struktur der Falldefinitionen

Falldefinitionskategorien

Referenzdefinition

Hilfestellung beim Umgang mit den Falldefinitionen

o1 Adenovirus im Konjunktivalabstrich (Adenovirus-Keratokonjunktivitis, Adenovirus-Konjunktivitis) 18

02 Bacillus anthracis (Milzbrand)

03 Borrelia recurrentis (Läuserückfallfieber)

04 Brucella spp. (Brucellose)

o5 Campylobacterspp., darmpathogen (Campylobacter-Enteritis) 26

o6 Chlamydophila psittaci (Ornithose)

o7a Creutzfeldt-Jakob-Krankheit (CJK) 30

o7b Variante CJK (vCJK) 33

08 Clostridium botulinum (Botulismus) 36

०9 Corynebacterium spp., Diphtherie-Toxin bildend (Diphtherie) 38

10 Coxiella burnetii (Q-Fieber) 40

Denguevirus (Denguefieber - virales hämorrhagisches Fieber)

13 Ebolavirus (Ebolafieber - virales hämorrhagisches Fieber)

14a Escherichia coli, enterohämorrhagisch (EHEC-Erkrankung)

14b Escherichia coli, sonstige darmpathogene Stämme (E.-coli-Enteritis)

15 Francisella tularensis (Tularämie) 52

16 FSME-Virus (Frühsommer-Meningoenzephalitis, FSME) 56

17 Gelbfiebervirus (Gelbfieber - virales hämorrhagisches Fieber) 58

18 Giardia lamblia (Giardiasis) 60

19 Haemophilus influenzae (invasive Haemophilus-influenzae-Erkrankung) 62

20 Hantavirus (Hantavirus-Erkrankung - virales hämorrhagisches Fieber) 64

24 Hepatitis-D-Virus (HDV - akute Virushepatitis D)

25 Hepatitis-E-Virus (HEV - akute Virushepatitis E)

26 Akute Virushepatitis Non A - E 76

27 Hämolytisch-urämisches Syndrom (HUS), enteropathisch

28 Influenzavirus (Influenza A, B oder C)

29 Lassavirus (Lassafieber - virales hämorrhagisches Fieber) 
$30 \quad$ Legionella spp. (Legionärskrankheit)

$31 \quad$ Leptospira interrogans (Leptospirose) $\quad 88$

$32 \quad$ Listeria monocytogenes (Listeriose) 90

33 Marburgvirus (Marburgfieber - virales hämorrhagisches Fieber) 94

34 Masernvirus (Masern) $\quad 96$

35 Mycobacterium leprae (Lepra) $\quad 98$

36 M.-tuberculosis-Komplex außer BCG (Tuberkulose) 100

37 Neisseria meningitidis (invasive Meningokokken-Erkrankung) 102

38 Norovirus (Norovirus-Gastroenteritis) 106

39 Poliovirus (Poliomyelitis) 108

40 Rabiesvirus, Lyssa-Virus (Tollwut) 110

$41 \quad$ Rickettsia prowazekii (Fleckfieber) 112

42 Rotavirus (Rotavirus-Erkrankung) 114

43 Salmonella Paratyphi A, B oder C (Paratyphus) 116

44 Salmonella Typhi (Typhus abdominalis) $\quad 118$

45 Salmonella spp., außer S. Typhi oder S. Paratyphi (Salmonellose) 120

46 Shigella spp. (Shigellose) 124

$47 \quad$ Trichinella spiralis (Trichinellose) 126

$\begin{array}{lll}48 & \text { Vibrio cholerae (Cholera) } & 128\end{array}$

49 Yersinia enterocolitica, darmpathogen (Yersiniose) 130

50 Yersinia pestis (Pest) 132

$51 \quad$ Andere Erreger hämorrhagischer Fieber (virale hämorrhagische Fieber) 134

$\begin{array}{ll}\text { Index } & 136\end{array}$ 


\section{Allgemeiner Teil}

\section{Abkürzungen}

a.E. $\quad \underline{a m}$ Ende

BAL Bronchoalveoläre Lavage (Luftröhren- und Lungenspülung)

BCG Bacille Calmette-Guérin

CJK $\quad$ Creutzfeldt-Jakob-Krankheit

CMV Cytomegalie-Virus

EBV Epstein- Barr-Virus

EEG Elektroenzephalogramm

EHEC Enterohämorrhagische Escherichia coli

ELISA Enzyme Linked Immunosorbent $\underline{\text { Assay }}$

HBsAg Hepatitis $\underline{B} \underline{\text { Surface }}$ Antigen

$\mathrm{HBC} \quad \underline{H}$ epatitis $\underline{\mathbf{B}}$ Core

HFRS Hämorrhagisches Fieber mit renalem Syndrom

HSV $\quad$ Herpes- implex-Virus

HUS $\quad \underline{H} a ̈ m o l y t i s c h-\underline{u r a ̈ m i s c h e s ~} \underline{S} y n d r o m$

IfSG Infektionsschutzgesetz

IFT Immunfluoreszenztest

ICD Io International Classification of Diseases oㅡ

KBR Komplementbindungsreaktion

LPS Lipopolysaccharide

MAT Mikroagglutinationstest

MIF Mikroimmunfluoreszenz

MOMP Major Outer Membrane Protein

MRT Magnetresonanztomographie

NT Neutralisationstest

o.n.A. ohne nähere Angabe

PCR Polymerase Chain Reaction

PGL $\quad \underline{P h e n o l g l y k o l i p i d e ~}$

PrP Prionprotein

RKI $\quad$ Robert Koch-Institut

SLA Serum-Langsam-Agglutination (Widal)

spp. $\quad$ species (Plural; bezeichnet alle Arten einer Gattung; gelegentlich (z.B. im IfSG) auch als sp.)

STEC $\quad$ Shigatoxin-bildende Escherichia coli

Stx $\quad \underline{\text { Shigatoxin }}$

syn. $\quad$ Synonym

VT $\quad$ Verocytotoxin

WHO World $\underline{\text { Health }}$ Organization (Weltgesundheitsorganisation) 


\section{Definition wiederholt verwendeter Begriffe}

In diesem Abschnitt sind Begriffe definiert, die im speziellen Teil der Falldefinitionen wiederholt verwendet werden. Sie sind dort durch ein vorangestelltes Dreieck $(\bullet)$ gekennzeichnet.

Deutlich erhöhter Wert, definiert als

- hinreichende Überschreitung des nach Maßgabe von Hersteller und Labor festgelegten Grenzwertes, um nach Auffassung des durchführenden Labors eine akute Infektion anzunehmen.

Deutliche Änderung zwischen zwei Proben, definiert als

- hinreichender Anstieg (oder in Einzelfällen Abfall) des maßgeblichen Laborwerts zwischen zwei in geeignetem zeitlichen Abstand entnommenen vergleichbaren Proben, um nach Auffassung des durchführenden Labors eine akute Infektion anzunehmen (z.B. negatives Ergebnis, gefolgt von positivem Ergebnis (z.B. ELISA) oder mindestens vierfacher Titeranstieg (z.B. KBR)).

Durchfall, definiert als

- $\geq 3$ ungeformte Stühle in 24 Stunden. Ersatzweise können auch die Auskunft des/der Betroffenen, der Pflegeperson oder des behandelnden Arztes, dass Durchfall vorgelegen habe, entsprechend gewertet werden.

Fieber, definiert als

- Körpertemperatur (unabhängig vom Ort der Messung) mindestens einmal $\geq 38,5^{\circ} \mathrm{C}$. Bei plausibler Beschreibung der typischen Fieberbeschwerden (z.B. Nachtschweiß) durch den Patienten können auch anamnestische Angaben ohne erfolgte Temperaturmessung entsprechend gewertet werden.

Grippeähnliche Beschwerden, definiert als mindestens zwei der vier folgenden Kriterien:

- Frösteln,

- schweres Krankheitsgefühl,

- Kopfschmerzen,

- Muskel-, Glieder- ODER Rückenschmerzen.

Hämorrhagische Verlaufsform, definiert als Vorliegen aller drei folgenden Kriterien:

- Thrombozytopenie $\leq \mathrm{I} 50.000$ Zellen $/ \mathrm{mm}^{3}$.

- Hämorrhagie, definiert als mindestens einer der vier folgenden Kriterien:

- Petechien, Ecchymosen ODER Purpura (Hauteinblutungen unterschiedlichen Grades),

- positiver Tourniquet-Test (gemäß WHO; Auslösung von Hauteinblutungen durch Abschnürung des Arms mit einer Blutdruckmanschette),

- Blutung aus Schleimhaut, Magen-Darm-Trakt, Injektions- oder anderen Stellen,

- Bluthusten ODER Melaena (Blutstuhl, auch Teerstuhl).

- Erhöhte Gefäßdurchlässigkeit, definiert als mindestens einer der drei folgenden Kriterien:

- Hämatokrit > 120\% des Normwertes,

- Absinken des Hämatokrit nach Volumenersatztherapie um $\geq 20 \%$ des Ausgangswertes,

- Anzeichen für Plasmaaustritt (z.B. Pleuraerguss, Aszitis, Hypoproteinämie). 
Kontakt, definiert als

- räumliche Nähe, bei der es gemäß epidemiologischer Erfahrung zu einer Erregerübertragung kommen kann.

Was einen epidemiologisch relevanten Kontakt darstellt, hängt wesentlich von den Übertragungseigenschaften des jeweiligen Erregers und den daraus resultierenden typischen Übertragungswegen ab. Auf weitergehende Differenzierungen wie „direkter Kontakt“ oder „enger Kontakt“ wurde bewusst verzichtet.

Lungenentzündung, definiert als mindestens einer der beiden folgenden Kriterien:

- Anzeichen einer Lungenentzündung in einer ärztlichen klinischen Untersuchung,

- radiologische Hinweise auf Lungenentzündung.

Nierenfunktionsstörung, definiert als mindestens einer der vier folgenden Kriterien:

- Einschränkung der Nierenfunktion (z.B. Serumkreatininerhöhung, Oligurie (verminderte Harnausscheidung, unter $500 \mathrm{ml} / 24 \mathrm{~h})$ ),

- Nierenversagen (z.B. Anurie (Harnausscheidung unter $100 \mathrm{ml} / 24$ h)),

- Proteinurie (Eiweißausscheidung im Urin),

- Hämaturie (blutiger Urin).

Normalerweise steriles klinisches Material/Substrat, definiert als

- Körpergewebe oder -flüssigkeit ohne Kontakt zu normalerweise von Mikroorganismen besiedelten äußeren (Haut) oder inneren (Verdauungstrakt, Atemwege) Körperoberflächen, z.B. Blut, Liquor, Urin, Fruchtwasser vor dem Blasensprung.

Nukleinsäure-Nachweis (z.B. PCR), definiert als

- Genamplifikation, gefolgt von einer geeigneten Spezifitätskontrolle (z.B. Sequenzierung).

Septisches Krankheitsbild, definiert als mindestens eines der beiden folgenden Kriterien:

- Vorliegen eines septischen Krankheitsbildes nach Einschätzung des behandelnden Arztes ODER

- Vorliegen aller vier folgenden Kriterien:

- Hyperthermie $\left(>38^{\circ} \mathrm{C}\right)$ oder Hypothermie $\left(<36^{\circ} \mathrm{C}\right)$,

- Hyperventilation (Atemfrequenz $>20 / \mathrm{min}$ ),

- Tachykardie (> 9०/min),

- Leukozytose (> I2.000), Leukopenie $(<4.000)$ ODER > IO\% Stabkernige. 
Epidemiologischer Zusammenhang Badegewässer, definiert als

- Kontakt mit demselben potentiell kontaminierten Gewässer.

Epidemiologischer Zusammenhang Lebensmittel, definiert als mindestens eine der beiden folgenden Expositionen:

- Verzehr potentiell kontaminierter Lebensmittel derselben Herkunft,

- Aufnahme (Trinken, Verschlucken) potentiell kontaminierter Flüssigkeit derselben Herkunft.

Epidemiologischer Zusammenhang Tierkontakt, definiert als mindestens eine der drei folgenden Expositionen:

- Kontakt mit denselben potentiell infizierten Tieren,

- Kontakt mit den potentiell kontaminierten Ausscheidungen oder Produkten derselben Tiere,

- Verzehr der potentiell kontaminierten Produkte derselben Tiere.

Lebendgeburt, Totgeburt und Fehlgeburt, definiert nach \29 der Verordnung zur Ausführung des Personenstandsgesetzes (PStGAV):

(I) Eine Lebendgeburt, für die die allgemeinen Bestimmungen über die Anzeige und die Eintragung von Geburten gelten, liegt vor, wenn bei einem Kind nach der Scheidung vom Mutterleib entweder das Herz geschlagen oder die Nabelschnur pulsiert oder die natürliche Lungenatmung eingesetzt hat.

(2) Hat sich keines der in Absatz I genannten Merkmale des Lebens gezeigt, beträgt das Gewicht der Leibesfrucht jedoch mindestens 500g, so gilt sie im Sinne des \2I Abs. 2 des Gesetzes als ein totgeborenes oder in der Geburt verstorbenes Kind.

(3) Hat sich keines der in Absatz I genannten Merkmale des Lebens gezeigt und beträgt das Gewicht der Leibesfrucht weniger als 5oog, so ist die Frucht eine Fehlgeburt. Sie wird in den Personenstandsbüchern nicht bekundet.

Frühgeburt, definiert nach medizinischem Sprachgebrauch und BAG-Urteil vom I2. März I997 (5 AZR 329/96):

Von einer Frühgeburt (Partus prämaturus) spricht man bei einem Geburtsgewicht von $500 \mathrm{~g}$ bis unter 2.500g oder bei einer Geburt vor der vollendeten 37. Schwangerschaftswoche. 


\section{Hinweise zur Anwendung der Falldefinitionen}

Die vorliegende dritte Ausgabe der Falldefinitionen gilt ab dem I. Januar 2007 und löst die zum Jahresanfang 2004 in Kraft getretene zweite Ausgabe der Falldefinitionen ab. Die neuen Falldefinitionen 2007 werden im Bundesgesundheitsblatt, Heft I2, Dezember 2006 veröffentlicht.

Eine Beschreibung der Änderungen der Falldefinitionen im Vergleich zur Ausgabe von 2004 ist in einer Version mit Randnotizen auf der Homepage des RKI veröffentlicht und als PDF-Dokument verfügbar (www.rki.de > Infektionsschutz > Infektionsschutzgesetz > Falldefinitionen).

\section{Wofür und für wen diese Falldefinitionen gedacht sind}

Gemäß $\llbracket 4$ Abs. 2 Nr. 2 Buchst. a IfSG hat das RKI die Aufgabe, Falldefinitionen zu erstellen, die die Kriterien für die Übermittlung vom Gesundheitsamt an die zuständige Landesbehörde und von dort an das RKI festlegen.

Die Falldefinitionen haben zum Ziel, bundesweit einheitliche Kriterien im Rahmen der epidemiologischen Überwachung von Infektionskrankheiten sicherzustellen. Damit sollen sie zu standardisierten Bewertungen, objektiveren Entscheidungen und letztlich aussagekräftigeren Statistiken beitragen. Vor dem Hintergrund dieser primär epidemiologischen Aufgabenstellung beschränken sich die Falldefinitionen weitgehend auf solche Kriterien, die für die Entscheidungsfindung zur Übermittlungspflicht notwendig sind.

Mitarbeiter der Gesundheitsämter entscheiden demnach anhand der Falldefinitionen, ob Erkrankungsoder Todesfälle bzw. Nachweise von Krankheitserregern, die ihnen gemeldet oder anderweitig bekannt wurden, an die zuständige Landesbehörde zu übermitteln sind.

Die Zielgruppe dieser Falldefinitionen sind deshalb primär die Gesundheitsaufseher, Hygieneinspektoren und andere nicht-ärztlichen Mitarbeiter der Gesundheitsämter, die die Entscheidung zur Übermittlung hauptsächlich treffen.

\section{Wofür diese Falldefinitionen nicht gedacht sind}

Die Falldefinitionen legen nicht die Kriterien für die Meldung an das Gesundheitsamt fest. Sie richten sich deshalb nicht an klinisch oder labordiagnostisch tätige Ärzte. Auf keinen Fall sollten die Falldefinitionen als Empfehlungen zum diagnostischen Vorgehen in Klinik oder Labor missverstanden werden.

Auf eine umfassende Beschreibung des Krankheitsbildes oder differentialdiagnostische Erwägungen wird bewusst verzichtet, um nicht von der eigentlichen Funktion der Falldefinitionen als Entscheidungsinstrument für die Übermittlung abzulenken.

\section{Warum eine neue Ausgabe der Falldefinitionen?}

Die vorliegenden Erfahrungen bei der Anwendung der Falldefinitionen in der täglichen Praxis zeigen, dass diese innerhalb des Öffentlichen Gesundheitsdienstes gut angenommen wurden und ihre Funktion erfüllt haben.

Eine Überarbeitung der Falldefinitionen war jedoch notwendig geworden, um der fortschreitenden Entwicklung der Labormethoden Rechnung zu tragen und die Kriterien der Übermittlung zu präzisieren bzw. zu vereinheitlichen.

Die daraus folgenden strukturellen und inhaltlichen Änderungen der Falldefinitionen haben zum Ziel, Fehlinterpretationen im Umgang mit ihnen zu vermeiden und den Bearbeitungsaufwand für die Gesundheitsämter zu reduzieren. 


\section{Grundlagen für die Überarbeitung der Falldefinitionen}

Das RKI hat interne und externe Experten in die Überarbeitung der Falldefinitionen eingebunden, dazu gehören die Nationalen Referenzzentren, die Konsiliarlabore, die Beauftragten für den Infektionsschutz und die Epidemiologen der Bundesländer sowie Amtsärzte in Gesundheitsämtern.

Die Berücksichtigung der Kommentare erfolgte mit der Absicht, einerseits einen breiten fachlichen Konsens und andererseits eine hohe Anwenderfreundlichkeit für die Gesundheitsämter herzustellen.

Weiterhin wurden gezielte Recherchen in der Fachliteratur und in den Falldefinitionen anderer nationaler oder internationaler Einrichtungen durchgeführt.

Hinweise für Korrekturen oder andere Verbesserungsmöglichkeiten der hier vorliegenden Falldefinitionen sind stets willkommen. Bitte richten Sie diese an Frau PD Dr. G. Poggensee (PoggenseeG@rki.de), Postanschrift:

Robert Koch-Institut

Abteilung für Infektionsepidemiologie (Abt. 3)

Fachgebiet Surveillance (FG 32)

Seestr. Io

I3353 Berlin 


\section{Struktur der Falldefinitionen}

Für jede Übermittlungskategorie (in der Regel ein übermittlungspflichtiger Erreger und die von ihm verursachte Krankheit) liegt eine Falldefinition vor, die derselben einheitlichen Struktur folgt.

\section{Titel der Falldefinition}

Der Titel der Übermittlungskategorie richtet sich in der Regel nach der Erregerbezeichnung, gefolgt von der Krankheitsbezeichnung. Die Falldefinitionen sind nach diesem Titel alphabetisch geordnet.

\section{Einordnung nach ICD 10}

Um die Vergleichbarkeit mit anderen Gesundheitsstatistiken und -indikatoren zu unterstützen, sind die 4-stelligen Kodierungen der Internationalen Krankheitsklassifikation ICD ıo aufgeführt, die der Übermittlungskategorie entsprechen.

Dabei ist jedoch zu beachten, dass ICD-Io-Kodierungen nicht in dem Detail definiert sind wie die Falldefinitionen. Da die ICD ıo nicht primär der infektionsepidemiologischen Überwachung dient, sind die Falldefinitionen oftmals nicht eindeutig in ICD-Io-Kodierungen abbildbar, noch ist dies umgekehrt immer möglich.

\section{Ausschlusskriterien}

Die Ausschlusskriterien dienen der frühzeitigen Ablehnung eines Falles bezüglich seiner Übermittlung. Oft finden sich hier Kriterien, die sich aus dem Gesetzestext ergeben oder die der gegenseitigen Abgrenzung zweier Übermittlungskategorien dienen. Treffen bei einem Fall die Ausschlusskriterien zu, so muss der übrige Teil der Falldefinition nicht mehr geprüft werden, weil eine Übermittlung ohnehin abzulehnen ist.

\section{Evidenztypen}

Bei den weiteren Kriterien wird zwischen drei verschiedenen Evidenztypen unterschieden. Kriterien, die wiederholt bei verschiedenen Falldefinitionen auftreten, werden eingangs in dem Kapitel 'Definition wiederholt verwendeter Begriffe' definiert. Sie sind in der Falldefinition durch ein vorangestelltes Dreieck $($ ) gekennzeichnet, so dass leicht erkennbar ist, wenn ein Begriff genauer definiert ist.

\section{Klinisches Bild}

Hier sind die klinischen Symptome, Zeichen, Befunde und anamnestischen Angaben aufgeführt, die je nach Übermittlungskategorie einzeln oder in Kombination zutreffen müssen, damit der Evidenztyp 'klinisches Bild' erfüllt ist. Dies wird in der Übermittlungssoftware entsprechend eingetragen.

Unter dem Evidenztyp 'klinisches Bild' können unter Umständen auch Laborbefunde aufgeführt sein, sofern diese nicht direkte oder indirekte Erregernachweise darstellen.

Bei der Auswahl der Kriterien wurde versucht, ein ausgeglichenes Verhältnis von Sensitivität und Spezifität herzustellen. Bei Vorliegen eines labordiagnostischen Nachweises ist eine hohe Sensitivität des klinischen Bildes (d.h. geringe Anforderungen an die Symptomatik) wichtig. Bei epidemiologisch bestätigten Erkrankungen ohne labordiagnostischen Nachweis ist dagegen eine hohe Spezifität des klinischen Bildes zu fordern. Diese an epidemiologischen Bedürfnissen orientierte Balance ist naturgemäß eine andere als bei individualdiagnostischen Entscheidungen mit therapeutischen Konsequenzen.

Es wurde bewusst darauf verzichtet, Symptome in ihrer krankheitsspezifischen Komplexität darzustellen. So gibt es bei einigen Krankheiten z.B. recht typische Fieberverläufe, die differentialdiagnostisch hinweisend sind. Jedoch ist es selten, dass Symptome entsprechend differenziert gemeldet werden, und schwierig, die fehlenden Angaben zu erfragen. Deshalb werden in den Falldefinitionen bevorzugt undifferenziertere Angaben wie 'Fieber' verwendet. 
Generell sind bei der Bewertung des klinischen Bildes nur solche Symptome und Zeichen zu berücksichtigen, die in einem sinnvollen zeitlichen Zusammenhang zur vermuteten Infektion oder zur Materialentnahme bei labordiagnostischen Nachweisen stehen und die nicht vollständig durch eine andere Diagnose erklärt sind.

\section{Labordiagnostischer Nachweis}

Hier sind die direkten, indirekten und anderen Nachweise aufgeführt, die als Kriterien für die Übermittlung zugelassen sind. Auch hier gilt, dass je nach Übermittlungskategorie festgelegt ist, ob Erregernachweise einzeln oder in Kombination notwendig sind.

\section{Art des Nachweises}

Die Art des Nachweises unterscheidet zwischen direkten und indirekten (serologischen) Erregernachweisen. Direkte Nachweise zeigen die Anwesenheit des Erregers oder seiner Bestandteile an. Dabei kann es sich um intakte lebens- und vermehrungsfähige Erreger handeln, möglicherweise aber auch nur um Bruchteile der Zellwand oder Erbsubstanz. Indirekte Nachweise zeigen die Immunantwort des menschlichen Organismus auf eine Infektion mit dem betreffenden Erreger an. Bei einigen Krankheiten kommen zusätzlich Toxinnachweise oder histologische bzw. pathologische Nachweise vor.

Obwohl direkte Nachweise im Allgemeinen eine höhere Aussagekraft hinsichtlich akuter (im Sinne „gegenwärtiger“) Infektionen haben, stellt die Reihenfolge der Nachweisnennungen keine Rangfolge hinsichtlich des diagnostischen Werts dar. Die Art des Nachweises ist den Einzelkriterien in eckiger Klammer vorangestellt, um zu verdeutlichen, dass dieser Hinweis selbst keine der zu bewertenden Methoden darstellt.

\section{Material}

Sofern in der Falldefinition keine Angaben zum Material gemacht werden, bedeutet dies, dass jedes beliebige klinische Material für den entsprechenden Nachweis zulässig ist. Einschränkungen auf bestimmte Untersuchungsmaterialien werden nur dann formuliert, wenn Erregernachweise in anderen Materialien entweder nicht auf eine akute Infektion, sondern z.B. auf eine Kontamination hinweisen, oder wenn entsprechende Einschränkungen durch das IfSG vorgegeben sind. Die Hinweise auf das Material sind durch Formatierung in halbfett hervorgehoben. Wenn sich die Anforderungen an das Material auf mehrere Methoden beziehen, so finden sich diese in der jeweils übergeordneten Gliederungsebene, also zum Teil hinter der Art des Nachweises. Die Tatsache, dass sie dort in eckige Klammern gesetzt sind, soll ihre Bedeutung nicht mindern.

\section{Nachweismethode}

Grundsätzlich wird erwartet, dass nur solche Erregernachweise gemeldet werden, die mittels ausreichend validierter Verfahren erfolgt sind. Dies gilt insbesondere für seltene Erreger, deren Nachweise nicht als Routinemethoden etabliert sind. Die Verantwortung hierfür trägt das ausführende Labor. Leitlinien hierzu werden in der Regel von den entsprechenden Fachgesellschaften herausgegeben.

\section{Ausführendes Labor}

Grundsätzlich werden in den Falldefinitionen keine Aussagen darüber gemacht, in welchen Laboren oder unter welchen Bedingungen (z.B. Sicherheitsstufen, Teilnahme an Ringversuchen) die Erregernachweise erfolgen sollen.

\section{Feindifferenzierung}

Die Feindifferenzierung des Erregers ist im Allgemeinen kein Kriterium der Übermittlung. Die Bestimmung der Spezies und ggf. von Subspezies, Serovar, Lysotyp und weiteren Charakterisierungen sind aber für Belange der Surveillance von großer Bedeutung. Derartige Zusatzinformationen sollten - sofern sie vorliegen oder ermittelbar sind - vom Gesundheitsamt in jedem Fall übermittelt werden.

(Vergl. 』II Abs. I Nr. 5 IfSG.) 


\section{Epidemiologische Bestätigung}

Bei diesem Evidenztyp wird explizit genannt, welche epidemiologischen Zusammenhänge und Expositionen als epidemiologische Bestätigung anerkannt werden.

Die epidemiologische Bestätigung darf nicht mit dem epidemiologischen Zusammenhang im Sinne einer Zuordnung zu einem Ausbruchsgeschehen bzw. Herd verwechselt werden. Ein Fall kann durchaus Teil eines Herdes sein, ohne dass die Kriterien der epidemiologischen Bestätigung erfüllt sind, z.B. wenn zu keinem der Fälle des Herdes ein labordiagnostischer Nachweis vorliegt. Ebenso ist die epidemiologische Bestätigung eines Falles möglich, der keinem registrierten Herd angehört, z.B. wenn der Erreger in einem Tier oder Lebensmittel nachgewiesen wurde und keine weiteren Personen betroffen sind. In der Praxis gehen Zuordnung zu einem Herd und epidemiologische Bestätigung allerdings oft Hand in Hand.

\section{Übertragungswege}

Für Mensch-zu-Mensch-Übertragungen kommen u.a. folgende Übertragungswege in Betracht:

- fäkal-oral (z.B. durch Schmierinfektionen z.B. im Kindergarten, beim Wickeln von Säuglingen oder Kleinkindern),

- respiratorisch (Tröpfcheninfektion, z.B. Anhusten oder -niesen, Küssen),

- Sexualkontakt,

- Blut (z.B. durch kontaminierte Spritzen bei i.v.-Drogengebrauch).

Mensch-zu-Mensch-Übertragungen können auch als nosokomiale Infektionen z.B. in Krankenhäusern vorkommen.

\section{Reiseanamnese}

Der Aufenthalt in einem typischen Endemiegebiet allein ist kein Kriterium der epidemiologischen Bestätigung. Die Reiseanamnese (d.h. Angaben zu den Aufenthaltsländern unter Berücksichtigung der Inkubationszeit) sollte aber - sofern sie vorliegt oder ermittelbar ist - vom Gesundheitsamt in jedem Fall übermittelt werden. (Vergl. \II Abs. I Nr. 7 IfSG.)

Auf Angaben zur geographischen Verbreitung von Erregern wurde in den Falldefinitionen bewusst verzichtet, um Angaben zur Reiseanamnese nicht zu beeinflussen und so das Erkennen neuer oder bislang unbekannter Endemiegebiete nicht zu erschweren.

\section{Inkubationszeiten}

Die Angaben zu Inkubationszeiten wurden einer Reihe von Standardwerken entnommen. Bei widersprüchlichen Angaben wurde das weiteste Intervall für die Inkubationszeit angegeben, das sich aus den Daten dieser Quellen ergab.

\section{Gesetzliche Grundlage}

$\mathrm{Zu}$ jeder Falldefinition wird die gesetzliche Grundlage für Meldepflicht und Übermittlung genannt. Hierbei wird auch der Unterschied zwischen Meldung und Übermittlung deutlich. Der Begriff 'Meldung' bezeichnet die Information des zuständigen Gesundheitsamtes - bzw. bei Erregernachweisen gemäß \7 Abs. 3 IfSG des RKI - durch den Meldepflichtigen. Der Begriff 'Übermittlung' hingegen bezeichnet die Informationsweitergabe vom Gesundheitsamt über die Landesbehörde an das RKI. Mit Ausnahme der Sachverhalte nach \6 Abs. I Nr. 2 IfSG, \6 Abs. I Nr. 5 IfSG und $\ 7$ Abs. 2 IfSG, die nicht erreger- oder krankheitsspezifisch definiert sind, enthalten die vorliegenden Falldefinitionen alle nach IfSG übermittlungspflichtigen Sachverhalte. 


\section{Falldefinitionskategorien}

Die o.g. Evidenztypen werden für die Veröffentlichung der Daten in fünf verschiedene Falldefinitionskategorien zusammengeführt. Diese Einordnung wird von der Übermittlungssoftware auf der Grundlage der Einträge, die zu den einzelnen Evidenztypen gemacht wurden, automatisch vorgenommen.

Die nachfolgend verwendeten Begriffe 'klinisches Bild', 'labordiagnostischer Nachweis' und 'epidemiologische Bestätigung' beziehen sich auf den jeweils zuvor definierten Evidenztyp. Der Begriff 'labordiagnostischer Nachweis' meint hier also immer den Erregernachweis bei dem zu übermittelnden Fall.

\section{A. Klinisch diagnostizierte Erkrankung}

Klinisches Bild einer akuten Erkrankung an der ausgewählten Krankheit, ohne labordiagnostischen Nachweis und ohne epidemiologische Bestätigung.

Diese Kategorie ist nur bei einem kleinen Teil der Krankheiten anwendbar.

\section{Tabelle A:}

Kombinationen der Antwortmöglichkeiten in den drei Evidenztypen, die die Falldefinitionskategorie 'klinisch diagnostizierte Erkrankung' ergeben:

Antwortmöglichkeit in der Übermittlungssoftware

\begin{tabular}{l|c|c|c|c|c|}
\multirow{2}{*}{ Evidenztyp } & Ja & Nein & $\begin{array}{c}\text { Nicht } \\
\text { erhoben }\end{array}$ & $\begin{array}{c}\text { Nicht } \\
\text { ermittelbar }\end{array}$ & $\begin{array}{c}\text { Nicht } \\
\text { anwendbar }\end{array}$ \\
\hline Klinisches Bild & $\mathrm{X}$ & - & - & - & - \\
\cline { 2 - 5 } $\begin{array}{l}\text { Labordiagnostischer Nachweis } \\
\text { Epidemiologische Bestätigung }\end{array}$ & - & \multicolumn{3}{|c|}{$\mathrm{X}$ (in einer der vier Spalten) } \\
\cline { 2 - 5 } & - & \multicolumn{3}{|c|}{$X$ (in einer der vier Spalten) } \\
\cline { 2 - 5 }
\end{tabular}

\section{B. Klinisch-epidemiologisch bestätigte Erkrankung}

Klinisches Bild einer akuten Erkrankung an der ausgewählten Krankheit, ohne labordiagnostischen Nachweis, aber mit epidemiologischer Bestätigung.

Wird bei einem solchen Fall der labordiagnostische Nachweis nachträglich erbracht, wird er zu einem klinisch-labordiagnostisch bestätigten Fall umgesetzt.

\section{Tabelle B:}

Kombinationen der Antwortmöglichkeiten in den drei Evidenztypen, die die Falldefinitionskategorie 'klinisch-epidemiologisch bestätigte Erkrankung' ergeben:

Antwortmöglichkeit in der Übermittlungssoftware

\begin{tabular}{l|c|c|c|c|c|}
\multirow{2}{*}{ Evidenztyp } & Ja & Nein & $\begin{array}{c}\text { Nicht } \\
\text { erhoben }\end{array}$ & $\begin{array}{c}\text { Nicht } \\
\text { ermittelbar }\end{array}$ & $\begin{array}{c}\text { Nicht } \\
\text { anwendbar }\end{array}$ \\
\hline Klinisches Bild & $\mathrm{X}$ & - & - & - & - \\
Labordiagnostischer Nachweis & - & \multicolumn{4}{|c|}{$\mathrm{X}$ (in einer der vier Spalten) } \\
\cline { 2 - 6 } Epidemiologische Bestätigung & $\mathrm{X}$ & - & - & - & - \\
\cline { 2 - 6 }
\end{tabular}




\section{Klinisch-labordiagnostisch bestätigte Erkrankung}

Klinisches Bild einer akuten Erkrankung an der ausgewählten Krankheit und labordiagnostischer Nachweis.

Für Fälle mit labordiagnostischem Nachweis ist es unerheblich, ob eine epidemiologische Bestätigung vorliegt.

Tabelle C:

Kombinationen der Antwortmöglichkeiten in den drei Evidenztypen,

die die Falldefinitionskategorie 'klinisch-labordiagnostisch bestätigte Erkrankung' ergeben:

Antwortmöglichkeit in der Übermittlungssoftware

\begin{tabular}{l|c|c|c|c|c|}
\multirow{2}{*}{ Evidenztyp } & Ja & Nein & $\begin{array}{c}\text { Nicht } \\
\text { erhoben }\end{array}$ & $\begin{array}{c}\text { Nicht } \\
\text { ermittelbar }\end{array}$ & $\begin{array}{c}\text { Nicht } \\
\text { anwendbar }\end{array}$ \\
\hline Klinisches Bild & $\mathrm{X}$ & - & - & - & - \\
Labordiagnostischer Nachweis & $\mathrm{X}$ & - & - & - & - \\
\cline { 2 - 6 } & Epidemiologische Bestätigung & \multicolumn{5}{|c|}{$\mathrm{X}$ (in einer der fünf Spalten) } \\
\cline { 2 - 6 }
\end{tabular}

\section{Labordiagnostisch nachgewiesene Infektion bei nicht erfülltem klinischen Bild}

Labordiagnostischer Nachweis bei bekanntem klinischen Bild, das die Kriterien für eine akute Erkrankung an der ausgewählten Krankheit nicht erfüllt. Hierunter fallen auch asymptomatische Infektionen.

Für Fälle mit labordiagnostischem Nachweis ist es unerheblich, ob eine epidemiologische Bestätigung vorliegt.

Tabelle D:

Kombinationen der Antwortmöglichkeiten in den drei Evidenztypen, die die Falldefinitionskategorie 'labordiagnostisch nachgewiesene Infektion bei nicht erfülltem klinischen Bild' ergeben:

Antwortmöglichkeit in der Übermittlungssoftware

\begin{tabular}{l|c|c|c|c|c|}
\multirow{2}{*}{ Evidenztyp } & Ja & Nein & $\begin{array}{c}\text { Nicht } \\
\text { erhoben }\end{array}$ & $\begin{array}{c}\text { Nicht } \\
\text { ermittelbar }\end{array}$ & $\begin{array}{c}\text { Nicht } \\
\text { anwendbar }\end{array}$ \\
\hline Klinisches Bild & - & $\mathrm{X}$ & - & - & - \\
Labordiagnostischer Nachweis & $\mathrm{X}$ & - & - & - & - \\
\cline { 2 - 6 } Epidemiologische Bestätigung & \multicolumn{5}{|c}{$\mathrm{X}$ (in einer der fünf Spalten) } \\
\cline { 2 - 6 }
\end{tabular}




\section{E. Labordiagnostisch nachgewiesene Infektion bei unbekanntem klinischen Bild}

Labordiagnostischer Nachweis bei fehlenden Angaben zum klinischen Bild (nicht ermittelbar oder nicht erhoben).

Für Fälle mit labordiagnostischem Nachweis ist es unerheblich, ob eine epidemiologische Bestätigung vorliegt.

\section{Tabelle E:}

Kombinationen der Antwortmöglichkeiten in den drei Evidenztypen, die die Falldefinitionskategorie 'labordiagnostisch nachgewiesene Infektion bei unbekanntem klinischen Bild' ergeben:

Antwortmöglichkeit in der Übermittlungssoftware

\begin{tabular}{l|c|c|c|c|c|}
\multirow{2}{*}{ Evidenztyp } & Ja & Nein & $\begin{array}{c}\text { Nicht } \\
\text { erhoben }\end{array}$ & $\begin{array}{c}\text { Nicht } \\
\text { ermittelbar }\end{array}$ & $\begin{array}{c}\text { Nicht } \\
\text { anwendbar }\end{array}$ \\
\hline Klinisches Bild & - & - & \multicolumn{2}{|c|}{ X (in einer der drei Spalten) } \\
Labordiagnostischer Nachweis & $\mathrm{X}$ & - & - & - & - \\
\cline { 2 - 6 } Epidemiologische Bestätigung & \multicolumn{5}{|c|}{ X (in einer der fünf Spalten) } \\
\cline { 2 - 5 }
\end{tabular}

\section{Übermittlung}

Nicht alle der fünf o.g. Falldefinitionskategorien sind für alle Übermittlungskategorien zur Übermittlung zugelassen. Dies ist in der Übermittlungssoftware entsprechend berücksichtigt. Die zu den Falldefinitionskategorien oben aufgeführte ergänzende Beschreibung trifft für die meisten Übermittlungskategorien zu; bei einzelnen Krankheiten musste die Beschreibung spezifisch angepasst werden.

\section{Referenzdefinition}

Aus den oben aufgeführten Falldefinitionskategorien wird deutlich, dass Fälle auch dann übermittelt werden können und müssen, wenn der Evidenztyp 'klinisches Bild' nicht erfüllt ist. Allerdings ist dabei zu beachten, dass für die vereinfachte statistische Darstellung durch das Robert Koch-Institut nur Fälle, die die Referenzdefinition erfüllen, gezählt werden.

Diese Referenzdefinition fasst in der Regel die Falldefinitionskategorien B 'Klinisch-epidemiologisch bestätigte Erkrankung' und C 'Klinisch-labordiagnostisch bestätigte Erkrankung' zusammen.

Ausnahmen bilden HUS, Hepatitis Non A-E, Masern, Tuberkulose, Poliomyelitis und CJK bzw. vCJK, bei denen auch die Falldefinitionskategorie A 'Klinisch diagnostizierte Erkrankung' allein die Übermittlungspflicht begründet. Daraus folgt, dass labordiagnostisch nachgewiesene Infektionen bei nicht erfülltem oder bei unbekanntem klinischen Bild in der Referenzdefinition in der Regel nicht ausgewiesen werden. Für einzelne Krankheiten weicht die Referenzdefinition von diesem Schema ab. Dies wird bei entsprechenden Veröffentlichungen explizit aufgeführt. 


\section{Hilfestellung beim Umgang mit den Falldefinitionen}

Es empfiehlt sich, die neuen Falldefinitionen aufmerksam zu lesen und gerade in der Einführungsphase bei jedem zu übermittelnden Einzelfall heranzuziehen, um zu vermeiden, dass aus Gewohnheit nicht mehr gültige Passagen der alten Falldefinition weiter angewendet werden.

Je genauer die Falldefinitionen auf der Gesundheitsamtsebene befolgt werden, desto seltener sind Rückfragen seitens der Landesstellen oder des Robert Koch-Instituts nötig. Dabei ist zu beachten, dass durch nachträglich hinzukommende Informationen zu einem Fall die Einordnung der Falldefinition gegebenenfalls aktualisiert werden muss. Werden Fälle erst dann in die Übermittlungssoftware eingegeben, wenn alle zu erwartenden Informationen vorliegen, kann dies die Übermittlung deutlich verzögern.

Für konkrete Fragen und Hilfestellungen bei der Interpretation der Falldefinitionen stehen die zuständigen Stellen der Bundesländer zur Verfügung. Zusätzlich bietet die IfSG-Hotline des RKI unter Tel. 030-18 754-4636 bzw. ifsg@rki.de Unterstützung an. 


\section{Übermittlungskategorien}




\section{Adenovirus im Konjunktivalabstrich (Adenovirus-Keratokonjunktivitis, Adenovirus-Konjunktivitis)}

ICDıo: B30.0 Keratokonjunktivitis durch Adenoviren (Keratoconjunctivitis epidemica),

B30.I Konjunktivitis durch Adenoviren (akute follikuläre Konjunktivitis durch Adenoviren, Schwimmbadkonjunktivitis)

\section{Vorbemerkung}

In dieser Übermittlungskategorie nicht enthalten sind sonstige Infektionen/Erkrankungen mit/durch Adenoviren, wie z.B. Enteritiden.

ICDıo: Ao8.2 Enteritis durch Adenoviren

\section{Klinisches Bild}

Klinisches Bild einer akuten Adenovirus-K(eratok)onjunktivitis, definiert als

- Rötung der Bindehaut.

\section{Labordiagnostischer Nachweis}

Positiver Befund mit mindestens einer der drei folgenden Methoden:

[direkter Erregernachweis nur im Konjunktivalabstrich:]

- Virusisolierung,

- Nukleinsäure-Nachweis (z.B. PCR),

- Antigennachweis (z.B. ELISA, IFT).

\section{Epidemiologische Bestätigung}

Epidemiologische Bestätigung, definiert als folgender Nachweis unter Berücksichtigung der Inkubationszeit:

- Epidemiologischer Zusammenhang mit einer labordiagnostisch nachgewiesenen Infektion beim Menschen durch

- Mensch-zu-Mensch-Übertragung ODER

- gemeinsame Expositionsquelle (z.B. augenärztliche Untersuchungsgeräte).

Inkubationszeit ca. 5-I2 Tage, manchmal länger. 


\section{Über die zuständige Landesbehörde an das RKI zu übermittelnder Fall}

\section{A. Klinisch diagnostizierte Erkrankung}

Entfällt.

\section{B. Klinisch-epidemiologisch bestätigte Erkrankung}

Klinisches Bild einer akuten Adenovirus-K(eratok)onjunktivitis, ohne labordiagnostischen Nachweis, aber mit epidemiologischer Bestätigung.

\section{Klinisch-labordiagnostisch bestätigte Erkrankung}

Klinisches Bild einer akuten Adenovirus-K(eratok)onjunktivitis und labordiagnostischer Nachweis.

D. Labordiagnostisch nachgewiesene Infektion bei nicht erfülltem klinischen Bild

Labordiagnostischer Nachweis bei bekanntem klinischen Bild, das die Kriterien für eine akute Adenovirus-K(eratok)onjunktivitis nicht erfüllt. Hierunter fallen auch asymptomatische Infektionen.

\section{E. Labordiagnostisch nachgewiesene Infektion bei unbekanntem klinischen Bild}

Labordiagnostischer Nachweis bei fehlenden Angaben zum klinischen Bild (nicht ermittelbar oder nicht erhoben).

\section{Referenzdefinition}

In Veröffentlichungen des Robert Koch-Instituts, die nicht nach Falldefinitionskategorien differenzieren (z.B. wöchentliche „Aktuelle Statistik meldepflichtiger Infektionskrankheiten“ im Epidemiologischen Bulletin), werden nur Erkrankungen der Kategorien $\mathbf{B}$ und $\mathbf{C}$ gezählt.

\section{Gesetzliche Grundlage}

\section{Meldepflicht}

Dem Gesundheitsamt wird gemäß $₫ 7$ Abs. I Nr. I IfSG nur der direkte Nachweis von Adenoviren im Konjunktivalabstrich, soweit er auf eine akute Infektion hinweist, namentlich gemeldet. Darüber hinaus stellt das Gesundheitsamt gemäß \25 Abs. I IfSG ggf. eigene Ermittlungen an.

\section{Übermittlung}

Das Gesundheitsamt übermittelt gemäß \II Abs. I IfSG an die zuständige Landesbehörde nur Erkrankungs- oder Todesfälle und Erregernachweise, die der Falldefinition gemäß \4 Abs. 2 Nr. 2 Buchst. a IfSG entsprechen. 


\section{Bacillus anthracis (Milzbrand)}

ICDıо: A22.- Anthrax [Milzbrand], inkl.: Infektion durch Bacillus anthracis,

A22.0 Hautmilzbrand (Milzbrandkarbunkel, Pustula maligna),

A22.I Lungenmilzbrand (Hadernkrankheit, Milzbrand, durch Inhalation erworben),

A22.2 Darmmilzbrand,

A22.7 Milzbrandsepsis,

A22.8 Sonstige Formen des Milzbrandes (Milzbrandmeningitis),

A22.9 Milzbrand, nicht näher bezeichnet

\section{Klinisches Bild}

Klinisches Bild eines akuten Milzbrands, definiert als mindestens eine der drei folgenden Formen:

- Hautmilzbrand (Pustula maligna), definiert als mindestens eines der beiden folgenden Kriterien:

- papulöse (erbsengroß über dem Hautniveau) oder vesikuläre (mit Flüssigkeit gefüllte) Hautläsion (Hautveränderung),

- schwarz belegtes Hautgeschwür mit umliegender Schwellung (Milzbrandkarbunkel).

ICDio: A22.o Hautmilzbrand (Milzbrandkarbunkel, Pustula maligna)

- Lungenmilzbrand, definiert als mindestens zwei der drei folgenden Kriterien:

- $\rightarrow$ Fieber,

- Dyspnoe (Atemstörung),

- radiologisch nachgewiesene Verbreiterung des Mediastinums.

ICDıo: A22.I Lungenmilzbrand (Hadernkrankheit, Milzbrand, durch Inhalation erworben)

- Darmmilzbrand, definiert als

- $\rightarrow$ Fieber UND

- mindestens eines der vier folgenden Kriterien:

- Übelkeit,

- Bauchschmerzen,

- Erbrechen,

- Durchfall.

ICDio: A22.2 Darmmilzbrand

Das klinische Bild kann zusätzlich das einer Milzbrandsepsis, definiert als systemischer Verlauf einer der vorgenannten Formen, annehmen.

ICDio: A22.7 Milzbrandsepsis

\section{Labordiagnostischer Nachweis}

Positiver Befund mit mindestens einer der drei folgenden Methoden:

[direkter Erregernachweis:]

- Erregerisolierung (kulturell),

- Nukleinsäure-Nachweis (z.B. PCR) des PA (protektives Antigen, eines der beiden Virulenzplasmide),

- Antigennachweis der Kapsel mittels IFT. 


\title{
Epidemiologische Bestätigung
}

Epidemiologische Bestätigung, definiert als mindestens einer der drei folgenden Nachweise unter Berücksichtigung der Inkubationszeit:

- Epidemiologischer Zusammenhang mit einer labordiagnostisch nachgewiesenen Infektion beim Menschen durch

- gemeinsame Expositionsquelle (z.B. $>$ Tierkontakt, $\triangleright$ Lebensmittel).

- Kontakt mit einem labordiagnostisch nachgewiesen infizierten Tier oder seinen Ausscheidungen oder Produkten (z.B. Felle, Häute) oder Verzehr seiner Produkte (z.B. Fleisch).

- Verzehr eines Lebensmittels (z.B. Fleisch), in dessen Resten Bacillus anthracis labordiagnostisch nachgewiesen wurde.

Inkubationszeit ca. I-7 Tage, gelegentlich bis zu 60 Tagen.

\section{Über die zuständige Landesbehörde an das RKI zu übermittelnder Fall}

\author{
A. Klinisch diagnostizierte Erkrankung \\ Entfällt.
}

\section{B. Klinisch-epidemiologisch bestätigte Erkrankung}

Klinisches Bild eines akuten Milzbrands, ohne labordiagnostischen Nachweis, aber mit epidemiologischer Bestätigung.

C. Klinisch-labordiagnostisch bestätigte Erkrankung

Klinisches Bild eines akuten Milzbrands und labordiagnostischer Nachweis.

D. Labordiagnostisch nachgewiesene Infektion bei nicht erfülltem klinischen Bild

Labordiagnostischer Nachweis bei bekanntem klinischen Bild, das die Kriterien für einen akuten Milzbrand nicht erfüllt. Hierunter fallen auch asymptomatische Infektionen.

E. Labordiagnostisch nachgewiesene Infektion bei unbekanntem klinischen Bild

Labordiagnostischer Nachweis bei fehlenden Angaben zum klinischen Bild (nicht ermittelbar oder nicht erhoben).

\section{Referenzdefinition}

In Veröffentlichungen des Robert Koch-Instituts, die nicht nach Falldefinitionskategorien differenzieren (z.B. wöchentliche „Aktuelle Statistik meldepflichtiger Infektionskrankheiten“ im Epidemiologischen Bulletin), werden nur Erkrankungen der Kategorien $\mathbf{B}$ und $\mathbf{C}$ gezählt.

\section{Gesetzliche Grundlage}

\section{Meldepflicht}

Dem Gesundheitsamt wird gemäß $\int 6$ Abs. I Nr. I Buchst. j IfSG der Krankheitsverdacht, die Erkrankung sowie der Tod an Milzbrand, sowie gemäß $\ 7$ Abs. I Nr. 2 IfSG der direkte oder indirekte Nachweis von Bacillus anthracis, soweit er auf eine akute Infektion hinweist, namentlich gemeldet. Darüber hinaus stellt das Gesundheitsamt gemäß $\int 25$ Abs. I IfSG ggf. eigene Ermittlungen an.

\section{Übermittlung}

Das Gesundheitsamt übermittelt gemäß \II Abs. I IfSG an die zuständige Landesbehörde nur Erkrankungs- oder Todesfälle und Erregernachweise, die der Falldefinition gemäß $\int 4$ Abs. 2 Nr. 2 Buchst. a IfSG entsprechen. 


\section{Borrelia recurrentis (Läuserückfallfieber)}

ICDıo: A68.o Durch Läuse übertragenes Rückfallfieber (Rückfallfieber durch Borrelia recurrentis)

\section{Klinisches Bild}

Klinisches Bild eines akuten Läuserückfallfiebers, definiert als

- Fieber.

\section{Labordiagnostischer Nachweis}

Positiver Befund mit mindestens einer der beiden folgenden Methoden:

[direkter Erregernachweis nur in Blut (direkt oder nach Tierpassage):]

- Erregerisolierung (kulturell),

- mikroskopischer Erregernachweis im Dunkelfeld, Phasenkontrast oder im gefärbten Ausstrich.

\section{Epidemiologische Bestätigung}

Epidemiologische Bestätigung, definiert als folgender Nachweis unter Berücksichtigung der Inkubationszeit:

- Epidemiologischer Zusammenhang mit einer labordiagnostisch nachgewiesenen Infektion beim Menschen durch

- gemeinsame Expositionsquelle (z.B. Kleiderläuse).

Inkubationszeit ca. 5-I5 Tage, gewöhnlich 8 Tage. 


\section{Über die zuständige Landesbehörde an das RKI zu übermittelnder Fall}

\section{A. Klinisch diagnostizierte Erkrankung}

Entfällt.

\section{B. Klinisch-epidemiologisch bestätigte Erkrankung}

Klinisches Bild eines akuten Läuserückfallfiebers, ohne labordiagnostischen Nachweis, aber mit epidemiologischer Bestätigung.

\section{Klinisch-labordiagnostisch bestätigte Erkrankung}

Klinisches Bild eines akuten Läuserückfallfiebers und labordiagnostischer Nachweis.

D. Labordiagnostisch nachgewiesene Infektion bei nicht erfülltem klinischen Bild

Labordiagnostischer Nachweis bei bekanntem klinischen Bild, das die Kriterien für ein akutes Läuserückfallfieber nicht erfüllt. Hierunter fallen auch asymptomatische Infektionen.

\section{E. Labordiagnostisch nachgewiesene Infektion bei unbekanntem klinischen Bild}

Labordiagnostischer Nachweis bei fehlenden Angaben zum klinischen Bild (nicht ermittelbar oder nicht erhoben).

\section{Referenzdefinition}

In Veröffentlichungen des Robert Koch-Instituts, die nicht nach Falldefinitionskategorien differenzieren (z.B. wöchentliche „Aktuelle Statistik meldepflichtiger Infektionskrankheiten“ im Epidemiologischen Bulletin), werden nur Erkrankungen der Kategorien $\mathbf{B}$ und $\mathbf{C}$ gezählt.

\section{Gesetzliche Grundlage}

\section{Meldepflicht}

Dem Gesundheitsamt wird gemäß $\mathbb{7}$ Abs. I Nr. 3 IfSG der direkte oder indirekte Nachweis von Borrelia recurrentis, soweit er auf eine akute Infektion hinweist, namentlich gemeldet. Darüber hinaus stellt das Gesundheitsamt gemäß 『25 Abs. I IfSG ggf. eigene Ermittlungen an.

\section{Übermittlung}

Das Gesundheitsamt übermittelt gemäß \ II Abs. I IfSG an die zuständige Landesbehörde nur Erkrankungs- oder Todesfälle und Erregernachweise, die der Falldefinition gemäß \4 Abs. 2 Nr. 2 Buchst. a IfSG entsprechen.

Zusätzlich ist gemäß 』I2 Abs. I IfSG das Auftreten von Läuserückfallfieber vom Gesundheitsamt unverzüglich an die zuständige oberste Landesgesundheitsbehörde und von dieser unverzüglich dem RKI zu übermitteln. Der Begriff 'Auftreten' schließt neben der Infektion/Erkrankung und dem Tod auch Verdachtsfälle ohne labordiagnostischen Nachweis und ohne epidemiologische Bestätigung ein. 


\section{Brucella spp. (Brucellose)}

syn. Malta-Fieber, Mittelmeer-Fieber

ICDıo: A23.- Brucellose, inkl.: Maltafieber, Mittelmeerfieber, Undulierendes Fieber,

A23.0 Brucellose durch Brucella melitensis (Maltafieber),

A23.I Brucellose durch Brucella abortus (Bang-Krankheit, Morbus Bang),

A23.2 Brucellose durch Brucella suis (Schweinebrucellose),

A23.3 Brucellose durch Brucella canis,

A23.8 Sonstige Brucellose,

A23.9 Brucellose, nicht näher bezeichnet

\section{Ausschlusskriterien}

- Klinisches Bild bei Diagnosestellung bereits länger als I2 Monate andauernd.

\section{Klinisches Bild}

Klinisches Bild einer akuten Brucellose, definiert als

- $\rightarrow$ Fieber ODER

- mindestens zwei der fünf folgenden Kriterien:

- Nachtschweiß,

- übermäßige Erschöpfung,

- Appetit- oder Gewichtsverlust,

- Kopfschmerzen,

- Gelenkschmerzen.

\section{Labordiagnostischer Nachweis}

Positiver Befund mit mindestens einer der beiden folgenden Methoden:

[direkter Erregernachweis:]

- Erregerisolierung (kulturell),

[indirekter (serologischer) Nachweis:]

- Antikörpernachweis $\triangleright$ deutliche Änderung zwischen zwei Proben ODER einmaliger $\triangleright$ deutlich erhöhter Wert, z.B. SLA, KBR, ELISA).

\section{Zusatzinformation}

ELISA differenziert zwischen IgM- und IgG-Antikörpern. Beide Nachweise ergeben für sich allein den geforderten labordiagnostischen Nachweis.

\section{Epidemiologische Bestätigung}

Epidemiologische Bestätigung, definiert als mindestens einer der drei folgenden Nachweise unter Berücksichtigung der Inkubationszeit:

- Epidemiologischer Zusammenhang mit einer labordiagnostisch nachgewiesenen Infektion beim Menschen durch

- gemeinsame Expositionsquelle (z.B. $>$ Tierkontakt, $>$ Lebensmittel).

- Kontakt mit einem labordiagnostisch nachgewiesen infizierten Tier oder seinen Ausscheidungen, oder Verzehr seiner Produkte (z.B. Rohmilch, Fleisch).

- Verzehr eines Lebensmittels, in dessen Resten Brucella spp. labordiagnostisch nachgewiesen wurde.

Inkubationszeit ca. 5-60 Tage. 


\section{Über die zuständige Landesbehörde an das RKI zu übermittelnder Fall (unter Berücksichtigung der Ausschlusskriterien)}

\section{A. Klinisch diagnostizierte Erkrankung \\ Entfällt.}

\section{B. Klinisch-epidemiologisch bestätigte Erkrankung}

Klinisches Bild einer akuten Brucellose, ohne labordiagnostischen Nachweis, aber mit epidemiologischer Bestätigung.

\section{Klinisch-labordiagnostisch bestätigte Erkrankung}

Klinisches Bild einer akuten Brucellose und labordiagnostischer Nachweis.

D. Labordiagnostisch nachgewiesene Infektion bei nicht erfülltem klinischen Bild

Labordiagnostischer Nachweis bei bekanntem klinischen Bild, das die Kriterien für eine akute Brucellose nicht erfüllt. Hierunter fallen auch asymptomatische Infektionen.

E. Labordiagnostisch nachgewiesene Infektion bei unbekanntem klinischen Bild

Labordiagnostischer Nachweis bei fehlenden Angaben zum klinischen Bild (nicht ermittelbar oder nicht erhoben).

\section{Referenzdefinition}

In Veröffentlichungen des Robert Koch-Instituts, die nicht nach Falldefinitionskategorien differenzieren (z.B. wöchentliche „Aktuelle Statistik meldepflichtiger Infektionskrankheiten“ im Epidemiologischen Bulletin), werden nur Erkrankungen der Kategorien $\mathbf{B}$ und $\mathbf{C}$ gezählt.

\section{Gesetzliche Grundlage}

\section{Meldepflicht}

Dem Gesundheitsamt wird gemäß $\ 7$ Abs. I Nr. 4 IfSG der direkte oder indirekte Nachweis von Brucella sp., soweit er auf eine akute Infektion hinweist, namentlich gemeldet. Darüber hinaus stellt das Gesundheitsamt gemäß $\int 25$ Abs. I IfSG ggf. eigene Ermittlungen an.

\section{Übermittlung}

Das Gesundheitsamt übermittelt gemäß \II Abs. I IfSG an die zuständige Landesbehörde nur Erkrankungs- oder Todesfälle und Erregernachweise, die der Falldefinition gemäß $\ 4$ Abs. 2 Nr. 2 Buchst. a IfSG entsprechen. 


\section{Campylobacterspp., darmpathogen (Campylobacter-Enteritis)}

ICDıo: A04.5 Enteritis durch Campylobacter

\section{Klinisches Bild}

Klinisches Bild einer akuten Campylobacter-Enteritis, definiert als mindestens eines der drei folgenden Kriterien:

- Durchfall,

- krampfartige Bauchschmerzen,

- Fieber.

\section{Labordiagnostischer Nachweis}

Positiver Befund mit mindestens einer der beiden folgenden Methoden:

[direkter Erregernachweis:]

- Erregerisolierung (kulturell),

- Antigennachweis mittels ELISA.

\section{Zusatzinformation}

Das Ergebnis der Speziesbestimmung sollte übermittelt werden.

\section{Epidemiologische Bestätigung}

Epidemiologische Bestätigung, definiert als mindestens einer der vier folgenden Nachweise unter Berücksichtigung der Inkubationszeit:

- Epidemiologischer Zusammenhang mit einer labordiagnostisch nachgewiesenen Infektion beim Menschen durch

- Mensch-zu-Mensch-Übertragung ODER

- gemeinsame Expositionsquelle (z.B. \Badegewässer, $\gg$ Tierkontakt, $\gg$ Lebensmittel).

- Baden in einem labordiagnostisch nachgewiesen kontaminierten Gewässer.

- Kontakt mit einem labordiagnostisch nachgewiesen infizierten Tier oder seinen Ausscheidungen, oder Verzehr seiner Produkte (z.B. Rohmilch, Fleisch).

- Verzehr eines Lebensmittels (inkl. Trinkwasser), in dessen Resten Campylobacter spp. labordiagnostisch nachgewiesen wurde.

Inkubationszeit I-Io Tage, gewöhnlich 2-5 Tage. 


\section{Über die zuständige Landesbehörde an das RKI zu übermittelnder Fall}

\section{A. Klinisch diagnostizierte Erkrankung}

Entfällt.

\section{B. Klinisch-epidemiologisch bestätigte Erkrankung}

Klinisches Bild einer akuten Campylobacter-Enteritis, ohne labordiagnostischen Nachweis, aber mit epidemiologischer Bestätigung.

\section{Klinisch-labordiagnostisch bestätigte Erkrankung}

Klinisches Bild einer akuten Campylobacter-Enteritis und labordiagnostischer Nachweis.

D. Labordiagnostisch nachgewiesene Infektion bei nicht erfülltem klinischen Bild

Labordiagnostischer Nachweis bei bekanntem klinischen Bild, das die Kriterien für eine akute Campylobacter-Enteritis nicht erfüllt. Hierunter fallen auch asymptomatische Infektionen.

\section{E. Labordiagnostisch nachgewiesene Infektion bei unbekanntem klinischen Bild}

Labordiagnostischer Nachweis bei fehlenden Angaben zum klinischen Bild (nicht ermittelbar oder nicht erhoben).

\section{Referenzdefinition}

In Veröffentlichungen des Robert Koch-Instituts, die nicht nach Falldefinitionskategorien differenzieren (z.B. wöchentliche „Aktuelle Statistik meldepflichtiger Infektionskrankheiten“ im Epidemiologischen Bulletin), werden nur Erkrankungen der Kategorien $\mathbf{B}$ und $\mathbf{C}$ gezählt.

\section{Gesetzliche Grundlage}

\section{Meldepflicht}

Dem Gesundheitsamt wird gemäß $\rrbracket 7$ Abs. I Nr. 5 IfSG der direkte oder indirekte Nachweis von darmpathogenem Campylobacter sp., soweit er auf eine akute Infektion hinweist, namentlich gemeldet. Darüber hinaus stellt das Gesundheitsamt gemäß \25 Abs. I IfSG ggf. eigene Ermittlungen an.

\section{Weitergehende Meldepflicht}

Dem Gesundheitsamt wird gemäß \6 Abs. I Nr. 2 IfSG ggf. auch der Verdacht auf und die Erkrankung an einer akuten infektiösen Gastroenteritis ohne labordiagnostischen Nachweis und ohne epidemiologische Bestätigung gemeldet.

\section{Übermittlung}

Das Gesundheitsamt übermittelt gemäß 『 II Abs. I IfSG an die zuständige Landesbehörde nur Erkrankungs- oder Todesfälle und Erregernachweise, die der Falldefinition gemäß $\ 4$ Abs. 2 Nr. 2 Buchst. a IfSG entsprechen. 


\section{Chlamydophila psittaci (Ornithose)}

syn. Psittakose, Papageienkrankheit

ICDıo: A7o Infektionen durch Chlamydia psittaci (Ornithose, Papageienkrankheit, Psittakose)

\section{Klinisches Bild}

Klinisches Bild einer akuten Ornithose, definiert als mindestens eines der drei folgenden Kriterien:

- - Lungenentzündung,

- Endo- oder Myokarditis (Entzündung der Herzinnenhaut oder des Herzmuskels),

- mindestens zwei der drei folgenden Kriterien:

- $\rightarrow$ Fieber,

- Kopfschmerzen,

- Husten.

\section{Labordiagnostischer Nachweis}

Positiver Befund mit mindestens einer der vier folgenden Methoden:

[direkter Erregernachweis:]

- Erregerisolierung (kulturell),

- Nukleinsäure-Nachweis (z.B. PCR) des MOMPI-Gens,

[indirekter (serologischer) Nachweis:]

- Antikörpernachweis mittels C.-psittaci-spezifischer MIF,

- Chlamydiales-Antikörpernachweis mittels KBR (deutliche Änderung zwischen zwei Proben oDER einmaliger $\triangleright$ deutlich erhöhter Wert) nur bei $\triangleright$ Kontakt mit potentiell infizierten Vögeln oder ihren Ausscheidungen unter Berücksichtigung der Inkubationszeit.

\section{Zusatzinformationen}

- Chlamydiales-Antikörpernachweis mittels KBR unterscheiden nicht zwischen meldepflichtiger Chlamydophila psittaci und nicht meldepflichtigen Chlamydophila pneumoniae und Chlamydia trachomatis.

- Da Chlamydiales-Infektionen bei Vögeln asymptomatisch und langfristig persistierend verlaufen können, muss jeder Vogel, bei dem eine solche Infektion nicht ausgeschlossen wurde, als potentiell infiziert gewertet werden.

\section{Epidemiologische Bestätigung}

Epidemiologische Bestätigung, definiert als mindestens einer der beiden folgenden Nachweise unter Berücksichtigung der Inkubationszeit:

- Epidemiologischer Zusammenhang mit einer labordiagnostisch nachgewiesenen Infektion beim Menschen durch

- gemeinsame Expositionsquelle (z.B. \Kontakt mit potentiell infizierten Vögeln oder ihren Ausscheidungen).

- Kontakt mit einem labordiagnostisch nachgewiesen infizierten Tier (Vögel wie z.B. Papageien, Sittiche, Geflügel, auch Wildtauben) oder seinen Ausscheidungen.

Inkubationszeit ca. I-4 Wochen. 


\section{Über die zuständige Landesbehörde an das RKI zu übermittelnder Fall}

\section{A. Klinisch diagnostizierte Erkrankung}

Entfällt.

\section{B. Klinisch-epidemiologisch bestätigte Erkrankung}

Klinisches Bild einer akuten Ornithose, ohne labordiagnostischen Nachweis, aber mit epidemiologischer Bestätigung.

\section{Klinisch-labordiagnostisch bestätigte Erkrankung}

Klinisches Bild einer akuten Ornithose und labordiagnostischer Nachweis.

D. Labordiagnostisch nachgewiesene Infektion bei nicht erfülltem klinischen Bild

Labordiagnostischer Nachweis bei bekanntem klinischen Bild, das die Kriterien für eine akute Ornithose nicht erfüllt. Hierunter fallen auch asymptomatische Infektionen.

\section{E. Labordiagnostisch nachgewiesene Infektion bei unbekanntem klinischen Bild}

Labordiagnostischer Nachweis bei fehlenden Angaben zum klinischen Bild (nicht ermittelbar oder nicht erhoben).

\section{Referenzdefinition}

In Veröffentlichungen des Robert Koch-Instituts, die nicht nach Falldefinitionskategorien differenzieren (z.B. wöchentliche „Aktuelle Statistik meldepflichtiger Infektionskrankheiten“ im Epidemiologischen Bulletin), werden nur Erkrankungen der Kategorien $\mathbf{B}$ und $\mathbf{C}$ gezählt.

\section{Gesetzliche Grundlage}

\section{Meldepflicht}

Dem Gesundheitsamt wird gemäß $\ 7$ Abs. I Nr. 6 IfSG der direkte oder indirekte Nachweis von Chlamydia psittaci (jetzt: Chlamydophila psittacl), soweit er auf eine akute Infektion hinweist, namentlich gemeldet. Darüber hinaus stellt das Gesundheitsamt gemäß 『25 Abs. I IfSG ggf. eigene Ermittlungen an.

\section{Übermittlung}

Das Gesundheitsamt übermittelt gemäß \ II Abs. I IfSG an die zuständige Landesbehörde nur Erkrankungs- oder Todesfälle und Erregernachweise, die der Falldefinition gemäß \4 Abs. 2 Nr. 2 Buchst. a IfSG entsprechen. 


\section{7a Creutzfeldt-Jakob-Krankheit (CJK)}

ICDıo: A8ı.o Creutzfeldt-Jakob-Krankheit (Subakute spongioforme Enzephalopathie)

\section{Ausschlusskriterien}

- Familiäre Form der CJK (ärztliche Diagnose einer CJK bei einem Blutsverwandten ersten Grades ODER Nachweis einer krankheitsspezifischen PrP-Gen-Mutation),

- ärztliche Diagnose einer vCJK.

\section{Zusatzinformation}

Zu den familiär-hereditären Formen der humanen spongioformen Enzephalopathie gehören weitere Krankheiten wie das Gerstmann-Sträussler-Scheinker-Syndrom (GSS) und die letale familiäre Insomnie (fatal familial insomnia, FFI), die aber nicht unter die hier behandelte Krankheitskategorie 'CJK' fallen.

\section{Klinisches Bild}

Klinisches Bild einer CJK, definiert als Vorliegen aller vier folgenden Kriterien:

- Differentialdiagnostische Routineuntersuchungen wurden durchgeführt und legen keine alternative Diagnose nahe.

- Fortschreitende Demenz.

- Mindestens zwei der vier folgenden Kriterien:

- Myoklonien,

- visuelle oder zerebelläre Krankheitszeichen,

- pyramidale oder extrapyramidale Krankheitszeichen,

- akinetischer Mutismus.

- Mindestens einer der beiden folgenden Nachweise:

- typische 'sharp-wave'-Komplexe* im EEG,

- I4-3-3-Protein im Liquor (nur bei einer Erkrankungsdauer von weniger als zwei Jahren bis zum Tod).

\section{Neuropathologischer Nachweis}

Positiver Befund mit mindestens einer der drei folgenden Methoden nur im Hirngewebe (post mortem oder zu Lebzeiten durch Hirnbiopsie):

- für CJK typische Histopathologie oder Immunhistopathologie,

- Nachweis (immunzytochemisch oder Western-Blot) des proteaseresistenten Prionproteins,

- Nachweis Scrapie-assoziierter Fibrillen (prion rods).

\section{Zusatzinformation}

Proteaseresistentes Prionprotein (Nachweis im Hirngewebe) darf nicht mit I4-3-3-Protein (Nachweis im Liquor) verwechselt werden.

\footnotetext{
* generalisierte triphasische periodische Komplexe mit einer Frequenz von ca. I pro Sekunde
} 


\section{Epidemiologische Bestätigung}

Epidemiologische Bestätigung, definiert als folgender Nachweis unter Berücksichtigung der Inkubationszeit:

- iatrogener Kontakt (d.h. durch medizinischen Eingriff) mit potentiell kontaminierten klinischen Materialien (oder neurochirurgischen Instrumenten), bei dem besondere Umstände auf ein erhöhtes Risiko einer CJK-Übertragung hinweisen (z.B. bei Kornea- oder Duratransplantation, Behandlung mit aus Leichenhypophysen gewonnenen Hormonen, insbesondere Wachstumshormonen).

Eine CJK kann eine der beiden folgenden meldepflichtigen Formen annehmen:

- sporadische CJK, definiert als CJK ohne epidemiologische Bestätigung,

- iatrogene CJK, definiert als CJK mit epidemiologischer Bestätigung.

Inkubationszeit der iatrogenen CJK ca. I2 Monate bis 30 Jahre, möglicherweise länger. 


\section{Über die zuständige Landesbehörde an das RKI zu übermittelnder Fall (unter Berücksichtigung der Ausschlusskriterien)}

\section{A. Klinisch diagnostizierte Erkrankung}

Klinisches Bild einer CJK, ohne neuropathologischen Nachweis und ohne epidemiologische Bestätigung.

\section{B. Klinisch-epidemiologisch bestätigte Erkrankung}

Klinisches Bild einer CJK, ohne neuropathologischen Nachweis, aber mit epidemiologischer Bestätigung.

\section{Klinisch-neuropathologisch bestätigte Erkrankung}

Klinisches Bild einer CJK und neuropathologischer Nachweis.

D. Neuropathologisch nachgewiesener Fall bei nicht erfülltem klinischen Bild

Neuropathologischer Nachweis bei bekanntem klinischen Bild, das die Kriterien für eine CJK nicht erfüllt.

\section{E. Neuropathologisch nachgewiesener Fall bei unbekanntem klinischen Bild}

Neuropathologischer Nachweis bei fehlenden Angaben zum klinischen Bild (nicht ermittelbar oder nicht erhoben).

\section{Referenzdefinition und Internationale Klassifikation}

In Veröffentlichungen des Robert Koch-Instituts, die nicht nach Falldefinitionskategorien differenzieren (z.B. wöchentliche „Aktuelle Statistik meldepflichtiger Infektionskrankheiten“ im Epidemiologischen Bulletin), werden Fälle aller Kategorien A, B, C, D und E gezählt.

Fälle der Falldefinitionskategorien A (klinisch diagnostizierte Erkrankung) und B (klinisch-epidemiologisch bestätigte Erkrankung) entsprechen wahrscheinlichen Fällen und Fälle der Falldefinitionskategorien C (klinisch-neuropathologisch bestätigte Erkrankung), D und E (neuropathologisch nachgewiesene Infektion bei nicht erfülltem bzw. unbekanntem klinischen Bild) entsprechen gesicherten Fällen einer CJK in der internationalen Klassifikation gemäß Bekanntmachung der WHO vom II.02.1998 (WHO/EMC/ZDI/98.9).

\section{Gesetzliche Grundlage}

\section{Meldepflicht}

Dem Gesundheitsamt wird gemäß $\int 6$ Abs. I Nr. I Buchst. d IfSG der Krankheitsverdacht, die Erkrankung sowie der Tod an humaner spongioformer Enzephalopathie, außer familiär-hereditärer Formen namentlich gemeldet. Darüber hinaus stellt das Gesundheitsamt gemäß \25 Abs. I IfSG ggf. eigene Ermittlungen an.

\section{Übermittlung}

Das Gesundheitsamt übermittelt gemäß 』II Abs. I IfSG an die zuständige Landesbehörde nur Erkrankungs- oder Todesfälle und Erregernachweise, die der Falldefinition gemäß \ 4 Abs. 2 Nr. 2 Buchst. a IfSG entsprechen. 


\section{7b Variante CJK (vCJK)}

ICDio: A8ı.o Creutzfeldt-Jakob-Krankheit (Subakute spongioforme Enzephalopathie)

\section{Ausschlusskriterien}

- Familiäre Form CJK (ärztliche Diagnose einer CJK bei einem Blutsverwandten ersten Grades ODER Nachweis einer krankheitsspezifischen PrP-Gen-Mutation),

- ärztliche Diagnose einer sporadischen CJK.

\section{Zusatzinformation}

Siehe CJK.

\section{Klinisches Bild}

\section{Vorbemerkung:}

Abweichend von der für die anderen Übermittlungskategorien verwendeten Struktur ist das klinische Bild der vCJK in die vier Abschnitte Vorgeschichte, Symptomatik, klinische Zeichen und Biopsiebefund gegliedert. Diese entsprechen den römischen Ziffern I bis IV der internationalen Klassifikation, deren vollständige Kodierung - bestehend aus römischer Ziffer und lateinischem Großbuchstaben - hier zur besseren Orientierung ebenfalls wiedergegeben ist.

I. Vorgeschichte vereinbar mit vCJK, definiert als Vorliegen aller vier folgenden Kriterien:

IA. Fortschreitende neuropsychiatrische Erkrankung.

IB. Dauer der Erkrankung länger als sechs Monate.

IC. Differentialdiagnostische Routineuntersuchungen wurden durchgeführt und legen keine alternative Diagnose nahe.

ID. Kein Hinweis auf eine iatrogene CJK durch Exposition gegenüber humanen Hypophysenhormonen oder Dura mater.

II. Symptomatik vereinbar mit vCJK, definiert als mindestens vier der fünf folgenden Kriterien:

IIA. Frühe psychiatrische Symptome (z.B. Depressionen, Angstzustände, Apathie, Zurückgezogenheit, Wahnvorstellungen).

IIB. Anhaltende schmerzhafte Empfindungsstörungen (Dysästhesien).

IIC. Ataxie.

IID. Myoklonien, choreatiforme („überschießende“) Bewegungen ODER Dystonie.

IIE. Demenz.

III. Klinische Zeichen vereinbar mit vCJK, definiert als Vorliegen beider folgenden Kriterien:

IIIA. Keine typischen 'sharp-wave'-Komplexe* im EEG.

IIIB. Beidseits Signalanhebungen (Hyperintensitäten) im posterioren Thalamus (Pulvinar-Zeichen) in der Magnetresonanztomographie (MRT).

IV. Biopsiebefund vereinbar mit vCJK, definiert als positiver Befund mit mindestens einer der folgenden Methoden zu Lebzeiten:

IVA. Nachweis von pathologischem Prionprotein $\left(\operatorname{Pr}^{\mathrm{Sc}}\right)$ in einer Tonsillenbiopsie.

\footnotetext{
* generalisierte triphasische periodische Komplexe mit einer Frequenz von ca. I pro Sekunde
} 
Das klinische Bild einer vCJK ist erfüllt, wenn mindestens eine der folgenden Kombinationen vorliegt:

- Vorgeschichte, Symptomatik UND klinische Zeichen vereinbar mit vCJK.

- Vorgeschichte UND Biopsiebefund vereinbar mit vCJK.

\section{Neuropathologischer Nachweis}

Nachweis beider folgenden Phänomene im Bereich des gesamten Groß- und Kleinhirns post mortem:

- spongioforme Veränderungen,

- ausgeprägte PrP-Ablagerungen mit floriden Plaques.

\section{Epidemiologische Bestätigung}

Epidemiologische Bestätigung, definiert als

- iatrogener Kontakt (d.h. durch medizinischen Eingriff) mit potentiell kontaminierten klinischen Materialien (oder neurochirurgischen Instrumenten), bei dem besondere Umstände auf ein erhöhtes Risiko einer vCJK-Übertragung hinweisen (z.B. Empfang von Blut oder Blutprodukten von später an vCJK erkrankten Spendern). 


\section{Über die zuständige Landesbehörde an das RKI zu übermittelnder Fall (unter Berücksichtigung der Ausschlusskriterien)}

\section{A. Klinisch diagnostizierte Erkrankung}

Klinisches Bild einer vCJK, ohne neuropathologischen Nachweis und ohne epidemiologische Bestätigung.

\section{B. Klinisch-epidemiologisch bestätigte Erkrankung}

Klinisches Bild einer vCJK, ohne neuropathologischen Nachweis, aber mit epidemiologischer Bestätigung.

\section{Klinisch-neuropathologisch bestätigte Erkrankung}

Fortschreitende neuropsychiatrische Erkrankung und neuropathologischer Nachweis.

D. Neuropathologisch nachgewiesener Fall bei nicht erfülltem klinischen Bild

Neuropathologischer Nachweis ohne fortschreitende neuropsychiatrische Erkrankung.

E. Neuropathologisch nachgewiesener Fall bei unbekanntem klinischen Bild

Neuropathologischer Nachweis bei fehlenden Angaben zum klinischen Bild (nicht ermittelbar oder nicht erhoben).

\section{Referenzdefinition und Internationale Klassifikation}

In Veröffentlichungen des Robert Koch-Instituts, die nicht nach Falldefinitionskategorien differenzieren (z.B. wöchentliche „Aktuelle Statistik meldepflichtiger Infektionskrankheiten“ im Epidemiologischen Bulletin), werden nur Erkrankungen der Kategorien A, B und C gezählt.

Fälle der Falldefinitionskategorien A (klinisch diagnostizierte Erkrankung) entsprechen wahrscheinlichen Fällen und Fälle der Falldefinitionskategorie C (klinisch-neuropathologisch bestätigte Erkrankung) entsprechen gesicherten Fällen einer vCJK in der internationalen Klassifikation gemäß Bekanntmachung der WHO vom I7.05.200I (WHO/CDS/CSR/EPH/200I.5) und der Bundesärztekammer vom 28.02.2003 (DÄ 2003; IO० (9): A578-580). Die Falldefinitionskategorien B (klinisch-epidemiologisch bestätigte Erkrankung), D und E (neuropathologisch nachgewiesene Infektion bei nicht erfülltem bzw. unbekanntem klinischen Bild) haben in der internationalen Klassifikation keine Entsprechung.

\section{Gesetzliche Grundlage}

Siehe CJK. 


\section{Clostridium botulinum (Botulismus)}

ICDıo: A05.I Botulismus (Klassische Lebensmittelvergiftung durch Clostridium botulinum)

\section{Vorbemerkung}

In dieser Übermittlungskategorie sind auch Toxinnachweise bei anderen Botulinum-Toxin produzierenden Clostridien als C. botulinum enthalten, nämlich z.B. bei $C$. butyricum (nur Toxintyp E) oder C. baratii (nur Typ F).

\section{Klinisches Bild}

Klinisches Bild eines akuten Botulismus, definiert als eine der beiden folgenden Formen:

- Lebensmittelbedingter oder Wundbotulismus, definiert als mindestens eines der sechs folgenden Kriterien:

- Hirnnervenstörung, z.B. Ptosis (Herabhängen des Oberlids), Sehstörungen (Doppelbilder), Schluckstörungen,

- innerhalb weniger Tage fortschreitende, symmetrische, absteigende schlaffe Lähmung,

- Dyspnoe (Atemstörung),

- Erbrechen,

- Übelkeit,

- Bauchschmerzen.

ICDıo: A05.I Botulismus (Klassische Lebensmittelvergiftung durch Clostridium botulinum)

- Säuglingsbotulismus, definiert als mindestens eines der sieben folgenden Kriterien bei einem Kind im ersten Lebensjahr:

- schlaffe Lähmungen,

- anhaltende Obstipation (Verstopfung),

- Gedeihstörung,

- Trinkschwäche,

- Schluckstörungen,

- allgemeine Muskelschwäche,

- Dyspnoe (Atemstörung).

\section{Zusatzinformation}

Lebensmittelbedingter und Wundbotulismus sind nicht als eigenständige klinische Formen aufgeführt, da sie sich hinsichtlich der Definition ihres klinischen Bildes nicht unterscheiden. Ihre Unterscheidung basiert auf der Herkunft des Toxins, nämlich von kontaminierten Lebensmitteln bei lebensmittelbedingtem Botulismus, und von in Wunden siedelnden Botulinum-Toxin produzierenden Clostridien (typischerweise C. botulinum) bei Wundbotulismus.

\section{Labordiagnostischer Nachweis}

Positiver Befund mit mindestens einer der beiden folgenden Methoden:

[direkter Erregernachweis:]

- Erregerisolierung (kulturell) nur aus Stuhl (typischerweise bei Säuglingsbotulismus) ODER Wundmaterial (Wundbotulismus),

[Toxinnachweis:]

- Nachweis von Botulinum-Toxin (z.B. ELISA, Maus-Bioassay) nur in Blut, Stuhl, Mageninhalt oder Erbrochenem. 


\section{Epidemiologische Bestätigung}

Epidemiologische Bestätigung, definiert als mindestens einer der beiden folgenden Nachweise unter Berücksichtigung der Inkubationszeit:

- Epidemiologischer Zusammenhang mit einer labordiagnostisch nachgewiesenen Infektion beim Menschen durch

- gemeinsame Expositionsquelle (z.B. -Lebensmittel),

- Verzehr eines Lebensmittels, in dessen Resten Botulinum-Toxin oder (bei Säuglingsbotulismus) Sporen (z.B. in Honig) labordiagnostisch nachgewiesen wurden.

Inkubationszeit ca. 12-36 Stunden, gelegentlich mehrere Tage.

\section{Über die zuständige Landesbehörde an das RKI zu übermittelnder Fall}

\section{A. Klinisch diagnostizierte Erkrankung}

Entfällt.

\section{B. Klinisch-epidemiologisch bestätigte Erkrankung}

Klinisches Bild eines akuten Botulismus, ohne labordiagnostischen Nachweis, aber mit epidemiologischer Bestätigung.

\section{Klinisch-labordiagnostisch bestätigte Erkrankung}

Klinisches Bild eines akuten Botulismus und labordiagnostischer Nachweis.

D. Labordiagnostisch nachgewiesener Fall bei nicht erfülltem klinischen Bild

Labordiagnostischer Nachweis bei bekanntem klinischen Bild, das die Kriterien für einen akuten Botulismus nicht erfüllt.

\section{E. Labordiagnostisch nachgewiesener Fall bei unbekanntem klinischen Bild}

Labordiagnostischer Nachweis bei fehlenden Angaben zum klinischen Bild (nicht ermittelbar oder nicht erhoben).

\section{Referenzdefinition}

In Veröffentlichungen des Robert Koch-Instituts, die nicht nach Falldefinitionskategorien differenzieren (z.B. wöchentliche „Aktuelle Statistik meldepflichtiger Infektionskrankheiten“ im Epidemiologischen Bulletin), werden nur Erkrankungen der Kategorien $\mathbf{B}$ und $\mathbf{C}$ gezählt.

\section{Gesetzliche Grundlage}

\section{Meldepflicht}

Dem Gesundheitsamt wird gemäß \6 Abs. I Nr. I Buchst. a IfSG der Krankheitsverdacht, die Erkrankung sowie der Tod an Botulismus, sowie gemäß \7 Abs. I Nr. 7 IfSG der direkte oder indirekte Nachweis von Clostridium botulinum oder seinem Toxin, soweit er auf eine akute Infektion hinweist, namentlich gemeldet. Darüber hinaus stellt das Gesundheitsamt gemäß 『25 Abs. I IfSG ggf. eigene Ermittlungen an.

\section{Übermittlung}

Das Gesundheitsamt übermittelt gemäß 』 II Abs. I IfSG an die zuständige Landesbehörde nur Erkrankungs- oder Todesfälle und Erregernachweise, die der Falldefinition gemäß $\int 4$ Abs. 2 Nr. 2 Buchst. a IfSG entsprechen. 


\section{Corynebacterium spp., Diphtherie-Toxin bildend (Diphtherie)}

ICDio: A36.- Diphtherie,

A36.0 Rachendiphtherie (Angina pseudomembranacea diphtherica, Tonsillendiphtherie),

A36.I Nasenrachendiphtherie,

A36.2 Kehlkopfdiphtherie (Diphtherische Laryngotracheitis),

A36.3 Hautdiphtherie, exkl.: Erythrasma,

A36.8 Sonstige Diphtherie (diphtherisch: Konjunktivitis, Myokarditis, Polyneuritis),

A36.9 Diphtherie, nicht näher bezeichnet

\section{Klinisches Bild}

Klinisches Bild einer akuten Diphtherie, definiert als mindestens eine der beiden folgenden Formen:

- Rachendiphtherie, definiert als mindestens eines der beiden folgenden Kriterien:

- festhaftende pseudomembranöse Beläge im Nasen-Rachen-Raum (z.B. auf den Tonsillen),

- Fieber UND Halsschmerzen.

ICDıo: A36.0 Rachendiphtherie (Angina pseudomembranacea diphtherica, Tonsillendiphtherie),

A36.I Nasenrachendiphtherie,

A36.2 Kehlkopfdiphtherie (Diphtherische Laryngotracheitis)

- Hautdiphtherie, definiert als

- Haut- oder Bindehautläsion (-veränderung).

ICDıo: A36.3 Hautdiphtherie, exkl.: Erythrasma

\section{Zusatzinformation}

Bei impfpräventablen Krankheiten sollten stets Angaben zur Impfanamnese (Anzahl der vorangegangenen Impfungen, Art und Datum der letzten Impfung) erhoben (z.B. Impfbuchkontrolle) und übermittelt werden.

\section{Labordiagnostischer Nachweis}

Positiver Befund bei beiden folgenden Untersuchungsschritten:

[direkter Erregernachweis:]

- Erregerisolierung (kulturell) UND

[Toxinnachweis:]

- Nachweis des Diphtherie-Toxins (z.B. Elek-Test) bzw. Nukleinsäure-Nachweis (z.B. PCR) des Diphtherie-Toxin-Gens nur im Isolat.

\section{Zusatzinformation}

Als toxinbildende Erreger kommen neben $C$. diphtheriae in seltenen Fällen auch andere Spezies, typischerweise C. ulceras und C. pseudotuberculosis in Betracht. 


\section{Epidemiologische Bestätigung}

Epidemiologische Bestätigung, definiert als folgender Nachweis unter Berücksichtigung der Inkubationszeit:

- Epidemiologischer Zusammenhang mit einer labordiagnostisch nachgewiesenen Infektion beim Menschen durch

- Mensch-zu-Mensch-Übertragung ODER

- gemeinsame Expositionsquelle (z.B. potentiell kontaminierte Gegenstände).

Inkubationszeit ca. 2-5 Tage, gelegentlich länger.

\section{Über die zuständige Landesbehörde an das RKI zu übermittelnder Fall}

\section{A. Klinisch diagnostizierte Erkrankung \\ Entfällt.}

\section{B. Klinisch-epidemiologisch bestätigte Erkrankung}

Klinisches Bild einer akuten Diphtherie, ohne labordiagnostischen Nachweis, aber mit epidemiologischer Bestätigung.

C. Klinisch-labordiagnostisch bestätigte Erkrankung

Klinisches Bild einer akuten Diphtherie und labordiagnostischer Nachweis.

D. Labordiagnostisch nachgewiesene Infektion bei nicht erfülltem klinischen Bild

Labordiagnostischer Nachweis bei bekanntem klinischen Bild, das die Kriterien für eine akute Diphtherie nicht erfüllt. Hierunter fallen auch asymptomatische Infektionen.

\section{E. Labordiagnostisch nachgewiesene Infektion bei unbekanntem klinischen Bild}

Labordiagnostischer Nachweis bei fehlenden Angaben zum klinischen Bild (nicht ermittelbar oder nicht erhoben).

\section{Referenzdefinition}

In Veröffentlichungen des Robert Koch-Instituts, die nicht nach Falldefinitionskategorien differenzieren (z.B. wöchentliche „Aktuelle Statistik meldepflichtiger Infektionskrankheiten“ im Epidemiologischen Bulletin), werden nur Erkrankungen der Kategorien B und C gezählt.

\section{Gesetzliche Grundlage}

\section{Meldepflicht}

Dem Gesundheitsamt wird gemäß \6 Abs. I Nr. I Buchst. c IfSG der Krankheitsverdacht, die Erkrankung sowie der Tod an Diphtherie, sowie gemäß $₫ 7$ Abs. I Nr. 8 IfSG der direkte oder indirekte Nachweis von Toxin bildendem Corynebacterium diphtheriae, soweit er auf eine akute Infektion hinweist, namentlich gemeldet. Darüber hinaus stellt das Gesundheitsamt gemäß $『 25$ Abs. I IfSG ggf. eigene Ermittlungen an.

\section{Übermittlung}

Das Gesundheitsamt übermittelt gemäß 『II Abs. I IfSG an die zuständige Landesbehörde nur Erkrankungs- oder Todesfälle und Erregernachweise, die der Falldefinition gemäß $₫ 4$ Abs. 2 Nr. 2 Buchst. a IfSG entsprechen.

Zusätzlich ist gemäß \I2 Abs. I IfSG das Auftreten von Diphtherie vom Gesundheitsamt unverzüglich an die zuständige oberste Landesgesundheitsbehörde und von dieser unverzüglich dem RKI zu übermitteln. Der Begriff 'Auftreten' schließt neben der Infektion/Erkrankung und dem Tod auch Verdachtsfälle ohne labordiagnostischen Nachweis und ohne epidemiologische Bestätigung ein. 


\section{Coxiella burnetii (Q-Fieber)}

ICDio: A78 Q-Fieber (Balkangrippe, Infektion durch Rickettsia (Coxiella) burnetii, Query-Fieber)

\section{Klinisches Bild}

Klinisches Bild eines akuten Q-Fiebers, definiert als mindestens eines der drei folgenden Kriterien:

- Fieber,

- grippeähnliche Beschwerden,

- atypische - Lungenentzündung.

\section{Labordiagnostischer Nachweis}

Positiver Befund mit mindestens einer der vier folgenden Methoden:

[direkter Erregernachweis:]

- Erregerisolierung (kulturell, z.B. in Zellkultur, Brutei),

- Nukleinsäure-Nachweis (z.B. PCR),

[indirekter (serologischer) Nachweis:]

- IgM-Antikörpernachweis gegen Phase-2-Antigene (z.B. IFT, ELISA, MIF),

- Antikörpernachweis gegen Phase-2-Antigene mittels KBR ( deutliche Änderung zwischen zwei Proben ODER einmaliger $\$ deutlich erhöhter Wert).

\section{Epidemiologische Bestätigung}

Epidemiologische Bestätigung, definiert als mindestens einer der beiden folgenden Nachweise unter Berücksichtigung der Inkubationszeit:

- Epidemiologischer Zusammenhang mit einer labordiagnostisch nachgewiesenen Infektion beim Menschen durch

- gemeinsame Expositionsquelle (z.B. Aufenthalt nahe potentiell infizierten Tieren, ihren Ausscheidungen oder Nachgeburten).

- Aufenthalt nahe einem labordiagnostisch nachgewiesen infizierten Tier, seinen Ausscheidungen oder seiner Nachgeburt.

Inkubationszeit ca. I4-2I Tage. 


\section{Über die zuständige Landesbehörde an das RKI zu übermittelnder Fall}

\section{A. Klinisch diagnostizierte Erkrankung}

Entfällt.

\section{B. Klinisch-epidemiologisch bestätigte Erkrankung}

Klinisches Bild eines akuten Q-Fiebers, ohne labordiagnostischen Nachweis, aber mit epidemiologischer Bestätigung.

\section{Klinisch-labordiagnostisch bestätigte Erkrankung}

Klinisches Bild eines akuten Q-Fiebers und labordiagnostischer Nachweis.

D. Labordiagnostisch nachgewiesene Infektion bei nicht erfülltem klinischen Bild

Labordiagnostischer Nachweis bei bekanntem klinischen Bild, das die Kriterien für ein akutes Q-Fieber nicht erfüllt. Hierunter fallen auch asymptomatische Infektionen.

\section{E. Labordiagnostisch nachgewiesene Infektion bei unbekanntem klinischen Bild}

Labordiagnostischer Nachweis bei fehlenden Angaben zum klinischen Bild (nicht ermittelbar oder nicht erhoben).

\section{Referenzdefinition}

In Veröffentlichungen des Robert Koch-Instituts, die nicht nach Falldefinitionskategorien differenzieren (z.B. wöchentliche „Aktuelle Statistik meldepflichtiger Infektionskrankheiten“ im Epidemiologischen Bulletin), werden nur Erkrankungen der Kategorien B und C gezählt.

\section{Gesetzliche Grundlage}

\section{Meldepflicht}

Dem Gesundheitsamt wird gemäß \7 Abs. I Nr. 9 IfSG der direkte oder indirekte Nachweis von Coxiella burnetii, soweit er auf eine akute Infektion hinweist, namentlich gemeldet. Darüber hinaus stellt das Gesundheitsamt gemäß 『25 Abs. I IfSG ggf. eigene Ermittlungen an.

\section{Übermittlung}

Das Gesundheitsamt übermittelt gemäß \II Abs. I IfSG an die zuständige Landesbehörde nur Erkrankungs- oder Todesfälle und Erregernachweise, die der Falldefinition gemäß $\int 4$ Abs. 2 Nr. 2 Buchst. a IfSG entsprechen. 


\section{Cryptosporidium parvum (Kryptosporidiose)}

ICDio: A07.2 Kryptosporidiose

\section{Klinisches Bild}

Klinisches Bild einer akuten Kryptosporidiose, definiert als mindestens eines der beiden folgenden Kriterien:

- Durchfall,

- krampfartige Bauchschmerzen.

\section{Labordiagnostischer Nachweis}

Positiver Befund mit mindestens einer der beiden folgenden Methoden:

[direkter Erregernachweis:]

- mikroskopischer Nachweis von Kryptosporidien oder Cryptosporidium-Oozysten,

- Antigennachweis (z.B. ELISA, IFT).

\section{Epidemiologische Bestätigung}

Epidemiologische Bestätigung, definiert als mindestens einer der vier folgenden Nachweise unter Berücksichtigung der Inkubationszeit:

- Epidemiologischer Zusammenhang mit einer labordiagnostisch nachgewiesenen Infektion beim Menschen durch

- Mensch-zu-Mensch-Übertragung ODER

- gemeinsame Expositionsquelle (z.B.»Badegewässer, $\triangleright$ Tierkontakt, $\triangleright$ Lebensmittel).

- Baden in einem labordiagnostisch nachgewiesen kontaminierten Gewässer.

- Kontakt mit einem labordiagnostisch nachgewiesen infizierten Tier oder seinen Ausscheidungen.

- Verzehr eines Lebensmittels (inkl. Trinkwasser), in dessen Resten C. parvum labordiagnostisch nachgewiesen wurde.

Inkubationszeit ca. I-ı2 Tage, gewöhnlich 7 Tage. 


\section{Über die zuständige Landesbehörde an das RKI zu übermittelnder Fall}

\section{A. Klinisch diagnostizierte Erkrankung}

Entfällt.

\section{B. Klinisch-epidemiologisch bestätigte Erkrankung}

Klinisches Bild einer akuten Kryptosporidiose, ohne labordiagnostischen Nachweis, aber mit epidemiologischer Bestätigung.

\section{Klinisch-labordiagnostisch bestätigte Erkrankung}

Klinisches Bild einer akuten Kryptosporidiose und labordiagnostischer Nachweis.

D. Labordiagnostisch nachgewiesene Infektion bei nicht erfülltem klinischen Bild

Labordiagnostischer Nachweis bei bekanntem klinischen Bild, das die Kriterien für eine akute Kryptosporidiose nicht erfüllt. Hierunter fallen auch asymptomatische Infektionen.

\section{E. Labordiagnostisch nachgewiesene Infektion bei unbekanntem klinischen Bild}

Labordiagnostischer Nachweis bei fehlenden Angaben zum klinischen Bild (nicht ermittelbar oder nicht erhoben).

\section{Referenzdefinition}

In Veröffentlichungen des Robert Koch-Instituts, die nicht nach Falldefinitionskategorien differenzieren (z.B. wöchentliche „Aktuelle Statistik meldepflichtiger Infektionskrankheiten“ im Epidemiologischen Bulletin), werden nur Erkrankungen der Kategorien B und C gezählt.

\section{Gesetzliche Grundlage}

\section{Meldepflicht}

Dem Gesundheitsamt wird gemäß $₫ 7$ Abs. I Nr. Io IfSG der direkte oder indirekte Nachweis von Cryptosporidium parvum, soweit er auf eine akute Infektion hinweist, namentlich gemeldet. Darüber hinaus stellt das Gesundheitsamt gemäß $\int 25$ Abs. I IfSG ggf. eigene Ermittlungen an.

\section{Weitergehende Meldepflicht}

Dem Gesundheitsamt wird gemäß \6 Abs. I Nr. 2 IfSG ggf. auch der Verdacht auf und die Erkrankung an einer akuten infektiösen Gastroenteritis ohne labordiagnostischen Nachweis und ohne epidemiologische Bestätigung gemeldet.

\section{Übermittlung}

Das Gesundheitsamt übermittelt gemäß 』II Abs. I IfSG an die zuständige Landesbehörde nur Erkrankungs- oder Todesfälle und Erregernachweise, die der Falldefinition gemäß $\int 4$ Abs. 2 Nr. 2 Buchst. a IfSG entsprechen. 


\section{Denguevirus (Denguefieber - virales hämorrhagisches Fieber)}

ICDio: A9o Dengue-Fieber [Klassische Dengue],

A9I Hämorrhagisches Dengue-Fieber

\section{Klinisches Bild}

Klinisches Bild eines akuten Denguefiebers, definiert als

- Fieber.

ICDıo: A9o Dengue-Fieber [Klassische Dengue]

Das klinische Bild kann zusätzlich eine der beiden folgenden Formen annehmen:

- Klinisches Bild eines hämorrhagischen Denguefiebers, definiert als

- $\rightarrow$ Fieber UND

- hämorrhagischer Verlauf.

ICDıo: A9ı Hämorrhagisches Dengue-Fieber

- Klinisches Bild eines Dengue-Schock-Syndroms, definiert als Vorliegen aller drei folgenden Kriterien:

- $\rightarrow$ Fieber,

- hämorrhagischer Verlauf,

- Zeichen des Kreislaufversagens.

\section{Labordiagnostischer Nachweis}

Positiver Befund mit mindestens einer der vier folgenden Methoden:

[direkter Erregernachweis:]

- Virusisolierung,

- Nukleinsäure-Nachweis (z.B. PCR),

[indirekter (serologischer) Nachweis:]

- Nachweis von IgM-Antikörpern gegen Antigene eines der vier Dengue-Serotypen $($ deutliche Änderung zwischen zwei Proben ODER einmaliger deutlich erhöhter Wert),

- $>$ deutliche Änderung zwischen zwei Proben beim Nachweis von IgG-Antikörpern gegen Antigene eines der vier Dengue-Serotypen.

\section{Epidemiologische Bestätigung}

Entfällt.

\section{Zusatzinformation}

Inkubationszeit ca. 3-14 Tage, gewöhnlich 4-7 Tage. 


\section{Über die zuständige Landesbehörde an das RKI zu übermittelnder Fall}

\section{A. Klinisch diagnostizierte Erkrankung}

Entfällt.

B. Klinisch-epidemiologisch bestätigte Erkrankung

Entfällt.

\section{Klinisch-labordiagnostisch bestätigte Erkrankung}

Klinisches Bild eines akuten Denguefiebers und labordiagnostischer Nachweis.

D. Labordiagnostisch nachgewiesene Infektion bei nicht erfülltem klinischen Bild

Labordiagnostischer Nachweis bei bekanntem klinischen Bild, das die Kriterien für ein akutes

Denguefieber nicht erfüllt. Hierunter fallen auch asymptomatische Infektionen.

\section{E. Labordiagnostisch nachgewiesene Infektion bei unbekanntem klinischen Bild}

Labordiagnostischer Nachweis bei fehlenden Angaben zum klinischen Bild (nicht ermittelbar oder nicht erhoben).

\section{Referenzdefinition}

In Veröffentlichungen des Robert Koch-Instituts, die nicht nach Falldefinitionskategorien differenzieren (z.B. wöchentliche „Aktuelle Statistik meldepflichtiger Infektionskrankheiten“ im Epidemiologischen Bulletin), werden nur Erkrankungen der Kategorie $\mathbf{C}$ gezählt.

\section{Gesetzliche Grundlage}

\section{Meldepflicht}

Dem Gesundheitsamt wird gemäß $₫ 6$ Abs. I Nr. I Buchst. g IfSG der Krankheitsverdacht, die Erkrankung sowie der Tod an virusbedingtem hämorrhagischen Fieber, sowie gemäß $\ 7$ Abs. I Nr. 47 IfSG der direkte oder indirekte Nachweis von anderen Erregern hämorrhagischer Fieber (d.h. außer den in $\ 7$ Abs. I IfSG namentlich benannten), soweit er auf eine akute Infektion hinweist, namentlich gemeldet. Darüber hinaus stellt das Gesundheitsamt gemäß $\int 25$ Abs. I IfSG ggf. eigene Ermittlungen an.

\section{Übermittlung}

Das Gesundheitsamt übermittelt gemäß 』II Abs. I IfSG an die zuständige Landesbehörde nur Erkrankungs- oder Todesfälle und Erregernachweise, die der Falldefinition gemäß $\int 4$ Abs. 2 Nr. 2 Buchst. a IfSG entsprechen.

Zusätzlich ist gemäß \I2 Abs. I IfSG das Auftreten eines hämorrhagischen Verlaufs von Denguefieber vom Gesundheitsamt unverzüglich an die zuständige oberste Landesgesundheitsbehörde und von dieser unverzüglich dem RKI zu übermitteln. Der Begriff 'Auftreten' schließt neben der Infektion/Erkrankung und dem Tod auch Verdachtsfälle ohne labordiagnostischen Nachweis ein. 


\section{Ebolavirus (Ebolafieber - virales hämorrhagisches Fieber)}

ICDıо: A98.4 Ebola-Viruskrankheit

\section{Vorbemerkung}

Ebolafieber kann als akut fieberhaftes Krankheitsbild auch ohne Zeichen einer $\$ hämorrhagischen Verlaufsform auftreten.

\section{Klinisches Bild}

Klinisches Bild eines akuten Ebolafiebers, definiert als mindestens eines der beiden folgenden Kriterien:

- Fieber,

- hämorrhagischer Verlauf.

\section{Labordiagnostischer Nachweis}

Positiver Befund mit mindestens einer der vier folgenden Methoden:

[direkter Erregernachweis:]

- Virusisolierung,

- -Nukleinsäure-Nachweis (z.B. PCR),

- Antigennachweis (z.B. ELISA),

- Elektronenmikroskopie.

\section{Epidemiologische Bestätigung}

Entfällt.

\section{Zusatzinformation}

Inkubationszeit ca. 2-2I Tage. 


\section{Über die zuständige Landesbehörde an das RKI zu übermittelnder Fall}

\section{A. Klinisch diagnostizierte Erkrankung}

Entfällt.

B. Klinisch-epidemiologisch bestätigte Erkrankung

Entfällt.

\section{Klinisch-labordiagnostisch bestätigte Erkrankung}

Klinisches Bild eines akuten Ebolafiebers und labordiagnostischer Nachweis.

D. Labordiagnostisch nachgewiesene Infektion bei nicht erfülltem klinischen Bild

Labordiagnostischer Nachweis bei bekanntem klinischen Bild, das die Kriterien für ein akutes Ebolafieber nicht erfüllt. Hierunter fallen auch asymptomatische Infektionen.

\section{E. Labordiagnostisch nachgewiesene Infektion bei unbekanntem klinischen Bild}

Labordiagnostischer Nachweis bei fehlenden Angaben zum klinischen Bild (nicht ermittelbar oder nicht erhoben).

\section{Referenzdefinition}

In Veröffentlichungen des Robert Koch-Instituts, die nicht nach Falldefinitionskategorien differenzieren (z.B. wöchentliche „Aktuelle Statistik meldepflichtiger Infektionskrankheiten“ im Epidemiologischen Bulletin), werden nur Erkrankungen der Kategorie $\mathbf{C}$ gezählt.

\section{Gesetzliche Grundlage}

\section{Meldepflicht}

Dem Gesundheitsamt wird gemäß $\int 6$ Abs. I Nr. I Buchst. g IfSG der Krankheitsverdacht, die Erkrankung sowie der Tod an virusbedingtem hämorrhagischen Fieber, sowie gemäß $\int 7$ Abs. I Nr. II IfSG der direkte oder indirekte Nachweis von Ebolavirus, soweit er auf eine akute Infektion hinweist, namentlich gemeldet. Darüber hinaus stellt das Gesundheitsamt gemäß \25 Abs. I IfSG ggf. eigene Ermittlungen an.

\section{Übermittlung}

Das Gesundheitsamt übermittelt gemäß \II Abs. I IfSG an die zuständige Landesbehörde nur Erkrankungs- oder Todesfälle und Erregernachweise, die der Falldefinition gemäß $\ 4$ Abs. 2 Nr. 2 Buchst. a IfSG entsprechen.

Zusätzlich ist gemäß \I2 Abs. I IfSG das Auftreten von Ebolafieber vom Gesundheitsamt unverzüglich an die zuständige oberste Landesgesundheitsbehörde und von dieser unverzüglich dem RKI zu übermitteln. Der Begriff 'Auftreten' schließt neben der Infektion/Erkrankung und dem Tod auch Verdachtsfälle ohne labordiagnostischen Nachweis ein. 


\section{4a Escherichia coli, enterohämorrhagisch (EHEC-Erkrankung)}

syn. STEC-Erkrankung

ICDıo: Ao4.3 Darminfektion durch enterohämorrhagische Escherichia coli

\section{Vorbemerkung}

Diese Übermittlungskategorie hat sich durch Ausgliederung und Einrichtung einer separaten Übermittlungskategorie 'HUS, enteropathisch' früheren Versionen gegenüber geändert. Sie umfasst jetzt nur noch Fälle ohne das klinische Bild eines hämolytisch-urämischen Syndroms (HUS). Die in der früheren EHEC-Falldefinition enthaltene Differenzierung zwischen inkomplettem und komplettem HUS und thrombotisch-thrombozytopenischer Purpura (TTP) entfällt.

\section{Ausschlusskriterien}

- Klinisches Bild eines HUS (siehe Falldefinition des enteropathischen HUS).

\section{Klinisches Bild}

Klinisches Bild einer akuten EHEC-Erkrankung, definiert als mindestens eines der drei folgenden Kriterien:

- Durchfall,

- krampfartige Bauchschmerzen,

- Erbrechen.

\section{Labordiagnostischer Nachweis}

Positiver Befund mit mindestens einer der beiden folgenden Kombinationen:

[Toxinnachweis:]

- Erregeranzucht und -isolierung nur aus Stuhl UND Nachweis des Shigatoxins (Stxi bzw. Stx2; syn. Verocytotoxin, VT) mittels ELISA in der $\boldsymbol{E}$.-coli-Kultur,

- Erregeranzucht in Mischkultur, Stuhlanreicherungskultur oder Isolierung von E. coli UND

-Nukleinsäure-Nachweis (z.B. PCR) des Shigatoxin-Gens (stxI, stxz) aus dieser Probe.

\section{Zusatzinformationen}

- Das Ergebnis der Serovarbestimmung sollte übermittelt werden.

- Der alleinige Nachweis des Shigatoxins mittels ELISA in der Stuhlanreicherungskultur gilt nicht als labordiagnostischer Nachweis.

\section{Epidemiologische Bestätigung}

Epidemiologische Bestätigung, definiert als mindestens einer der vier folgenden Nachweise unter Berücksichtigung der Inkubationszeit:

- Epidemiologischer Zusammenhang mit einer labordiagnostisch nachgewiesenen Infektion beim Menschen durch

- Mensch-zu-Mensch-Übertragung ODER

- gemeinsame Expositionsquelle (z.B. $\triangleright$ Badegewässer, $>$ Lebensmittel, $>$ Tierkontakt).

- Baden in einem labordiagnostisch nachgewiesen kontaminierten Gewässer. 
- Kontakt mit einem labordiagnostisch nachgewiesen infizierten Tier (z.B. Streichelzoo) oder seinen Ausscheidungen, oder Verzehr seiner Produkte (z.B. Rohmilch).

- Verzehr eines Lebensmittels (z.B. Rohmilch, Trinkwasser), in dessen Resten Shigatoxin-bildende E. coli labordiagnostisch nachgewiesen wurde.

Inkubationszeit ca. 2-Io Tage.

\title{
Über die zuständige Landesbehörde an das RKI zu übermittelnder Fall (unter Berücksichtigung der Ausschlusskriterien)
}

\author{
A. Klinisch diagnostizierte Erkrankung \\ Entfällt.
}

\section{B. Klinisch-epidemiologisch bestätigte Erkrankung}

Klinisches Bild einer akuten EHEC-Erkrankung, ohne labordiagnostischen Nachweis, aber mit epidemiologischer Bestätigung.

\section{Klinisch-labordiagnostisch bestätigte Erkrankung}

Klinisches Bild einer akuten EHEC-Erkrankung und labordiagnostischer Nachweis.

D. Labordiagnostisch nachgewiesene Infektion bei nicht erfülltem klinischen Bild

Labordiagnostischer Nachweis bei bekanntem klinischen Bild, das die Kriterien für eine akute EHECErkrankung nicht erfüllt. Hierunter fallen auch asymptomatische Infektionen.

E. Labordiagnostisch nachgewiesene Infektion bei unbekanntem klinischen Bild

Labordiagnostischer Nachweis bei fehlenden Angaben zum klinischen Bild (nicht ermittelbar oder nicht erhoben).

\section{Referenzdefinition}

In Veröffentlichungen des Robert Koch-Instituts, die nicht nach Falldefinitionskategorien differenzieren (z.B. wöchentliche „Aktuelle Statistik meldepflichtiger Infektionskrankheiten“ im Epidemiologischen Bulletin), werden nur Erkrankungen der Kategorien B und C gezählt.

\section{Gesetzliche Grundlage}

\section{Meldepflicht}

Dem Gesundheitsamt wird gemäß $₫ 7$ Abs. I Nr. I2 Buchst. a IfSG der direkte oder indirekte Nachweis von enterohämorrhagischen Stämmen von Escherichia coli (EHEC), soweit er auf eine akute Infektion hinweist, namentlich gemeldet. Darüber hinaus stellt das Gesundheitsamt gemäß 『25 Abs. I IfSG ggf. eigene Ermittlungen an.

\section{Weitergehende Meldepflicht}

Dem Gesundheitsamt wird gemäß \6 Abs. I Nr. 2 IfSG ggf. auch der Krankheitsverdacht, definiert als klinisches Bild einer EHEC-Erkrankung mit alleinigem Shigatoxin-Nachweis in der Stuhlanreicherungskultur bei negativem kulturellen Nachweis und ohne epidemiologische Bestätigung, erfasst.

\section{Übermittlung}

Das Gesundheitsamt übermittelt gemäß \II Abs. I IfSG an die zuständige Landesbehörde nur Erkrankungs- oder Todesfälle und Erregernachweise, die der Falldefinition gemäß $\int 4$ Abs. 2 Nr. 2 Buchst. a IfSG entsprechen. 


\section{4b Escherichia coli, sonstige darmpathogene Stämme (E.-coli-Enteritis)}

ICDıo: Ao4.4 Sonstige Darminfektionen durch Escherichia coli (Enteritis durch Escherichia coli o.n.A.)

\section{Vorbemerkung}

Diese Übermittlungskategorie umfasst: enteropathogene $E$. coli (EPEC), enteroinvasive $E$. coli (EIEC), enterotoxische $E$. coli (ETEC), enteroaggregative $E$. coli (EAggEC), diffus-adhärente $E$. coli (DAEC).

\section{Ausschlusskriterien}

- Infektion mit EHEC,

- klinisches Bild eines HUS (siehe Falldefinition des enteropathischen HUS).

\section{Klinisches Bild}

Klinisches Bild einer akuten E.-coli-Enteritis, definiert als mindestens eines der beiden folgenden Kriterien:

- Durchfall,

- krampfartige Bauchschmerzen.

\section{Labordiagnostischer Nachweis}

Positiver Befund mit mindestens einer der beiden folgenden Methoden:

[direkter Erregernachweis:]

- Erregerisolierung (kulturell) nur aus Stuhl Und Zuordnung des Isolats zu einem E.-coli-Pathovar (EPEC; ETEC; EIEC; EAggEC; DAEC),

\section{[Virulenzfaktornachweis:]}

- Nukleinsäure-Nachweis (z.B. PCR) eines Gens für etablierte Virulenzfaktoren (z.B. eae, ipaH) nur in Mischkultur, Stuhlanreicherungskultur oder im E.-coli-Isolat UND Zuordnung zu einem E.-coli-Pathovar (EPEC; ETEC; EIEC; EAggEC; DAEC).

\section{Zusatzinformation}

Das Ergebnis der Serovarbestimmung (z.B. Agglutinationstest) und des Virulenzmusters (z.B. ELISA, PCR) sollte übermittelt werden.

\section{Epidemiologische Bestätigung}

Epidemiologische Bestätigung, definiert als folgender Nachweis unter Berücksichtigung der Inkubationszeit:

- Epidemiologischer Zusammenhang mit einer labordiagnostisch nachgewiesenen Infektion beim Menschen durch

- Mensch-zu-Mensch-Übertragung ODER

- gemeinsame Expositionsquelle (z.B. \Lebensmittel, $>$ Tierkontakt).

Inkubationszeit ca. 9-72 Stunden. 


\title{
Über die zuständige Landesbehörde an das RKI zu übermittelnder Fall (unter Berücksichtigung der Ausschlusskriterien)
}

\author{
A. Klinisch diagnostizierte Erkrankung \\ Entfällt.
}

\section{B. Klinisch-epidemiologisch bestätigte Erkrankung}

Klinisches Bild einer akuten E.-coli-Enteritis, ohne labordiagnostischen Nachweis, aber mit epidemiologischer Bestätigung.

\section{Klinisch-labordiagnostisch bestätigte Erkrankung}

Klinisches Bild einer akuten E.-coli-Enteritis und labordiagnostischer Nachweis.

D. Labordiagnostisch nachgewiesene Infektion bei nicht erfülltem klinischen Bild

Labordiagnostischer Nachweis bei bekanntem klinischen Bild, das die Kriterien für eine akute E.-coliEnteritis nicht erfüllt. Hierunter fallen auch asymptomatische Infektionen.

E. Labordiagnostisch nachgewiesene Infektion bei unbekanntem klinischen Bild

Labordiagnostischer Nachweis bei fehlenden Angaben zum klinischen Bild (nicht ermittelbar oder nicht erhoben).

\section{Referenzdefinition}

In Veröffentlichungen des Robert Koch-Instituts, die nicht nach Falldefinitionskategorien differenzieren (z.B. wöchentliche „Aktuelle Statistik meldepflichtiger Infektionskrankheiten“ im Epidemiologischen Bulletin), werden nur Erkrankungen der Kategorien B und C gezählt.

\section{Gesetzliche Grundlage}

\section{Meldepflicht}

Dem Gesundheitsamt wird gemäß $\mathbb{7}$ Abs. I Nr. I2 Buchst. b IfSG der direkte oder indirekte Nachweis von sonstigen darmpathogenen Stämmen von Escherichia coli (d.h. außer EHEC), soweit er auf eine akute Infektion hinweist, namentlich gemeldet. Darüber hinaus stellt das Gesundheitsamt gemäß 『25 Abs. I IfSG ggf. eigene Ermittlungen an.

\section{Weitergehende Meldepflicht}

Dem Gesundheitsamt wird gemäß \6 Abs. I Nr. 2 IfSG ggf. auch der Verdacht auf und die Erkrankung an einer akuten infektiösen Gastroenteritis ohne labordiagnostischen Nachweis und ohne epidemiologische Bestätigung gemeldet.

\section{Übermittlung}

Das Gesundheitsamt übermittelt gemäß 』II Abs. I IfSG an die zuständige Landesbehörde nur Erkrankungs- oder Todesfälle und Erregernachweise, die der Falldefinition gemäß $\int 4$ Abs. 2 Nr. 2 Buchst. a IfSG entsprechen. 


\section{Francisella tularensis (Tularämie)}

ICDıо: A2ı.- Tularämie (inkl.: Hasenpest, Hirschfliegenfieber, Infektion durch Francisella tularensis),

A2ı.o Ulzeroglanduläre Tularämie,

A2r.I Okuloglanduläre Tularämie,

A2r.2 Pulmonale Tularämie,

A2I.3 Gastrointestinale Tularämie (abdominale Tularämie),

A2I.7 Generalisierte Tularämie,

A2r.8 Sonstige Formen der Tularämie,

A2I.9 Tularämie, nicht näher bezeichnet

\section{Klinisches Bild}

Klinisches Bild einer akuten Tularämie, definiert als mindestens eines der sieben folgenden Kriterien:

- Fieber,

- Lymphknotenschwellung,

- Durchfall,

- Erbrechen,

- Dyspnoe (Atemstörung),

- - Lungenentzündung,

- septisches Krankheitsbild.

Das klinische Bild kann eine der sieben folgenden Formen annehmen:

- Ulzeroglandulär (regionale Lymphknotenschwellung mit Hautgeschwür).

ICDıо: A2ı.o Ulzeroglanduläre Tularämie

- Glandulär (regionale Lymphknotenschwellung ohne Hautgeschwür).

- Oculoglandulär (Bindehautentzündung UND Lymphknotenschwellung).

ICDıо: A2r.I Okuloglanduläre Tularämie

- Oropharyngeal (Entzündung der Mundschleimhaut, des Rachens oder der Tonsillen unD zervikale Lymphknotenschwellung).

- Intestinal (Bauchschmerzen, $>$ Durchfall, Erbrechen).

ICDıo: A2r.3 Gastrointestinale Tularämie (abdominale Tularämie)

- Pulmonal (Dyspnoe (Atemstörung) ODER \Lungenentzündung).

ICDıо: A2r.2 Pulmonale Tularämie

- Typhoidal ( Fieber UND $\gg$ septisches Krankheitsbild).

ICDıо: A2ı.7 Generalisierte Tularämie 


\section{Labordiagnostischer Nachweis}

Positiver Befund mit mindestens einer der vier folgenden Methoden:

[direkter Erregernachweis:]

- Erregerisolierung (kulturell),

- Dukleinsäure-Nachweis (z.B. PCR),

- Antigennachweis (z.B. ELISA, IFT).

[indirekter (serologischer) Nachweis:]

- Antikörpernachweis ( deutliche Änderung zwischen zwei Proben ODER einmaliger $\triangleright$ deutlich erhöhter Wert, z.B. ELISA, Western-Blot, MAT, Röhrchen-Agglutinationstest, Hämagglutinationstest, KBR).

\section{Epidemiologische Bestätigung}

Epidemiologische Bestätigung, definiert als mindestens einer der drei folgenden Nachweise unter Berücksichtigung der Inkubationszeit:

- Epidemiologischer Zusammenhang mit einer labordiagnostisch nachgewiesenen Infektion beim Menschen durch

- gemeinsame Expositionsquelle (z.B. $\triangleright$ Tierkontakt, $\triangleright$ Lebensmittel).

- Kontakt mit einem labordiagnostisch nachgewiesen infizierten Tier oder seinen Ausscheidungen, oder Verzehr seiner Produkte.

- Verzehr eines Lebensmittels (inkl. Trinkwasser), in dessen Resten $F$. tularensis labordiagnostisch nachgewiesen wurde.

Inkubationszeit ca. I-I4 Tage, gewöhnlich 3-5 Tage. 


\section{Über die zuständige Landesbehörde an das RKI zu übermittelnder Fall}

\section{A. Klinisch diagnostizierte Erkrankung}

Entfällt.

\section{B. Klinisch-epidemiologisch bestätigte Erkrankung}

Klinisches Bild einer akuten Tularämie, ohne labordiagnostischen Nachweis, aber mit epidemiologischer Bestätigung.

\section{Klinisch-labordiagnostisch bestätigte Erkrankung}

Klinisches Bild einer akuten Tularämie und labordiagnostischer Nachweis.

D. Labordiagnostisch nachgewiesene Infektion bei nicht erfülltem klinischen Bild

Labordiagnostischer Nachweis bei bekanntem klinischen Bild, das die Kriterien für eine akute Tularämie nicht erfüllt. Hierunter fallen auch asymptomatische Infektionen.

\section{E. Labordiagnostisch nachgewiesene Infektion bei unbekanntem klinischen Bild}

Labordiagnostischer Nachweis bei fehlenden Angaben zum klinischen Bild (nicht ermittelbar oder nicht erhoben).

\section{Referenzdefinition}

In Veröffentlichungen des Robert Koch-Instituts, die nicht nach Falldefinitionskategorien differenzieren (z.B. wöchentliche „Aktuelle Statistik meldepflichtiger Infektionskrankheiten“ im Epidemiologischen Bulletin), werden nur Erkrankungen der Kategorien $\mathbf{B}$ und $\mathbf{C}$ gezählt.

\section{Gesetzliche Grundlage}

\section{Meldepflicht}

Dem Gesundheitsamt wird gemäß $\int 7$ Abs. I Nr. I3 IfSG der direkte oder indirekte Nachweis von Francisella tularensis, soweit er auf eine akute Infektion hinweist, namentlich gemeldet. Darüber hinaus stellt das Gesundheitsamt gemäß $『 25$ Abs. I IfSG ggf. eigene Ermittlungen an.

\section{Übermittlung}

Das Gesundheitsamt übermittelt gemäß \II Abs. I IfSG an die zuständige Landesbehörde nur Erkrankungs- oder Todesfälle und Erregernachweise, die der Falldefinition gemäß $\ 4$ Abs. 2 Nr. 2 Buchst. a IfSG entsprechen. 


\title{
16 FSME-Virus (Frühsommer-Meningoenzephalitis, FSME)
}

ICDıо: A84.I Mitteleuropäische Enzephalitis, durch Zecken übertragen (Zentraleuropäische Frühsommer-Meningoenzephalitis [FSME])

\section{Klinisches Bild}

Klinisches Bild einer akuten FSME, definiert als mindestens eines der beiden folgenden Kriterien:

- -grippeähnliche Beschwerden,

- ZNS-Symptomatik (z.B. Meningitis, Enzephalitis, Myelitis).

\section{Zusatzinformationen}

- Typisch ist ein Verlauf in zwei Phasen, mit einer initialen grippeähnlichen Symptomatik und einer nach einem symptomfreien Intervall von 4-Io Tagen einsetzenden ZNS-Symptomatik. Jedoch kann jede dieser Phasen auch für sich allein auftreten.

- Bei impfpräventablen Krankheiten sollten stets Angaben zur Impfanamnese (Anzahl der vorangegangenen Impfungen, Art und Datum der letzten Impfung) erhoben (z.B. Impfbuchkontrolle) und übermittelt werden.

\section{Labordiagnostischer Nachweis}

Positiver Befund mit mindestens einer der vier folgenden Methoden:

[direkter Erregernachweis:]

- Nukleinsäure-Nachweis (z.B. PCR) nur in Blut oder Liquor, post mortem in Organgewebe,

[indirekter (serologischer) Nachweis:]

- IgM- UND IgG-Antikörpernachweis (einmalig \deutlich erhöhter Wert, z.B. ELISA, NT) nur in Blut oder Liquor,

- \deutliche Änderung zwischen zwei Proben beim IgG-Antikörpernachweis (z.B. ELISA, NT),

- Nachweis intrathekal gebildeter FSME-spezifischer Antikörper (erhöhter Liquor/Serum-Index).

\section{Zusatzinformation}

Die Bewertung von Antikörpernachweisen setzt die Kenntnis eines eventuellen zeitlichen Zusammenhangs mit einer FSME-Impfung voraus.

\section{Epidemiologische Bestätigung}

Entfällt.

\author{
Zusatzinformation \\ Inkubationszeit ca. 7-I4 Tage.
}




\section{Über die zuständige Landesbehörde an das RKI zu übermittelnder Fall}

\section{A. Klinisch diagnostizierte Erkrankung}

Entfällt.

B. Klinisch-epidemiologisch bestätigte Erkrankung

Entfällt.

C. Klinisch-labordiagnostisch bestätigte Erkrankung

Klinisches Bild einer akuten FSME und labordiagnostischer Nachweis.

D. Labordiagnostisch nachgewiesene Infektion bei nicht erfülltem klinischen Bild

Labordiagnostischer Nachweis bei bekanntem klinischen Bild, das die Kriterien für eine akute FSME nicht erfüllt. Hierunter fallen auch asymptomatische Infektionen.

\section{E. Labordiagnostisch nachgewiesene Infektion bei unbekanntem klinischen Bild}

Labordiagnostischer Nachweis bei fehlenden Angaben zum klinischen Bild (nicht ermittelbar oder nicht erhoben).

\section{Referenzdefinition}

In Veröffentlichungen des Robert Koch-Instituts, die nicht nach Falldefinitionskategorien differenzieren (z.B. wöchentliche „Aktuelle Statistik meldepflichtiger Infektionskrankheiten“ im Epidemiologischen Bulletin), werden nur Erkrankungen der Kategorie $\mathbf{C}$ gezählt.

\section{Gesetzliche Grundlage}

\section{Meldepflicht}

Dem Gesundheitsamt wird gemäß $\llbracket 7$ Abs. I Nr. I4 IfSG der direkte oder indirekte Nachweis von FSME-Virus, soweit er auf eine akute Infektion hinweist, namentlich gemeldet. Darüber hinaus stellt das Gesundheitsamt gemäß

$\int 25$ Abs. I IfSG ggf. eigene Ermittlungen an.

\section{Übermittlung}

Das Gesundheitsamt übermittelt gemäß 『II Abs. I IfSG an die zuständige Landesbehörde nur Erkrankungs- oder Todesfälle und Erregernachweise, die der Falldefinition gemäß $\int 4$ Abs. 2 Nr. 2 Buchst. a IfSG entsprechen. 


\section{Gelbfiebervirus (Gelbfieber - virales hämorrhagisches Fieber)}

ICDio: A95-- Gelbfieber,

A95.0 Buschgelbfieber (Dschungelgelbfieber, Silvatisches Gelbfieber),

A95.I Urbanes Gelbfieber,

A95.9 Gelbfieber, nicht näher bezeichnet

\section{Vorbemerkung}

Gelbfieber kann als akut fieberhaftes Krankheitsbild auch ohne Zeichen einer hämorrhagischen Verlaufsform auftreten.

\section{Klinisches Bild}

Klinisches Bild eines akuten Gelbfiebers, definiert als mindestens eines der beiden folgenden Kriterien:

- $\rightarrow$ Fieber,

- hämorrhagischer Verlauf.

\section{Zusatzinformation}

Bei impfpräventablen Krankheiten sollten stets Angaben zur Impfanamnese (Anzahl der vorangegangenen Impfungen, Art und Datum der letzten Impfung) erhoben (z.B. Impfbuchkontrolle) und übermittelt werden.

\section{Labordiagnostischer Nachweis}

Positiver Befund mit mindestens einer der drei folgenden Methoden:

[direkter Erregernachweis:]

- Virusisolierung,

- Nukleinsäure-Nachweis (z.B. PCR),

- Antigennachweis (z.B. IFT).

\section{Zusatzinformation}

Die Bewertung von Erregernachweisen setzt die Kenntnis eines eventuellen zeitlichen Zusammenhangs mit einer Gelbfieberimpfung voraus. Das Ergebnis der Differenzierung nach Wildvirus oder Impfvirus sollte übermittelt werden.

\section{Epidemiologische Bestätigung}

Entfällt.

\section{Zusatzinformation}

Inkubationszeit ca. 3-6 Tage. 


\section{Über die zuständige Landesbehörde an das RKI zu übermittelnder Fall}

\section{A. Klinisch diagnostizierte Erkrankung}

Entfällt.

B. Klinisch-epidemiologisch bestätigte Erkrankung

Entfällt.

\section{Klinisch-labordiagnostisch bestätigte Erkrankung}

Klinisches Bild eines akuten Gelbfiebers und labordiagnostischer Nachweis.

D. Labordiagnostisch nachgewiesene Infektion bei nicht erfülltem klinischen Bild

Labordiagnostischer Nachweis bei bekanntem klinischen Bild, das die Kriterien für ein akutes

Gelbfieber nicht erfüllt. Hierunter fallen auch asymptomatische Infektionen.

\section{E. Labordiagnostisch nachgewiesene Infektion bei unbekanntem klinischen Bild}

Labordiagnostischer Nachweis bei fehlenden Angaben zum klinischen Bild (nicht ermittelbar oder nicht erhoben).

\section{Referenzdefinition}

In Veröffentlichungen des Robert Koch-Instituts, die nicht nach Falldefinitionskategorien differenzieren (z.B. wöchentliche „Aktuelle Statistik meldepflichtiger Infektionskrankheiten“ im Epidemiologischen Bulletin), werden nur Erkrankungen der Kategorie $\mathbf{C}$ gezählt.

\section{Gesetzliche Grundlage}

\section{Meldepflicht}

Dem Gesundheitsamt wird gemäß \6 Abs. I Nr. I Buchst. g IfSG der Krankheitsverdacht, die Erkrankung sowie der Tod an virusbedingtem hämorrhagischen Fieber, sowie gemäß $\int 7$ Abs. I Nr. I5 IfSG der direkte oder indirekte Nachweis von Gelbfiebervirus, soweit er auf eine akute Infektion hinweist, namentlich gemeldet. Darüber hinaus stellt das Gesundheitsamt gemäß $\int 25$ Abs. I IfSG ggf. eigene Ermittlungen an.

\section{Übermittlung}

Das Gesundheitsamt übermittelt gemäß 『II Abs. I IfSG an die zuständige Landesbehörde nur Erkrankungs- oder Todesfälle und Erregernachweise, die der Falldefinition gemäß $\int 4$ Abs. 2 Nr. 2 Buchst. a IfSG entsprechen.

Zusätzlich ist gemäß \I2 Abs. I IfSG das Auftreten von Gelbfieber vom Gesundheitsamt unverzüglich an die zuständige oberste Landesgesundheitsbehörde und von dieser unverzüglich dem RKI zu übermitteln. Der Begriff 'Auftreten' schließt neben der Infektion/Erkrankung und dem Tod auch Verdachtsfälle ohne labordiagnostischen Nachweis ein. 


\section{Giardia lamblia (Giardiasis)}

syn. Lambliasis

ICDıо: Ao7.I Giardiasis [Lambliasis]

\section{Klinisches Bild}

Klinisches Bild einer akuten Giardiasis, definiert als mindestens eines der drei folgenden Kriterien:

- Durchfall,

- krampfartige Bauchschmerzen,

- Blähungen.

\section{Labordiagnostischer Nachweis}

Positiver Befund mit mindestens einer der beiden folgenden Methoden:

[direkter Erregernachweis:]

- mikroskopischer Nachweis von Trophozoiten oder Zysten nur in Stuhl, Duodenalsekret oder (histologisch) Darmschleimhaut,

- Antigennachweis (z.B. ELISA, IFT) nur im Stuhl.

\section{Epidemiologische Bestätigung}

Epidemiologische Bestätigung, definiert als mindestens einer der drei folgenden Nachweise unter Berücksichtigung der Inkubationszeit:

- Epidemiologischer Zusammenhang mit einer labordiagnostisch nachgewiesenen Infektion beim Menschen durch

- Mensch-zu-Mensch-Übertragung ODER

- gemeinsame Expositionsquelle (z.B. $\triangleright$ Badegewässer, $>$ Lebensmittel).

- Baden in einem labordiagnostisch nachgewiesen kontaminierten Gewässer.

- Verzehr eines Lebensmittels (inkl. Trinkwasser), in dessen Resten G. lamblia labordiagnostisch nachgewiesen wurde.

Inkubationszeit ca. 3-25 Tage, gelegentlich länger. 


\section{Über die zuständige Landesbehörde an das RKI zu übermittelnder Fall}

\section{A. Klinisch diagnostizierte Erkrankung}

Entfällt.

\section{B. Klinisch-epidemiologisch bestätigte Erkrankung}

Klinisches Bild einer akuten Giardiasis, ohne labordiagnostischen Nachweis, aber mit epidemiologischer Bestätigung.

\section{Klinisch-labordiagnostisch bestätigte Erkrankung}

Klinisches Bild einer akuten Giardiasis und labordiagnostischer Nachweis.

D. Labordiagnostisch nachgewiesene Infektion bei nicht erfülltem klinischen Bild

Labordiagnostischer Nachweis bei bekanntem klinischen Bild, das die Kriterien für eine akute Giardiasis nicht erfüllt. Hierunter fallen auch asymptomatische Infektionen.

\section{E. Labordiagnostisch nachgewiesene Infektion bei unbekanntem klinischen Bild}

Labordiagnostischer Nachweis bei fehlenden Angaben zum klinischen Bild (nicht ermittelbar oder nicht erhoben).

\section{Referenzdefinition}

In Veröffentlichungen des Robert Koch-Instituts, die nicht nach Falldefinitionskategorien differenzieren (z.B. wöchentliche „Aktuelle Statistik meldepflichtiger Infektionskrankheiten“ im Epidemiologischen Bulletin), werden nur Erkrankungen der Kategorien $\mathbf{B}$ und $\mathbf{C}$ gezählt.

\section{Gesetzliche Grundlage}

\section{Meldepflicht}

Dem Gesundheitsamt wird gemäß 『7 Abs. I Nr. I6 IfSG der direkte oder indirekte Nachweis von Giardia lamblia, soweit er auf eine akute Infektion hinweist, namentlich gemeldet. Darüber hinaus stellt das Gesundheitsamt gemäß $\int 25$ Abs. I IfSG ggf. eigene Ermittlungen an.

\section{Weitergehende Meldepflicht}

Dem Gesundheitsamt wird gemäß \6 Abs. I Nr. 2 IfSG ggf. auch der Verdacht auf und die Erkrankung an einer akuten infektiösen Gastroenteritis ohne labordiagnostischen Nachweis und ohne epidemiologische Bestätigung gemeldet.

\section{Übermittlung}

Das Gesundheitsamt übermittelt gemäß 『II Abs. I IfSG an die zuständige Landesbehörde nur Erkrankungs- oder Todesfälle und Erregernachweise, die der Falldefinition gemäß \4 Abs. 2 Nr. 2 Buchst. a IfSG entsprechen. 


\section{Haemophilus influenzae} (invasive Haemophilus-influenzae-Erkrankung)

ICDıо: A4r.3 Sepsis durch Haemophilus influenzae, Goo.o Meningitis durch Haemophilus influenzae,

A49.2 Infektion durch Haemophilus influenzae, nicht näher bezeichnet

\section{Klinisches Bild}

Klinisches Bild einer invasiven Haemophilus-influenzae-Erkrankung, definiert als mindestens eines der zwölf folgenden Kriterien:

- $\rightarrow$ Fieber,

- meningeale Zeichen (z.B. Nackensteifigkeit, Kopfschmerzen, veränderte Bewusstseinslage),

- Hirndruckzeichen (z.B. aufgetriebene Fontanelle, Erbrechen),

- -septisches Krankheitsbild,

- Epiglottitis (Kehldeckelentzündung),

- septische Arthritis (Gelenkentzündung),

- Osteomyelitis (Knochenmarkentzündung),

- Phlegmone oder Zellulitis (diffuse Bindegewebsentzündung),

- - Lungenentzündung,

- Endo-, Myo- oder Perikarditis (Herzinnenwand-, -muskel- oder -beutelentzündung),

- Empyem (Eiteransammlung in einer vorbestehenden Körperhöhle),

- Sinusitis (Nasennebenhöhlenentzündung).

\section{Zusatzinformation}

Bei impfpräventablen Krankheiten sollten stets Angaben zur Impfanamnese (Anzahl der vorangegangenen Impfungen, Art und Datum der letzten Impfung) erhoben (z.B. Impfbuchkontrolle) und übermittelt werden.

\section{Labordiagnostischer Nachweis}

Positiver Befund mit mindestens einer der beiden folgenden Methoden:

[direkter Erregernachweis nur in Liquor oder Blut:]

- Erregerisolierung (kulturell),

- Nukleinsäure-Nachweis (z.B. PCR).

\section{Zusatzinformation}

Das Ergebnis der Serotypbestimmung sollte übermittelt werden. Nur Kapseltyp B ist impfpräventabel.

\section{Epidemiologische Bestätigung}

Epidemiologische Bestätigung, definiert als folgender Nachweis unter Berücksichtigung der Inkubationszeit:

- Epidemiologischer Zusammenhang mit einer labordiagnostisch nachgewiesenen Infektion beim Menschen durch

- Mensch-zu-Mensch-Übertragung.

Inkubationszeit unbekannt, wahrscheinlich 2-4 Tage. 


\section{Über die zuständige Landesbehörde an das RKI zu übermittelnder Fall}

\section{A. Klinisch diagnostizierte Erkrankung}

Entfällt.

\section{B. Klinisch-epidemiologisch bestätigte Erkrankung}

Klinisches Bild einer invasiven Haemophilus-influenzae-Erkrankung, ohne labordiagnostischen Nachweis, aber mit epidemiologischer Bestätigung.

\section{Klinisch-labordiagnostisch bestätigte Erkrankung}

Klinisches Bild einer invasiven Haemophilus-influenzae-Erkrankung und labordiagnostischer Nachweis.

D. Labordiagnostisch nachgewiesene Infektion bei nicht erfülltem klinischen Bild

Labordiagnostischer Nachweis bei bekanntem klinischen Bild, das die Kriterien für eine invasive Haemophilus-influenzae-Erkrankung nicht erfüllt.

\section{E. Labordiagnostisch nachgewiesene Infektion bei unbekanntem klinischen Bild}

Labordiagnostischer Nachweis bei fehlenden Angaben zum klinischen Bild (nicht ermittelbar oder nicht erhoben).

\section{Referenzdefinition}

In Veröffentlichungen des Robert Koch-Instituts, die nicht nach Falldefinitionskategorien differenzieren (z.B. wöchentliche „Aktuelle Statistik meldepflichtiger Infektionskrankheiten“ im Epidemiologischen Bulletin), werden nur Erkrankungen der Kategorien B und C gezählt.

\section{Gesetzliche Grundlage}

\section{Meldepflicht}

Dem Gesundheitsamt wird gemäß $\ 7$ Abs. I Nr. I7 IfSG nur der direkte Nachweis von Haemophilus influenzae aus Liquor oder Blut, soweit er auf eine akute Infektion hinweist, namentlich gemeldet. Darüber hinaus stellt das Gesundheitsamt gemäß \25 Abs. I IfSG ggf. eigene Ermittlungen an.

\section{Übermittlung}

Das Gesundheitsamt übermittelt gemäß 』II Abs. I IfSG an die zuständige Landesbehörde nur Erkrankungs- oder Todesfälle und Erregernachweise, die der Falldefinition gemäß $\int 4$ Abs. 2 Nr. 2 Buchst. a IfSG entsprechen. 
20 Hantavirus

\section{(Hantavirus-Erkrankung - virales hämorrhagisches Fieber)}

ICDıo: A98.5 Hämorrhagisches Fieber mit renalem Syndrom (Epidemische Nephropathie; Hämorrhagisches Fieber: epidemisch, koreanisch, russisch; Infektion durch Hantan-Viren)

B33.4 Hantavirus-(Herz)Lungensyndrom

\section{Klinisches Bild}

Klinisches Bild einer akuten Hantavirus-Erkrankung, definiert als mindestens eines der drei folgenden Kriterien:

- Fieber,

- Nierenfunktionsstörung,

- mindestens zwei der neun folgenden Kriterien:

- Kopfschmerzen,

- Muskel-, Glieder- oder Rückenschmerzen,

- Übelkeit ODER Erbrechen,

- Durchfall,

- vorübergehende Myopie („Verschwommensehen“),

- Husten,

- Dyspnoe (Atemstörung),

- Lungeninfiltrate,

- Herzversagen.

\section{Zusatzinformation}

Das klinische Bild kann das einer $\gg$ hämorrhagischen Verlaufsform mit hämorrhagischen Manifestationen unterschiedlichen Ausmaßes bis hin zum Multiorganversagen annehmen.

Die Art und Schwere des klinischen Verlaufs wird durch den auslösenden Hantavirustyp mitbestimmt: schwere Verlaufsform des Hämorrhagischen Fiebers mit renalem Syndrom (HFRS): südosteuropäische Variante des Dobrava-Virus und Hantaan-Virus; moderate Verlaufsform des HFRS: Seoul-Virus; Nephropathia epidemica (leichte Verlaufsform des HFRS): Puumala-Virus und mitteleuropäische Variante des Dobrava-Virus; Hantavirus-Lungensyndrom (HPS): Sin-Nombre-Virus, Andes-Virus und verwandte Viren.

\section{Labordiagnostischer Nachweis}

Positiver Befund mit mindestens einer der vier folgenden Methoden:

[direkter Erregernachweis:]

- Virusisolierung,

- Nukleinsäure-Nachweis (z.B. PCR),

[indirekter (serologischer) Nachweis:]

- \deutliche Änderung zwischen zwei Proben beim IgG-Antikörpernachweis (z.B. IFT, ELISA),

- IgM- ODER IgA-Antikörpernachweis (z.B. ELISA, Immunoblot), bestätigt durch

- IgG-Antikörpernachweis (z.B. IFT, ELISA). 


\title{
Epidemiologische Bestätigung
}

Epidemiologische Bestätigung, definiert als mindestens einer der beiden folgenden Nachweise unter Berücksichtigung der Inkubationszeit:

- Epidemiologischer Zusammenhang mit einer labordiagnostisch nachgewiesenen Infektion beim Menschen durch

- gemeinsame Expositionsquelle (z.B. -Tierkontakt).

- Kontakt mit einem labordiagnostisch nachgewiesen infizierten Tier (z.B. Mäuse in Endemiegebieten, Labortiere) oder seinen Ausscheidungen.

Inkubationszeit 5-6o Tage, gewöhnlich 2-4 Wochen.

\section{Über die zuständige Landesbehörde an das RKI zu übermittelnder Fall}

\author{
A. Klinisch diagnostizierte Erkrankung \\ Entfällt.
}

B. Klinisch-epidemiologisch bestätigte Erkrankung

Klinisches Bild einer akuten Hantavirus-Erkrankung, ohne labordiagnostischen Nachweis, aber mit epidemiologischer Bestätigung.

\section{Klinisch-labordiagnostisch bestätigte Erkrankung}

Klinisches Bild einer akuten Hantavirus-Erkrankung und labordiagnostischer Nachweis.

D. Labordiagnostisch nachgewiesene Infektion bei nicht erfülltem klinischen Bild

Labordiagnostischer Nachweis bei bekanntem klinischen Bild, das die Kriterien für eine akute Hantavirus-Erkrankung nicht erfüllt. Hierunter fallen auch asymptomatische Infektionen.

\section{E. Labordiagnostisch nachgewiesene Infektion bei unbekanntem klinischen Bild}

Labordiagnostischer Nachweis bei fehlenden Angaben zum klinischen Bild (nicht ermittelbar oder nicht erhoben).

\section{Referenzdefinition}

In Veröffentlichungen des Robert Koch-Instituts, die nicht nach Falldefinitionskategorien differenzieren (z.B. wöchentliche „Aktuelle Statistik meldepflichtiger Infektionskrankheiten“ im Epidemiologischen Bulletin), werden nur Erkrankungen der Kategorien B und C gezählt.

\section{Gesetzliche Grundlage}

\section{Meldepflicht}

Dem Gesundheitsamt wird gemäß $\int 6$ Abs. I Nr. I Buchst. g IfSG der Krankheitsverdacht, die Erkrankung sowie der Tod an virusbedingtem hämorrhagischen Fieber, sowie gemäß $\int 7$ Abs. I Nr. I8 IfSG der direkte oder indirekte Nachweis von Hantaviren, soweit er auf eine akute Infektion hinweist, namentlich gemeldet. Darüber hinaus stellt das Gesundheitsamt gemäß 『25 Abs. I IfSG ggf. eigene Ermittlungen an.

\section{Übermittlung}

Das Gesundheitsamt übermittelt gemäß 』II Abs. I IfSG an die zuständige Landesbehörde nur Erkrankungs- oder

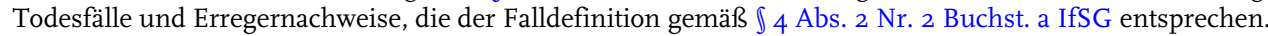

Zusätzlich ist gemäß 』I2 Abs. I IfSG das Auftreten eines hämorrhagischen Verlaufs einer Hantavirus-Erkrankung vom Gesundheitsamt unverzüglich an die zuständige oberste Landesgesundheitsbehörde und von dieser unverzüglich dem RKI zu übermitteln. Der Begriff 'Auftreten' schließt neben der Infektion/Erkrankung und dem Tod auch Verdachtsfälle ohne labordiagnostischen Nachweis und ohne epidemiologische Bestätigung ein. 


\section{Hepatitis-A-Virus (HAV - akute Virushepatitis A)}

ICDıo: Bi5.- Akute Virushepatitis A,

Br5.0 Virushepatitis A mit Coma hepaticum,

Bi5.9 Virushepatitis A ohne Coma hepaticum (Hepatitis A (akut) (durch Viren) o.n.A.)

\section{Klinisches Bild}

Klinisches Bild einer akuten Hepatitis, definiert als mindestens eines der vier folgenden Kriterien:

- Fieber,

- Ikterus (Gelbsucht),

- deutlich erhöhte Serumtransaminasen,

- Oberbauchbeschwerden.

\section{Zusatzinformation}

Bei impfpräventablen Krankheiten sollten stets Angaben zur Impfanamnese (Anzahl der vorangegangenen Impfungen, Art und Datum der letzten Impfung) erhoben (z.B. Impfbuchkontrolle) und übermittelt werden.

\section{Labordiagnostischer Nachweis}

Positiver Befund mit mindestens einer der vier folgenden Methoden:

[direkter Erregernachweis:]

- Nukleinsäure-Nachweis (z.B. PCR) nur in Serum/Plasma oder Stuhl,

- Antigennachweis (z.B. ELISA) nur im Stuhl,

[indirekter (serologischer) Nachweis:]

- IgM-Antikörpernachweis (z.B. ELISA),

- Ddeutliche Änderung zwischen zwei Proben beim IgG-Antikörpernachweis (z.B. ELISA).

\section{Zusatzinformation}

Die Bewertung von Antikörpernachweisen setzt die Kenntnis eines eventuellen zeitlichen Zusammenhangs mit einer Hepatitis-A-Impfung voraus.

\section{Epidemiologische Bestätigung}

Epidemiologische Bestätigung, definiert als mindestens einer der beiden folgenden Nachweise unter Berücksichtigung der Inkubationszeit:

- Epidemiologischer Zusammenhang mit einer labordiagnostisch nachgewiesenen Infektion beim Menschen durch

- Mensch-zu-Mensch-Übertragung ODER

- gemeinsame Expositionsquelle (z.B. DLebensmittel).

- Verzehr eines Lebensmittels (inkl. Trinkwasser), in dessen Resten HAV labordiagnostisch nachgewiesen wurde.

Inkubationszeit ca. I5-50 Tage. 


\section{Über die zuständige Landesbehörde an das RKI zu übermittelnder Fall}

\section{A. Klinisch diagnostizierte Erkrankung}

Entfällt.

\section{B. Klinisch-epidemiologisch bestätigte Erkrankung}

Klinisches Bild einer akuten Hepatitis, ohne labordiagnostischen Nachweis, aber mit epidemiologischer Bestätigung.

\section{Klinisch-labordiagnostisch bestätigte Erkrankung}

Klinisches Bild einer akuten Hepatitis und labordiagnostischer Nachweis.

D. Labordiagnostisch nachgewiesene Infektion bei nicht erfülltem klinischen Bild

Labordiagnostischer Nachweis bei bekanntem klinischen Bild, das die Kriterien für eine akute Hepatitis nicht erfüllt. Hierunter fallen auch asymptomatische Infektionen.

\section{E. Labordiagnostisch nachgewiesene Infektion bei unbekanntem klinischen Bild}

Labordiagnostischer Nachweis bei fehlenden Angaben zum klinischen Bild (nicht ermittelbar oder nicht erhoben).

\section{Referenzdefinition}

In Veröffentlichungen des Robert Koch-Instituts, die nicht nach Falldefinitionskategorien differenzieren (z.B. wöchentliche „Aktuelle Statistik meldepflichtiger Infektionskrankheiten“ im Epidemiologischen Bulletin), werden nur Erkrankungen der Kategorien $\mathbf{B}$ und $\mathbf{C}$ gezählt.

\section{Gesetzliche Grundlage}

\section{Meldepflicht}

Dem Gesundheitsamt wird gemäß \6 Abs. I Nr. I Buchst. e IfSG der Krankheitsverdacht, die Erkrankung sowie der Tod an akuter Virushepatitis, sowie gemäß \7 Abs. I Nr. I9 IfSG der direkte oder indirekte Nachweis von HepatitisA-Virus, soweit er auf eine akute Infektion hinweist, namentlich gemeldet. Darüber hinaus stellt das Gesundheitsamt gemäß \25 Abs. I IfSG ggf. eigene Ermittlungen an.

\section{Übermittlung}

Das Gesundheitsamt übermittelt gemäß \II Abs. I IfSG an die zuständige Landesbehörde nur Erkrankungs- oder Todesfälle und Erregernachweise, die der Falldefinition gemäß $\int 4$ Abs. 2 Nr. 2 Buchst. a IfSG entsprechen. 


\section{Hepatitis-B-Virus (HBV - akute Virushepatitis B)}

ICDıo: Bı6.- Akute Virushepatitis B,

Bı6.o Akute Virushepatitis B mit Delta-Virus (Begleitinfektion) und mit Coma hepaticum,

Bı6.I Akute Virushepatitis B mit Delta-Virus (Begleitinfektion) ohne Coma hepaticum,

Bı6.2 Akute Virushepatitis B ohne Delta-Virus mit Coma hepaticum,

Bı6.9 Akute Virushepatitis B ohne Delta-Virus und ohne Coma hepaticum (Hepatitis B (akut) (durch Viren) o.n.A.)

\section{Ausschlusskriterien}

- Dem behandelnden Arzt, dem nachweisenden Labor oder dem zuständigen Gesundheitsamt liegen Informationen vor, dass eine Infektion mit dem Hepatitis-B-Virus bereits zu einem früheren Zeitpunkt nachgewiesen wurde.

\section{Klinisches Bild}

Klinisches Bild einer akuten Hepatitis, definiert als mindestens eines der drei folgenden Kriterien:

- Ikterus (Gelbsucht),

- deutlich erhöhte Serumtransaminasen,

- Oberbauchbeschwerden.

\section{Zusatzinformation}

Bei impfpräventablen Krankheiten sollten stets Angaben zur Impfanamnese (Anzahl der vorangegangenen Impfungen, Art und Datum der letzten Impfung) erhoben (z.B. Impfbuchkontrolle) und übermittelt werden.

\section{Labordiagnostischer Nachweis}

Positiver Befund mit mindestens einer der drei folgenden Methoden:

[direkter Erregernachweis nur im Serum/Plasma:]

- Nukleinsäure-Nachweis (z.B. PCR),

- HBs-Antigennachweis (z.B. ELISA),

nur in Kombination mit mindestens einer der beiden folgenden Methoden:

- bestätigt durch Zusatztest (z.B. HBsAg-NT),

- HBc-Gesamt-Antikörpernachweis (indirekter (serologischer) Nachweis),

[indirekter (serologischer) Nachweis:]

- HBc-IgM-Antikörpernachweis (z.B. ELISA).

\section{Epidemiologische Bestätigung}

Entfälltt.

\section{Zusatzinformation}

Inkubationszeit ca. 45-I80 Tage. 


\title{
Über die zuständige Landesbehörde an das RKI zu übermittelnder Fall (unter Berücksichtigung der Ausschlusskriterien)
}

\author{
A. Klinisch diagnostizierte Erkrankung \\ Entfällt.
}

B. Klinisch-epidemiologisch bestätigte Erkrankung

Entfällt.

C. Klinisch-labordiagnostisch bestätigte Erkrankung

Klinisches Bild einer akuten Hepatitis und labordiagnostischer Nachweis.

D. Labordiagnostisch nachgewiesene Infektion bei nicht erfülltem klinischen Bild

Labordiagnostischer Nachweis bei bekanntem klinischen Bild, das die Kriterien für eine akute Hepatitis nicht erfüllt. Hierunter fallen auch asymptomatische Infektionen.

\section{E. Labordiagnostisch nachgewiesene Infektion bei unbekanntem klinischen Bild}

Labordiagnostischer Nachweis bei fehlenden Angaben zum klinischen Bild (nicht ermittelbar oder nicht erhoben).

\section{Referenzdefinition}

In Veröffentlichungen des Robert Koch-Instituts, die nicht nach Falldefinitionskategorien differenzieren (z.B. wöchentliche „Aktuelle Statistik meldepflichtiger Infektionskrankheiten“ im Epidemiologischen Bulletin), werden nur Erkrankungen der Kategorie C gezählt.

\section{Gesetzliche Grundlage}

\section{Meldepflicht}

Dem Gesundheitsamt wird gemäß $₫ 6$ Abs. I Nr. I Buchst. e IfSG der Krankheitsverdacht, die Erkrankung sowie der Tod an akuter Virushepatitis, sowie gemäß $\ 7$ Abs. I Nr. 20 IfSG der direkte oder indirekte Nachweis von HepatitisB-Virus, soweit er auf eine akute Infektion hinweist, namentlich gemeldet. Darüber hinaus stellt das Gesundheitsamt gemäß \25 Abs. I IfSG ggf. eigene Ermittlungen an.

\section{Übermittlung}

Das Gesundheitsamt übermittelt gemäß \II Abs. I IfSG an die zuständige Landesbehörde nur Erkrankungs- oder Todesfälle und Erregernachweise, die der Falldefinition gemäß \4 Abs. 2 Nr. 2 Buchst. a IfSG entsprechen. 


\section{Hepatitis-C-Virus (HCV - Virushepatitis C)}

ICDıo: Bi7.I Akute Virushepatitis C

(Bı9.- Nicht näher bezeichnete Virushepatitis,

Bıg.० Nicht näher bezeichnete Virushepatitis mit Koma,

Bı9.9 Nicht näher bezeichnete Virushepatitis ohne Koma (Virushepatitis o.n.A.))

\section{Ausschlusskriterien}

- Dem behandelnden Arzt, dem nachweisenden Labor oder dem zuständigen Gesundheitsamt liegen Informationen vor, dass eine Infektion mit dem Hepatitis-C-Virus bereits zu einem früheren Zeitpunkt nachgewiesen wurde.

\section{Klinisches Bild}

Klinisches Bild einer Hepatitis, definiert als mindestens eines der drei folgenden Kriterien:

- Ikterus (Gelbsucht),

- deutlich erhöhte Serumtransaminasen,

- Oberbauchbeschwerden.

\section{Labordiagnostischer Nachweis}

Positiver Befund mit mindestens einer der beiden folgenden Methoden:

[direkter Erregernachweis nur im Serum/Plasma:]

- Nukleinsäure-Nachweis (z.B. PCR),

[indirekter (serologischer) Nachweis (nicht bei Kindern in den ersten 18 Lebensmonaten):]

- Antikörpernachweis (z.B. ELISA), bestätigt durch

- Zusatztest (z.B. Immunoblot).

\section{Epidemiologische Bestätigung}

Entfällt.

\section{Zusatzinformation}

Wegen der Persistenz mütterlicher Antikörper ist der Antikörpernachweis zur Hepatitis-C-Diagnostik bei Kindern in den ersten I8 Lebensmonaten nicht geeignet.

Inkubationszeit ca. 2 Wochen bis 6 Monate, gewöhnlich 6-9 Wochen. 


\title{
Über die zuständige Landesbehörde an das RKI zu übermittelnder Fall (unter Berücksichtigung der Ausschlusskriterien)
}

\author{
A. Klinisch diagnostizierte Erkrankung \\ Entfällt.
}

B. Klinisch-epidemiologisch bestätigte Erkrankung

Entfällt.

C. Klinisch-labordiagnostisch bestätigte Erkrankung

Klinisches Bild einer Hepatitis und labordiagnostischer Nachweis.

D. Labordiagnostisch nachgewiesene Infektion bei nicht erfülltem klinischen Bild

Labordiagnostischer Nachweis bei bekanntem klinischen Bild, das die Kriterien für eine Hepatitis nicht erfüllt. Hierunter fallen auch asymptomatische Infektionen.

E. Labordiagnostisch nachgewiesene Infektion bei unbekanntem klinischen Bild

Labordiagnostischer Nachweis bei fehlenden Angaben zum klinischen Bild (nicht ermittelbar oder nicht erhoben).

\section{Referenzdefinition}

In Veröffentlichungen des Robert Koch-Instituts, die nicht nach Falldefinitionskategorien differenzieren (z.B. wöchentliche „Aktuelle Statistik meldepflichtiger Infektionskrankheiten“ im Epidemiologischen Bulletin), werden Fälle aller zu übermittelnden Kategorien C, D und E gezählt.

\section{Gesetzliche Grundlage}

\section{Meldepflicht}

Dem Gesundheitsamt werden gemäß \6 Abs. I Nr. I Buchst. e IfSG der Krankheitsverdacht, die Erkrankung sowie der Tod an akuter Virushepatitis, sowie gemäß $\ 7$ Abs. I Nr. 2I IfSG alle Nachweise von Hepatitis-C-Virus, soweit nicht bekannt ist, dass eine chronische Infektion vorliegt, namentlich gemeldet. Darüber hinaus stellt das Gesundheitsamt gemäß $\int 25$ Abs. I IfSG ggf. eigene Ermittlungen an.

\section{Übermittlung}

Das Gesundheitsamt übermittelt gemäß \II Abs. I IfSG an die zuständige Landesbehörde nur Erkrankungs- oder Todesfälle und Erregernachweise, die der Falldefinition gemäß $\ 4$ Abs. 2 Nr. 2 Buchst. a IfSG entsprechen. 


\section{Hepatitis-D-Virus (HDV - akute Virushepatitis D)}

ICDıo: Bı6.o Akute Virushepatitis B mit Delta-Virus (Begleitinfektion) und mit Coma hepaticum, Bı6.I Akute Virushepatitis B mit Delta-Virus (Begleitinfektion) ohne Coma hepaticum, BI7.0 Akute Delta-Virus- (Super-) Infektion eines Hepatitis-B- (Virus-) Trägers

\section{Ausschlusskriterien}

- Dem behandelnden Arzt, dem nachweisenden Labor oder dem zuständigen Gesundheitsamt liegen Informationen vor, dass eine Infektion mit dem Hepatitis-D-Virus bereits zu einem früheren Zeitpunkt nachgewiesen wurde.

\section{Klinisches Bild}

Klinisches Bild einer akuten Hepatitis, definiert als mindestens eines der drei folgenden Kriterien:

- Ikterus (Gelbsucht),

- deutlich erhöhte Serumtransaminasen,

- Oberbauchbeschwerden.

\section{Labordiagnostischer Nachweis}

Nachweis einer HBV-Infektion (HBsAg-positiv oder $>$ HBV-Nukleinsäure-Nachweis (z.B. PCR)) und positiver Befund mit mindestens einer der drei folgenden Methoden:

[direkter Erregernachweis nur im Serum/Plasma:]

- Nukleinsäure-Nachweis (z.B. PCR),

- Antigennachweis,

[indirekter (serologischer) Nachweis:]

- IgM-Antikörpernachweis.

\section{Zusatzinformation}

Hepatitis D tritt nur zusammen mit oder bei bestehender Hepatitis-B-Infektion auf.

\section{Epidemiologische Bestätigung}

Entfällt. 


\title{
Über die zuständige Landesbehörde an das RKI zu übermittelnder Fall (unter Berücksichtigung der Ausschlusskriterien)
}

\author{
A. Klinisch diagnostizierte Erkrankung \\ Entfällt.
}

B. Klinisch-epidemiologisch bestätigte Erkrankung

Entfällt.

C. Klinisch-labordiagnostisch bestätigte Erkrankung

Klinisches Bild einer akuten Hepatitis und labordiagnostischer Nachweis.

D. Labordiagnostisch nachgewiesene Infektion bei nicht erfülltem klinischen Bild

Labordiagnostischer Nachweis bei bekanntem klinischen Bild, das die Kriterien für eine akute Hepatitis nicht erfüllt. Hierunter fallen auch asymptomatische Infektionen.

\section{E. Labordiagnostisch nachgewiesene Infektion bei unbekanntem klinischen Bild}

Labordiagnostischer Nachweis bei fehlenden Angaben zum klinischen Bild (nicht ermittelbar oder nicht erhoben).

\section{Referenzdefinition}

In Veröffentlichungen des Robert Koch-Instituts, die nicht nach Falldefinitionskategorien differenzieren (z.B. wöchentliche „Aktuelle Statistik meldepflichtiger Infektionskrankheiten“ im Epidemiologischen Bulletin), werden nur Erkrankungen der Kategorie C gezählt.

\section{Gesetzliche Grundlage}

\section{Meldepflicht}

Dem Gesundheitsamt wird gemäß $₫ 6$ Abs. I Nr. I Buchst. e IfSG der Krankheitsverdacht, die Erkrankung sowie der Tod an akuter Virushepatitis, sowie gemäß $\ 7$ Abs. I Nr. 22 IfSG der direkte oder indirekte Nachweis von HepatitisD-Virus, soweit er auf eine akute Infektion hinweist, namentlich gemeldet. Darüber hinaus stellt das Gesundheitsamt gemäß \25 Abs. I IfSG ggf. eigene Ermittlungen an.

\section{Übermittlung}

Das Gesundheitsamt übermittelt gemäß \II Abs. I IfSG an die zuständige Landesbehörde nur Erkrankungs- oder Todesfälle und Erregernachweise, die der Falldefinition gemäß $\ 4$ Abs. 2 Nr. 2 Buchst. a IfSG entsprechen. 


\section{Hepatitis-E-Virus (HEV - akute Virushepatitis E)}

ICDıo: Bı7.2 Akute Virushepatitis E

\section{Klinisches Bild}

Klinisches Bild einer akuten Hepatitis, definiert als mindestens eines der vier folgenden Kriterien:

- Fieber,

- Ikterus (Gelbsucht),

- deutlich erhöhte Serumtransaminasen,

- Oberbauchbeschwerden.

\section{Labordiagnostischer Nachweis}

Positiver Befund mit mindestens einer der drei folgenden Methoden:

[direkter Erregernachweis:]

- Nukleinsäure-Nachweis (z.B. PCR) nur in Serum/Plasma oder Stuhl,

[indirekter (serologischer) Nachweis:]

- IgM-Antikörpernachweis (z.B. ELISA),

- \deutliche Änderung zwischen zwei Proben beim IgG-Antikörpernachweis (z.B. ELISA).

\section{Epidemiologische Bestätigung}

Epidemiologische Bestätigung, definiert als mindestens einer der drei folgenden Nachweise unter Berücksichtigung der Inkubationszeit:

- Epidemiologischer Zusammenhang mit einer labordiagnostisch nachgewiesenen Infektion beim Menschen durch

- Mensch-zu-Mensch-Übertragung ODER

- gemeinsame Expositionsquelle (z.B. $\triangleright$ Lebensmittel, $\triangleright$ Tierkontakt).

- Verzehr eines Lebensmittels (inkl. Trinkwasser), in dessen Resten HEV labordiagnostisch nachgewiesen wurde.

- Kontakt mit einem labordiagnostisch nachgewiesen infizierten Tier oder seinen Ausscheidungen.

Inkubationszeit ca. 15-64 Tage. 


\section{Über die zuständige Landesbehörde an das RKI zu übermittelnder Fall}

\section{A. Klinisch diagnostizierte Erkrankung}

Entfällt.

\section{B. Klinisch-epidemiologisch bestätigte Erkrankung}

Klinisches Bild einer akuten Hepatitis, ohne labordiagnostischen Nachweis, aber mit epidemiologischer Bestätigung.

\section{Klinisch-labordiagnostisch bestätigte Erkrankung}

Klinisches Bild einer akuten Hepatitis und labordiagnostischer Nachweis.

D. Labordiagnostisch nachgewiesene Infektion bei nicht erfülltem klinischen Bild

Labordiagnostischer Nachweis bei bekanntem klinischen Bild, das die Kriterien für eine akute Hepatitis nicht erfüllt. Hierunter fallen auch asymptomatische Infektionen.

\section{E. Labordiagnostisch nachgewiesene Infektion bei unbekanntem klinischen Bild}

Labordiagnostischer Nachweis bei fehlenden Angaben zum klinischen Bild (nicht ermittelbar oder nicht erhoben).

\section{Referenzdefinition}

In Veröffentlichungen des Robert Koch-Instituts, die nicht nach Falldefinitionskategorien differenzieren (z.B. wöchentliche „Aktuelle Statistik meldepflichtiger Infektionskrankheiten“ im Epidemiologischen Bulletin), werden nur Erkrankungen der Kategorien $\mathbf{B}$ und $\mathbf{C}$ gezählt.

\section{Gesetzliche Grundlage}

\section{Meldepflicht}

Dem Gesundheitsamt wird gemäß \6 Abs. I Nr. I Buchst. e IfSG der Krankheitsverdacht, die Erkrankung sowie der Tod an akuter Virushepatitis, sowie gemäß $\ 7$ Abs. I Nr. 23 IfSG der direkte oder indirekte Nachweis von Hepatitis-EVirus, soweit er auf eine akute Infektion hinweist, namentlich gemeldet. Darüber hinaus stellt das Gesundheitsamt gemäß \25 Abs. I IfSG ggf. eigene Ermittlungen an.

\section{Übermittlung}

Das Gesundheitsamt übermittelt gemäß \II Abs. I IfSG an die zuständige Landesbehörde nur Erkrankungs- oder Todesfälle und Erregernachweise, die der Falldefinition gemäß $\int 4$ Abs. 2 Nr. 2 Buchst. a IfSG entsprechen. 


\section{Akute Virushepatitis Non A - E}

ICDıo: BI7.8 Sonstige näher bezeichnete akute Virushepatitis (Hepatitis Non-A, Non-B (akut) (durch Viren), anderenorts nicht klassifiziert)

\section{Ausschlusskriterien}

- Andere bekannte Erreger (neben HAV bis HEV z.B. EBV, CMV, Coxiella burnetii, HSV, Parvovirus Bıg) oder nichtinfektiöse Ursachen einer akuten Hepatitis (z.B. Autoimmunkrankheiten, Intoxikationen).

- Positiver Befund bei mindestens einer der folgenden Untersuchungen:

- Anti-HAV-IgM,

- Anti-HBc-IgM,

- HBsAg,

- HCV-Nukleinsäure-Nachweis,

- Anti-HEV-IgM,

- HEV-Nukleinsäure-Nachweis.

\section{Klinisches Bild}

Klinisches Bild einer akuten Hepatitis, definiert als mindestens eines der drei folgenden Kriterien:

- Ikterus (Gelbsucht),

- deutlich erhöhte Serumtransaminasen,

- Oberbauchbeschwerden.

\section{Labordiagnostischer Nachweis}

Entfällt.

\section{Epidemiologische Bestätigung}

Entfällt. 


\section{Über die zuständige Landesbehörde an das RKI zu übermittelnder Fall (unter Berücksichtigung der Ausschlusskriterien)}

\section{A. Klinisch diagnostizierte Erkrankung}

Klinisches Bild einer akuten Hepatitis.

B. Klinisch-epidemiologisch bestätigte Erkrankung

Entfällt.

C. Klinisch-labordiagnostisch bestätigte Erkrankung

Entfällt.

D. Labordiagnostisch nachgewiesene Infektion bei nicht erfülltem klinischen Bild

Entfällt.

E. Labordiagnostisch nachgewiesene Infektion bei unbekanntem klinischen Bild

Entfällt.

\section{Referenzdefinition}

Da nur Erkrankungen der Kategorie A zu übermitteln sind, entfällt eine weitere Eingrenzung nach Falldefinitionskategorie.

\section{Gesetzliche Grundlage}

\section{Meldepflicht}

Dem Gesundheitsamt wird gemäß \6 Abs. I Nr. I Buchst. e IfSG der Krankheitsverdacht, die Erkrankung sowie der Tod an akuter Virushepatitis namentlich gemeldet. Darüber hinaus stellt das Gesundheitsamt gemäß 『25 Abs. I IfSG ggf. eigene Ermittlungen an.

\section{Übermittlung}

Das Gesundheitsamt übermittelt gemäß \II Abs. I IfSG an die zuständige Landesbehörde nur Erkrankungs- oder Todesfälle und Erregernachweise, die der Falldefinition gemäß $\int 4$ Abs. 2 Nr. 2 Buchst. a IfSG entsprechen. 


\section{Hämolytisch-urämisches Syndrom (HUS), enteropathisch}

ICDıo: D59.3 Hämolytisch-urämisches Syndrom,

M3I.I Thrombotische Mikroangiopathie (Thrombotische thrombozytopenische Purpura [Moschkowitz])

\section{Vorbemerkung}

Diese Übermittlungskategorie ist durch Ausgliederung aus der jetzt separaten Übermittlungskategorie 'EHEC' entstanden. Sie umfasst alle Fälle mit dem klinischen Bild eines enteropathischen hämolytisch-urämischen Syndroms (HUS), unabhängig vom Erreger oder seinem Nachweis. Es wird nicht mehr zwischen inkomplettem und komplettem HUS und thrombotisch-thrombozytopenischer Purpura (TTP) unterschieden.

\section{Ausschlusskriterien}

- Nachweis nichtinfektiöser Ursachen.

\section{Klinisches Bild}

Klinisches Bild eines akuten enteropathischen HUS, definiert als mindestens zwei der drei folgenden Kriterien:

- Hämolytische Anämie,

- Thrombozytopenie $\leq$ I50.000 Zellen $/ \mathrm{mm}^{3}$,

- Nierenfunktionsstörung.

\section{Zusatzinformation}

Typischerweise gehen dem enteropathischen HUS Magen-Darm-Beschwerden (z.B. Durchfälle (oft blutig), Erbrechen, krampfartige Bauchschmerzen) voraus. Zusätzlich können zerebrale Symptome (z.B. Krampfanfälle) auftreten. Diese Kriterien sind jedoch nicht notwendig, um das klinische Bild des akuten enteropathischen HUS zu erfüllen. 


\section{Labordiagnostischer Nachweis}

Positiver Befund bei mindestens einer der vier folgenden Untersuchungen:

[Toxinnachweis:]

- Erregeranzucht und -isolierung nur aus Stuhl UND Nachweis des Shigatoxins (Stxi bzw. Stx2; syn. Verocytotoxin, VT) mittels ELISA in der $\boldsymbol{E}$.-coli-Kultur,

- Erregeranzucht in Mischkultur, Stuhlanreicherungskultur oder Isolierung von E.-coli UND -Nukleinsäure-Nachweis (z.B. PCR) des Shigatoxin-Gens (stxI, stx2) aus dieser Probe.

[indirekter (serologischer) Nachweis:]

- Nachweis von Anti-LPS-IgM-Antikörpern gegen E.-coli-Serogruppen (einmaliger $\$ deutlich erhöhter Wert, z.B. ELISA, Western-Blot),

- $\triangleright$ deutliche Änderung zwischen zwei Proben beim Nachweis von Anti-LPS-IgG-Antikörpern gegen E.-coli-Serogruppen (z.B. ELISA).

\section{Zusatzinformationen}

- Neben E. coli kommen in seltenen Fällen auch andere Erreger wie z.B. Shigellen als Träger des Shigatoxin-Gens in Betracht.

- Das Ergebnis der Bestimmung des Erregers und des Serovars sollte übermittelt werden.

- Der alleinige Shigatoxin-Nachweis mittels ELISA in der Stuhlanreicherungskultur gilt nicht als labordiagnostischer Nachweis. Kann der Erreger nicht isoliert werden, so ist ein Fall mit alleinigem Shigatoxin-Nachweis mittels ELISA in der Stuhlanreicherungskultur als klinisch oder klinischepidemiologisch bestätigte Erkrankung einzuordnen, sofern entsprechende Symptome vorliegen.

\section{Epidemiologische Bestätigung}

Epidemiologische Bestätigung, definiert als mindestens einer der vier folgenden Nachweise unter Berücksichtigung der Inkubationszeit:

- Epidemiologischer Zusammenhang mit einer labordiagnostisch nachgewiesenen Infektion beim Menschen durch

- Mensch-zu-Mensch-Übertragung ODER

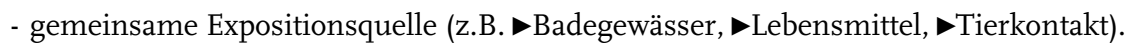

- Baden in einem labordiagnostisch nachgewiesen kontaminierten Gewässer.

- $\rightarrow$ Kontakt mit einem labordiagnostisch nachgewiesen infizierten Tier (z.B. Streichelzoo) oder seinen Ausscheidungen, oder Verzehr seiner Produkte (z.B. Rohmilch).

- Verzehr eines Lebensmittels (z.B. Rohmilch, Trinkwasser), in dessen Resten Shigatoxin-bildende Erreger labordiagnostisch nachgewiesen wurden.

Inkubationszeit z.B. für EHEC ca. 2-Io Tage, für Shigellen ca. I2-96 Stunden; Latenzzeit zwischen Beginn der Magen-Darm-Beschwerden und enteropathischem HUS bis zu ca. 2 Wochen. 


\section{Über die zuständige Landesbehörde an das RKI zu übermittelnde Erkrankung (unter Berücksichtigung der Ausschlusskriterien)}

\section{A. Klinisch diagnostizierte Erkrankung}

Klinisches Bild eines akuten enteropathischen HUS, ohne labordiagnostischen Nachweis und ohne epidemiologische Bestätigung.

\section{B. Klinisch-epidemiologisch bestätigte Erkrankung}

Klinisches Bild eines akuten enteropathischen HUS, ohne labordiagnostischen Nachweis, aber mit epidemiologischer Bestätigung.

\section{Klinisch-labordiagnostisch bestätigte Erkrankung}

Klinisches Bild eines akuten enteropathischen HUS und labordiagnostischer Nachweis.

D. Labordiagnostisch nachgewiesene Infektion bei nicht erfülltem klinischen Bild

Entfällt.

E. Labordiagnostisch nachgewiesene Infektion bei unbekanntem klinischen Bild

Entfällt.

\section{Referenzdefinition}

In Veröffentlichungen des Robert Koch-Instituts, die nicht nach Falldefinitionskategorien differenzieren (z.B. wöchentliche „Aktuelle Statistik meldepflichtiger Infektionskrankheiten“ im Epidemiologischen Bulletin), werden Erkrankungen aller zu übermittelnden Kategorien A, B und C gezählt.

\section{Gesetzliche Grundlage}

\section{Meldepflicht}

Dem Gesundheitsamt wird gemäß \6 Abs. I Nr. I Buchst. f IfSG der Krankheitsverdacht, die Erkrankung sowie der Tod an enteropathischem hämolytisch-urämischem Syndrom (HUS) namentlich gemeldet. Darüber hinaus stellt das

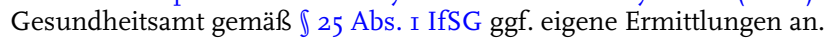

\section{Übermittlung}

Das Gesundheitsamt übermittelt gemäß \II Abs. I IfSG an die zuständige Landesbehörde nur Erkrankungs- oder Todesfälle und Erregernachweise, die der Falldefinition gemäß $\ 4$ Abs. 2 Nr. 2 Buchst. a IfSG entsprechen. 


\section{Influenzavirus (Influenza A, B oder C)}

ICDıо: Jı.- Grippe durch nachgewiesene Influenzaviren,

Jı.o Grippe mit Pneumonie, Influenzaviren nachgewiesen (Grippe(broncho)pneumonie, Influenzaviren nachgewiesen),

Jio.I Grippe mit sonstigen Manifestationen an den Atemwegen, Influenzaviren nachgewiesen (Grippe: akute Infektion der oberen Atemwege, Laryngitis, Pharyngitis, Pleuraerguss),

Jı.8 Grippe mit sonstigen Manifestationen, Influenzaviren nachgewiesen (Enzephalopathie bei Grippe, Grippe: Gastroenteritis, Myokarditis (akut)),

JıI.- Grippe, Viren nicht nachgewiesen, inkl.: Grippe/Virus-Grippe ohne Angabe eines spezifischen Virusnachweises

\section{Klinisches Bild}

Klinisches Bild einer Influenza, definiert als mindestens zwei der vier folgenden Kriterien:

- akuter Krankheitsbeginn,

- Husten,

- Fieber,

- Muskel-, Glieder-, Rücken- ODER Kopfschmerzen.

\section{Zusatzinformation}

Bei impfpräventablen Krankheiten sollten stets Angaben zur Impfanamnese (Anzahl der vorangegangenen Impfungen, Art und Datum der letzten Impfung) erhoben (z.B. Impfbuchkontrolle) und übermittelt werden.

\section{Labordiagnostischer Nachweis}

Positiver Befund mit mindestens einer der drei folgenden Methoden:

[direkter Erregernachweis:]

- Virusisolierung (einschließlich Schnellkultur),

- -Nukleinsäure-Nachweis (z.B. PCR),

- Antigennachweis (z.B. ELISA (einschließlich Influenza-Schnelltest), IFT).

\section{Zusatzinformation}

Direkte Erregernachweise werden typischerweise in klinischen Materialien des oberen Respirationstrakts (z.B. Nasen- oder Rachenabstriche) durchgeführt, jedoch gelten auch direkte Erregernachweise aus anderen klinischen Materialien (z.B. Liquor, Myokardgewebe) als labordiagnostischer Nachweis, nicht jedoch indirekte (serologische) Nachweise.

\section{Epidemiologische Bestätigung}

Epidemiologische Bestätigung, definiert als mindestens einer der beiden folgenden Nachweise unter Berücksichtigung der Inkubationszeit:

- Epidemiologischer Zusammenhang mit einer labordiagnostisch nachgewiesenen Infektion beim Menschen durch

- Mensch-zu-Mensch-Übertragung ODER

- gemeinsame Expositionsquelle (z.B. -Tierkontakt).

- Kontakt mit einem labordiagnostisch nachgewiesen infizierten Tier oder seinen Ausscheidungen. Inkubationszeit ca. I-3 Tage. 


\section{Über die zuständige Landesbehörde an das RKI zu übermittelnder Fall}

\section{A. Klinisch diagnostizierte Erkrankung}

Entfällt.

\section{B. Klinisch-epidemiologisch bestätigte Erkrankung}

Klinisches Bild einer Influenza, ohne labordiagnostischen Nachweis, aber mit epidemiologischer Bestätigung.

\section{Klinisch-labordiagnostisch bestätigte Erkrankung}

Klinisches Bild einer Influenza und labordiagnostischer Nachweis.

D. Labordiagnostisch nachgewiesene Infektion bei nicht erfülltem klinischen Bild

Labordiagnostischer Nachweis bei bekanntem klinischen Bild, das die Kriterien für Influenza nicht erfüllt. Hierunter fallen auch asymptomatische Infektionen.

\section{E. Labordiagnostisch nachgewiesene Infektion bei unbekanntem klinischen Bild}

Labordiagnostischer Nachweis bei fehlenden Angaben zum klinischen Bild (nicht ermittelbar oder nicht erhoben).

\section{Referenzdefinition}

In Veröffentlichungen des Robert Koch-Instituts, die nicht nach Falldefinitionskategorien differenzieren (z.B. wöchentliche „Aktuelle Statistik meldepflichtiger Infektionskrankheiten“ im Epidemiologischen Bulletin), werden nur Erkrankungen der Kategorien $\mathbf{B}$ und $\mathbf{C}$ gezählt.

\section{Gesetzliche Grundlage}

\section{Meldepflicht}

Dem Gesundheitsamt wird gemäß $\ 7$ Abs. I Nr. 24 IfSG nur der direkte Nachweis von Influenzaviren, soweit er auf eine akute Infektion hinweist, namentlich gemeldet. Darüber hinaus stellt das Gesundheitsamt gemäß \25 Abs. I IfSG ggf. eigene Ermittlungen an.

\section{Übermittlung}

Das Gesundheitsamt übermittelt gemäß 』II Abs. I IfSG an die zuständige Landesbehörde nur Erkrankungs- oder Todesfälle und Erregernachweise, die der Falldefinition gemäß $\int 4$ Abs. 2 Nr. 2 Buchst. a IfSG entsprechen.

Gemäß 』I2 Abs. I IfSG sind Fälle von Influenza-Nachweisen vom Gesundheitsamt unverzüglich an die zuständige Landesbehörde und von dieser unverzüglich dem RKI zu übermitteln. 


\section{Lassavirus (Lassafieber - virales hämorrhagisches Fieber)}

ICDıo: A96.2 Lassa-Fieber (Hämorrhagisches Fieber durch Lassa-Viren)

\section{Vorbemerkung}

Lassafieber kann als akut fieberhaftes Krankheitsbild auch ohne Zeichen einer $\$ hämorrhagischen Verlaufsform auftreten.

\section{Klinisches Bild}

Klinisches Bild eines akuten Lassafiebers, definiert als mindestens eines der beiden folgenden Kriterien:

- $\rightarrow$ Fieber,

- hämorrhagischer Verlauf.

\section{Labordiagnostischer Nachweis}

Positiver Befund mit mindestens einer der vier folgenden Methoden:

[direkter Erregernachweis:]

- Virusisolierung UND Differenzierung mit monoklonalen Antikörpern,

- Nukleinsäure-Nachweis (z.B. PCR),

- Elektronenmikroskopie (z.B. Leberbiopsien, post mortem),

[indirekter (serologischer) Nachweis:]

- IgM-Antikörpernachweis (z.B. $\mu$ Capture-ELISA).

\section{Epidemiologische Bestätigung}

Entfällt.

\section{Zusatzinformation}

Inkubationszeit ca. 6-2I Tage. 


\section{Über die zuständige Landesbehörde an das RKI zu übermittelnder Fall}

\section{A. Klinisch diagnostizierte Erkrankung}

Entfällt.

B. Klinisch-epidemiologisch bestätigte Erkrankung

Entfällt.

\section{Klinisch-labordiagnostisch bestätigte Erkrankung}

Klinisches Bild eines akuten Lassafiebers und labordiagnostischer Nachweis.

D. Labordiagnostisch nachgewiesene Infektion bei nicht erfülltem klinischen Bild

Labordiagnostischer Nachweis bei bekanntem klinischen Bild, das die Kriterien für ein akutes Lassafieber nicht erfüllt. Hierunter fallen auch asymptomatische Infektionen.

\section{E. Labordiagnostisch nachgewiesene Infektion bei unbekanntem klinischen Bild}

Labordiagnostischer Nachweis bei fehlenden Angaben zum klinischen Bild (nicht ermittelbar oder nicht erhoben).

\section{Referenzdefinition}

In Veröffentlichungen des Robert Koch-Instituts, die nicht nach Falldefinitionskategorien differenzieren (z.B. wöchentliche „Aktuelle Statistik meldepflichtiger Infektionskrankheiten“ im Epidemiologischen Bulletin), werden nur Erkrankungen der Kategorie $\mathbf{C}$ gezählt.

\section{Gesetzliche Grundlage}

\section{Meldepflicht}

Dem Gesundheitsamt wird gemäß \6 Abs. I Nr. I Buchst. g IfSG der Krankheitsverdacht, die Erkrankung sowie der Tod an virusbedingtem hämorrhagischen Fieber, sowie gemäß $\int 7$ Abs. I Nr. 25 IfSG der direkte oder indirekte Nachweis von Lassavirus, soweit er auf eine akute Infektion hinweist, namentlich gemeldet. Darüber hinaus stellt das Gesundheitsamt gemäß \25 Abs. I IfSG ggf. eigene Ermittlungen an.

\section{Übermittlung}

Das Gesundheitsamt übermittelt gemäß 』II Abs. I IfSG an die zuständige Landesbehörde nur Erkrankungs- oder Todesfälle und Erregernachweise, die der Falldefinition gemäß \4 Abs. 2 Nr. 2 Buchst. a IfSG entsprechen.

Zusätzlich ist gemäß \I2 Abs. I IfSG das Auftreten von Lassafieber vom Gesundheitsamt unverzüglich an die zuständige oberste Landesgesundheitsbehörde und von dieser unverzüglich dem RKI zu übermitteln. Der Begriff 'Auftreten' schließt neben der Infektion/Erkrankung und dem Tod auch Verdachtsfälle ohne labordiagnostischen Nachweis ein. 


\section{Legionella spp. (Legionärskrankheit)}

ICDıо: A48.I Legionellose mit Pneumonie (Legionärskrankheit),

\section{Klinisches Bild}

Klinisches Bild einer akuten Legionärskrankheit, definiert als

- - Lungenentzündung

\section{Labordiagnostischer Nachweis}

Positiver Befund mit mindestens einer der vier folgenden Methoden:

[direkter Erregernachweis:]

- Erregerisolierung (kulturell) nur aus Sekreten des Respirationstrakts (z.B. BAL, Trachealsekret, Sputum), Lungengewebe oder Pleuraflüssigkeit,

- Nukleinsäure-Nachweis (z.B. PCR) nur aus Sekreten des Respirationstrakts (s.o.), Lungengewebe oder Pleuraflüssigkeit,

- L.-pneumophila-Antigennachweis (z.B. ELISA, Immunchromatographie) nur im Urin,

[indirekter (serologischer) Nachweis:]

- Legionella-Antikörpernachweis mittels IFT ( $\triangleright$ deutliche Änderung zwischen zwei Proben oDER einmaliger $\triangleright$ deutlich erhöhter Wert).

\section{Zusatzinformation}

Antigennachweis in Sekreten des Respirationstrakts und IgM- und IgG-Antikörpernachweise mittels ELISA (auch in Kombination) gelten wegen bisher unzureichender Validierung nicht als labordiagnostischer Nachweis.

\section{Epidemiologische Bestätigung}

Epidemiologische Bestätigung, definiert als folgender Nachweis unter Berücksichtigung der Inkubationszeit:

- Epidemiologischer Zusammenhang mit einer labordiagnostisch nachgewiesenen Infektion beim Menschen durch

- gemeinsame Expositionsquelle (z.B. Aerosolbildung durch labordiagnostisch nachgewiesen kontaminiertes Wasser z.B. in Luftbefeuchtern, Whirlpools, Duschen in Hotels oder Krankenhausanlagen).

Inkubationszeit ca. 2-Io Tage. 


\section{Über die zuständige Landesbehörde an das RKI zu übermittelnder Fall}

\section{A. Klinisch diagnostizierte Erkrankung}

Entfällt.

\section{B. Klinisch-epidemiologisch bestätigte Erkrankung}

Klinisches Bild einer akuten Legionärskrankheit, ohne labordiagnostischen Nachweis, aber mit epidemiologischer Bestätigung.

\section{Klinisch-labordiagnostisch bestätigte Erkrankung}

Klinisches Bild einer akuten Legionärskrankheit und labordiagnostischer Nachweis.

D. Labordiagnostisch nachgewiesene Infektion bei nicht erfülltem klinischen Bild

Labordiagnostischer Nachweis bei bekanntem klinischen Bild, das die Kriterien für eine akute Legionärskrankheit nicht erfüllt. Hierunter fallen auch asymptomatische Infektionen.

\section{E. Labordiagnostisch nachgewiesene Infektion bei unbekanntem klinischen Bild}

Labordiagnostischer Nachweis bei fehlenden Angaben zum klinischen Bild (nicht ermittelbar oder nicht erhoben).

\section{Referenzdefinition}

In Veröffentlichungen des Robert Koch-Instituts, die nicht nach Falldefinitionskategorien differenzieren (z.B. wöchentliche „Aktuelle Statistik meldepflichtiger Infektionskrankheiten“ im Epidemiologischen Bulletin), werden nur Erkrankungen der Kategorien $\mathbf{B}$ und $\mathbf{C}$ gezählt.

\section{Gesetzliche Grundlage}

\section{Meldepflicht}

Dem Gesundheitsamt wird gemäß $\mathbb{7}$ Abs. I Nr. 26 IfSG der direkte oder indirekte Nachweis von Legionella sp., soweit er auf eine akute Infektion hinweist, namentlich gemeldet. Darüber hinaus stellt das Gesundheitsamt gemäß \25 Abs. I IfSG ggf. eigene Ermittlungen an.

\section{Übermittlung}

Das Gesundheitsamt übermittelt gemäß \II Abs. I IfSG an die zuständige Landesbehörde nur Erkrankungs- oder Todesfälle und Erregernachweise, die der Falldefinition gemäß \4 Abs. 2 Nr. 2 Buchst. a IfSG entsprechen. 


\section{$31 \quad$ Leptospira interrogans (Leptospirose)}

syn./Formen: Morbus Weil, Schlammfieber, Sumpffieber, Feldfieber, Canicola-Fieber, u. a.

ICDio: A27.- Leptospirose,

A27.0 Leptospirosis icterohaemorrhagica [Weil-Krankheit] (Leptospirose durch Leptospira interrogans Serovar Icterohaemorrhagiae),

A27.8 Sonstige Formen der Leptospirose,

A27.9 Leptospirose, nicht näher bezeichnet

\section{Klinisches Bild}

Klinisches Bild einer akuten Leptospirose, definiert als mindestens eines der acht folgenden Kriterien:

- Fieber,

- grippeähnliche Beschwerden,

- Nierenfunktionsstörung,

- Ikterus (Gelbsucht),

- respiratorische Symptomatik (z.B. Husten, Dyspnoe (Atemstörung)),

- Meningitis oder Meningoenzephalitis,

- Hämorrhagien (z.B. Lungenblutungen, subkonjunktivale Blutungen),

- Myokarditis (Herzmuskelentzündung).

\section{Labordiagnostischer Nachweis}

Positiver Befund mit mindestens einer der drei folgenden Methoden:

[direkter Erregernachweis:]

- Erregerisolierung (kulturell),

- Dukleinsäure-Nachweis (z.B. PCR),

[indirekter (serologischer) Nachweis:]

- Antikörpernachweis $\gg$ deutliche Änderung zwischen zwei Proben oDER einmaliger $\triangleright$ deutlich erhöhter Wert, z.B. MAT, ELISA, KBR).

\section{Zusatzinformationen}

- Beim Antikörpernachweis sollte wegen seiner höheren Spezifität nach Möglichkeit der MAT verwendet werden. Das dem Nachweis zugrunde liegende Verfahren sollte übermittelt werden.

- ELISA differenziert zwischen IgM- und IgG-Antikörpern. Beide Nachweise ergeben für sich allein den geforderten labordiagnostischen Nachweis.

\section{Epidemiologische Bestätigung}

Epidemiologische Bestätigung, definiert als mindestens einer der beiden folgenden Nachweise unter Berücksichtigung der Inkubationszeit:

- Epidemiologischer Zusammenhang mit einer labordiagnostisch nachgewiesenen Infektion beim Menschen durch

- gemeinsame Expositionsquelle (z.B. \Badegewässer, $\triangleright$ Tierkontakt).

- $>$ Kontakt mit einem labordiagnostisch nachgewiesen infizierten Tier (u.a. Ratten, Schweine, Kühe, Hunde) oder seinen Ausscheidungen.

Inkubationszeit ca. 2-30 Tage, gewöhnlich Io Tage. 


\section{Über die zuständige Landesbehörde an das RKI zu übermittelnder Fall}

\section{A. Klinisch diagnostizierte Erkrankung}

Entfällt.

\section{B. Klinisch-epidemiologisch bestätigte Erkrankung}

Klinisches Bild einer akuten Leptospirose, ohne labordiagnostischen Nachweis, aber mit epidemiologischer Bestätigung.

\section{Klinisch-labordiagnostisch bestätigte Erkrankung}

Klinisches Bild einer akuten Leptospirose und labordiagnostischer Nachweis.

D. Labordiagnostisch nachgewiesene Infektion bei nicht erfülltem klinischen Bild

Labordiagnostischer Nachweis bei bekanntem klinischen Bild, das die Kriterien für eine akute Leptospirose nicht erfüllt. Hierunter fallen auch asymptomatische Infektionen.

\section{E. Labordiagnostisch nachgewiesene Infektion bei unbekanntem klinischen Bild}

Labordiagnostischer Nachweis bei fehlenden Angaben zum klinischen Bild (nicht ermittelbar oder nicht erhoben).

\section{Referenzdefinition}

In Veröffentlichungen des Robert Koch-Instituts, die nicht nach Falldefinitionskategorien differenzieren (z.B. wöchentliche „Aktuelle Statistik meldepflichtiger Infektionskrankheiten“ im Epidemiologischen Bulletin), werden nur Erkrankungen der Kategorien B und C gezählt.

\section{Gesetzliche Grundlage}

\section{Meldepflicht}

Dem Gesundheitsamt wird gemäß $\ 7$ Abs. I Nr. 27 IfSG der direkte oder indirekte Nachweis von Leptospira interrogans, soweit er auf eine akute Infektion hinweist, namentlich gemeldet. Darüber hinaus stellt das Gesundheitsamt gemäß \25 Abs. I IfSG ggf. eigene Ermittlungen an.

\section{Übermittlung}

Das Gesundheitsamt übermittelt gemäß 』II Abs. I IfSG an die zuständige Landesbehörde nur Erkrankungs- oder Todesfälle und Erregernachweise, die der Falldefinition gemäß $\int 4$ Abs. 2 Nr. 2 Buchst. a IfSG entsprechen. 


\section{Listeria monocytogenes (Listeriose)}

ICDıо: A32.- Listeriose (inkl.: Nahrungsmittelbedingte Infektion durch Listerien),

A32.0 Kutane Listeriose,

A32.I Meningitis und Meningoenzephalitis durch Listerien,

A32.7 Listeriensepsis,

A32.8 Sonstige Formen der Listeriose (Endokarditis durch Listerien, okuloglanduläre Listeriose, zerebrale Arteriitis durch Listerien),

A32.9 Listeriose, nicht näher bezeichnet,

P37.2 Neugeborenenlisteriose (disseminiert)

\section{Klinisches Bild}

Klinisches Bild einer akuten Listeriose, definiert als eine der drei folgenden Formen:

- Listeriose des Neugeborenen, definiert als $\gg$ Totgeburt ODER mindestens eines der fünf folgenden Kriterien bei einem Kind im ersten Lebensmonat:

- Granulomatosis infantiseptica (Mikroabszesse in verschiedenen Organen),

- Meningitis oder Meningoenzephalitis,

- septisches Krankheitsbild,

- Dyspnoe (Atemstörung),

- Haut-, Bindehaut- oder Schleimhautläsionen (-veränderungen).

ICDıO: P37.2 Neugeborenenlisteriose (disseminiert)

- Schwangerschafts-Listeriose, definiert als mindestens eines der drei folgenden Kriterien:

- $\rightarrow$ Fehl-, $\gg$ Früh- oder $\gg$ Totgeburt,

- grippeähnliche Beschwerden,

- Fieber.

- Andere Form, definiert als mindestens eines der drei folgenden Kriterien:

- $\rightarrow$ Fieber,

- Meningitis oder Meningoenzephalitis,

- lokalisierte Infektionen (z.B. Abszesse, septische Arthritis (Gelenkentzündung), Endokarditis).

\section{Labordiagnostischer Nachweis}

Positiver Befund mit der folgenden Methode:

\section{[direkter Erregernachweis:]}

- Erregerisolierung (kulturell) nur aus Blut, Liquor oder anderen \normalerweise sterilen klinischen Materialien bei allen Formen der Listeriose; bei Neugeborenenlisteriose und Schwangerschaftslisteriose aus Abstrichen vom Fetus, Tot- oder Neugeborenen ODER aus Abstrichen von mütterlichem Gewebe (Plazenta, Uterus, Zervix). 


\section{Epidemiologische Bestätigung}

Epidemiologische Bestätigung, definiert als mindestens einer der beiden folgenden Nachweise unter Berücksichtigung der Inkubationszeit:

- Epidemiologischer Zusammenhang mit einer labordiagnostisch nachgewiesenen Infektion beim Menschen durch

- Mutter-Kind-Beziehung (d.h. zwischen Tot- oder Neugeborenem und seiner Mutter) ODER

- gemeinsame Expositionsquelle (z.B. - Lebensmittel).

- Verzehr eines Lebensmittels (inkl. Trinkwasser), in dessen Resten L. monocytogenes labordiagnostisch nachgewiesen wurde.

Inkubationszeit ca. 3-70 Tage.

\section{Über die zuständige Landesbehörde an das RKI zu übermittelnder Fall}

\section{A. Klinisch diagnostizierte Erkrankung}

Entfällt.

\section{B. Klinisch-epidemiologisch bestätigte Erkrankung}

Klinisches Bild einer akuten Listeriose, ohne labordiagnostischen Nachweis, aber mit epidemiologischer Bestätigung. In diese Kategorie fallen auch Mütter ohne klinisches Bild und ohne labordiagnostischen Nachweis bei Geburt eines mit Listeria monocytogenes infizierten Kindes.

\section{Klinisch-labordiagnostisch bestätigte Erkrankung}

Klinisches Bild einer akuten Listeriose und labordiagnostischer Nachweis.

\section{Labordiagnostisch nachgewiesene Infektion bei nicht erfülltem klinischen Bild}

Labordiagnostischer Nachweis bei bekanntem klinischen Bild, das die Kriterien für eine akute Listeriose nicht erfüllt. Hierunter fallen auch asymptomatische Infektionen.

\section{E. Labordiagnostisch nachgewiesene Infektion bei unbekanntem klinischen Bild}

Labordiagnostischer Nachweis bei fehlenden Angaben zum klinischen Bild (nicht ermittelbar oder nicht erhoben).

\section{Zusatzinformation}

Mutter und Tot- oder Neugeborenes werden jeweils als eigener Fall übermittelt und gezählt.

\section{Referenzdefinition}

In Veröffentlichungen des Robert Koch-Instituts, die nicht nach Falldefinitionskategorien differenzieren (z.B. wöchentliche „Aktuelle Statistik meldepflichtiger Infektionskrankheiten“ im Epidemiologischen Bulletin), werden nur Erkrankungen der Kategorien B und C gezählt.

Ausnahme: Labordiagnostische Nachweise bei einem Kind im ersten Lebensmonat werden als Neugeborenenlisteriose gewertet und erfüllen unabhängig vom klinischen Bild (also auch bei Fällen der Kategorien D und E) immer die Referenzdefinition. 


\section{Gesetzliche Grundlage}

\section{Meldepflicht}

Dem Gesundheitsamt wird gemäß $\ 7$ Abs. I Nr. 28 IfSG nur der direkte Nachweis von Listeria monocytogenes aus Blut, Liquor oder anderen normalerweise sterilen Substraten sowie aus Abstrichen von Neugeborenen, soweit er auf eine akute Infektion hinweist, namentlich gemeldet. Darüber hinaus stellt das Gesundheitsamt gemäß \25 Abs. I IfSG ggf. eigene Ermittlungen an.

\section{Weitergehende Meldepflicht}

Dem Gesundheitsamt wird gemäß \6 Abs. I Nr. 2 IfSG ggf. auch der Verdacht auf und die Erkrankung an einer akuten infektiösen Gastroenteritis ohne labordiagnostischen Nachweis und ohne epidemiologische Bestätigung gemeldet.

\section{Übermittlung}

Das Gesundheitsamt übermittelt gemäß \II Abs. I IfSG an die zuständige Landesbehörde nur Erkrankungs- oder Todesfälle und Erregernachweise, die der Falldefinition gemäß $\ 4$ Abs. 2 Nr. 2 Buchst. a IfSG entsprechen. 


\section{Marburgvirus (Marburgfieber - virales hämorrhagisches Fieber)}

ICDıo: A98.3 Marburg-Viruskrankheit

\section{Vorbemerkung}

Marburgfieber kann als akut fieberhaftes Krankheitsbild auch ohne Zeichen einer hämorrhagischen Verlaufsform auftreten.

\section{Klinisches Bild}

Klinisches Bild eines akuten Marburgfiebers, definiert als mindestens eines der beiden folgenden Kriterien:

- $\rightarrow$ Fieber,

- hämorrhagischer Verlauf.

\section{Labordiagnostischer Nachweis}

Positiver Befund mit mindestens einer der vier folgenden Methoden:

[direkter Erregernachweis:]

- Virusisolierung,

- Nukleinsäure-Nachweis (z.B. PCR),

- Antigennachweis (z.B. ELISA),

- Elektronenmikroskopie.

\section{Epidemiologische Bestätigung}

Entfällt.

\section{Zusatzinformation}

Inkubationszeit ca. 2-2I Tage. 


\section{Über die zuständige Landesbehörde an das RKI zu übermittelnder Fall}

\section{A. Klinisch diagnostizierte Erkrankung}

Entfällt.

B. Klinisch-epidemiologisch bestätigte Erkrankung

Entfällt.

\section{Klinisch-labordiagnostisch bestätigte Erkrankung}

Klinisches Bild eines akuten Marburgfiebers und labordiagnostischer Nachweis.

D. Labordiagnostisch nachgewiesene Infektion bei nicht erfülltem klinischen Bild

Labordiagnostischer Nachweis bei bekanntem klinischen Bild, das die Kriterien für ein akutes Marburgfieber nicht erfüllt. Hierunter fallen auch asymptomatische Infektionen.

\section{E. Labordiagnostisch nachgewiesene Infektion bei unbekanntem klinischen Bild}

Labordiagnostischer Nachweis bei fehlenden Angaben zum klinischen Bild (nicht ermittelbar oder nicht erhoben).

\section{Referenzdefinition}

In Veröffentlichungen des Robert Koch-Instituts, die nicht nach Falldefinitionskategorien differenzieren (z.B. wöchentliche „Aktuelle Statistik meldepflichtiger Infektionskrankheiten“ im Epidemiologischen Bulletin), werden nur Erkrankungen der Kategorie $\mathbf{C}$ gezählt.

\section{Gesetzliche Grundlage}

\section{Meldepflicht}

Dem Gesundheitsamt wird gemäß \6 Abs. I Nr. I Buchst. g IfSG der Krankheitsverdacht, die Erkrankung sowie der Tod an virusbedingtem hämorrhagischen Fieber, sowie gemäß \7 Abs. I Nr. 29 IfSG der direkte oder indirekte Nachweis von Marburgvirus, soweit er auf eine akute Infektion hinweist, namentlich gemeldet. Darüber hinaus stellt das Gesundheitsamt gemäß 『25 Abs. I IfSG ggf. eigene Ermittlungen an.

\section{Übermittlung}

Das Gesundheitsamt übermittelt gemäß 』 II Abs. I IfSG an die zuständige Landesbehörde nur Erkrankungs- oder Todesfälle und Erregernachweise, die der Falldefinition gemäß $\int 4$ Abs. 2 Nr. 2 Buchst. a IfSG entsprechen.

Zusätzlich ist gemäß』I2 Abs. I IfSG das Auftreten von Marburgfieber vom Gesundheitsamt unverzüglich an die zuständige oberste Landesgesundheitsbehörde und von dieser unverzüglich dem RKI zu übermitteln. Der Begriff 'Auftreten' schließt neben der Infektion/Erkrankung und dem Tod auch Verdachtsfälle ohne labordiagnostischen Nachweis ein. 


\section{Masernvirus (Masern)}

ICDıо: Bo5.- Masern, inkl.: Morbilli,

B05.0 Masern, kompliziert durch Enzephalitis (Enzephalitis bei Masern),

Bo5.I Masern, kompliziert durch Meningitis (Meningitis bei Masern),

Bo5.2 Masern, kompliziert durch Pneumonie (Pneumonie bei Masern),

Bo5.3 Masern, kompliziert durch Otitis media (Otitis media bei Masern),

Bo5.4 Masern mit Darmkomplikationen,

Bo5.8 Masern mit sonstigen Komplikationen (Keratitis und Keratokonjunktivitis bei Masern),

Bo5.9 Masern ohne Komplikation (Masern o.n.A.)

\section{Klinisches Bild}

Klinisches Bild der Masern, definiert als

- ein mehr als drei Tage anhaltender, generalisierter Ausschlag (makulopapulös) UND

- Fieber UND

- mindestens eines der vier folgenden Kriterien:

- Husten,

- Katarrh (wässriger Schnupfen),

- Kopliksche Flecken,

- Rötung der Bindehaut.

\section{Zusatzinformation}

Bei impfpräventablen Krankheiten sollten stets Angaben zur Impfanamnese (Anzahl der vorangegangenen Impfungen, Art und Datum der letzten Impfung) erhoben (z.B. Impfbuchkontrolle) und übermittelt werden.

\section{Labordiagnostischer Nachweis}

Positiver Befund mit mindestens einer der fünf folgenden Methoden:

[direkter Erregernachweis nur in Zellen des Nasen-Rachen-Raums, Zahntaschenflüssigkeit, Konjunktiven, Urin oder Blut:]

- Virusisolierung,

- Nukleinsäure-Nachweis (z.B. PCR),

[indirekter (serologischer) Nachweis:]

- IgM-Antikörpernachweis (z.B. ELISA),

- \deutliche Änderung zwischen zwei Proben beim IgG-Antikörpernachweis (z.B. ELISA),

- Deutliche Änderung zwischen zwei Proben beim Antikörpernachweis (z.B. NT).

\section{Zusatzinformation}

Die Bewertung von Virus- und Antikörpernachweisen setzt die Kenntnis eines eventuellen zeitlichen Zusammenhangs mit einer Masernimpfung voraus. 


\section{Epidemiologische Bestätigung}

Epidemiologische Bestätigung, definiert als folgender Nachweis unter Berücksichtigung der Inkubationszeit:

- Epidemiologischer Zusammenhang mit einer labordiagnostisch nachgewiesenen Infektion beim Menschen durch

- Mensch-zu-Mensch-Übertragung.

Inkubationszeit ca. 7-I8 Tage.

\section{Über die zuständige Landesbehörde an das RKI zu übermittelnder Fall}

\section{A. Klinisch diagnostizierte Erkrankung}

Klinisches Bild der Masern, ohne labordiagnostischen Nachweis und ohne epidemiologische Bestätigung.

\section{B. Klinisch-epidemiologisch bestätigte Erkrankung}

Klinisches Bild der Masern, ohne labordiagnostischen Nachweis, aber mit epidemiologischer Bestätigung.

\section{Klinisch-labordiagnostisch bestätigte Erkrankung}

Klinisches Bild der Masern und labordiagnostischer Nachweis.

\section{Labordiagnostisch nachgewiesene Infektion bei nicht erfülltem klinischen Bild}

Labordiagnostischer Nachweis bei bekanntem klinischen Bild, das die Kriterien für Masern nicht erfüllt. Hierunter fallen auch asymptomatische Infektionen.

\section{E. Labordiagnostisch nachgewiesene Infektion bei unbekanntem klinischen Bild}

Labordiagnostischer Nachweis bei fehlenden Angaben zum klinischen Bild (nicht ermittelbar oder nicht erhoben).

\section{Referenzdefinition}

In Veröffentlichungen des Robert Koch-Instituts, die nicht nach Falldefinitionskategorien differenzieren (z.B. wöchentliche „Aktuelle Statistik meldepflichtiger Infektionskrankheiten“ im Epidemiologischen Bulletin), werden nur Erkrankungen der Kategorien A, B und C gezählt.

\section{Gesetzliche Grundlage}

\section{Meldepflicht}

Dem Gesundheitsamt wird gemäß \6 Abs. I Nr. I Buchst. h IfSG der Krankheitsverdacht, die Erkrankung sowie der Tod an Masern, sowie gemäß $₫ 7$ Abs. I Nr. 30 IfSG der direkte oder indirekte Nachweis von Masernvirus, soweit er auf eine akute Infektion hinweist, namentlich gemeldet. Darüber hinaus stellt das Gesundheitsamt gemäß

『25 Abs. I IfSG ggf. eigene Ermittlungen an.

\section{Übermittlung}

Das Gesundheitsamt übermittelt gemäß 』II Abs. I IfSG an die zuständige Landesbehörde nur Erkrankungs- oder Todesfälle und Erregernachweise, die der Falldefinition gemäß $\ 4$ Abs. 2 Nr. 2 Buchst. a IfSG entsprechen. 


\section{Mycobacterium leprae (Lepra)}

ICDıo: A30.- Lepra [Aussatz], inkl.: Infektion durch Mycobacterium leprae, exkl.: Folgezustände der Lepra,

A30.0 Indeterminierte Lepra (I-Lepra),

A30.I Tuberkuloide Lepra (TT-Lepra),

A30.2 Borderline-tuberkuloide Lepra (BT-Lepra),

A30.3 Borderline-Lepra (BB-Lepra),

A30.4 Borderline-lepromatöse Lepra (BL-Lepra),

A30.5 Lepromatöse Lepra (LL-Lepra),

A30.8 Sonstige Formen der Lepra,

A30.9 Lepra, nicht näher bezeichnet

\section{Klinisches Bild}

Klinisches Bild einer Lepra, definiert als mindestens eine der vier folgenden Formen:

- Indeterminierte Lepra, definiert als

- einzelne, hypopigmentierte, makulöse (fleckige) Hautläsionen (Hautveränderungen).

ICDıо: A30.0 Indeterminierte Lepra (I-Lepra)

- Tuberkuloide Lepra, definiert als Vorliegen beider folgenden Kriterien:

- einzelne, abgegrenzte, hypopigmentierte, am Rande papulös erhabene, sensibilitätsgestörte Hautareale,

- verdickte periphere Hautnerven.

ICDio: A30.I Tuberkuloide Lepra (TT-Lepra)

- Lepromatöse Lepra, definiert als Vorliegen beider folgenden Kriterien:

- zahlreiche beidseitig, symmetrisch angeordnete makulopapulöse (fleckig-erhabene) Störungen der Haut oder Schleimhaut der oberen Atemwege,

- knotig-flächenhafte Hautinfiltrationen.

ICDıo: A30.5 Lepromatöse Lepra (LL-Lepra)

- Borderline Lepra, definiert als mindestens je eines der Kriterien der tuberkuloiden und lepromatösen Form.

ICDıо: A30.2 Borderline-tuberkuloide Lepra (BT-Lepra),

A30.3 Borderline-Lepra (BB-Lepra),

A30.4 Borderline-lepromatöse Lepra (BL-Lepra)

\section{Labordiagnostischer Nachweis}

Positiver Befund mit

[direkter Erregernachweis nur in verdächtigen Hautarealen, Nasenabstrich oder peripheren Nerven (Biopsie):]

- Nukleinsäure-Nachweis (z.B. PCR) UND

- mindestens einer der drei folgenden Methoden:

- mikroskopischer Nachweis säurefester Stäbchen,

[indirekter (serologischer) Nachweis:]

- PGL-I-Antikörpernachweis (einmaliger deutlich erhöhter Wert, z.B. ELISA),

[histologisch:]

- für Lepra charakteristische histologische Veränderungen in Gewebeproben

(z.B. Haut, Lymphknoten). 


\section{Epidemiologische Bestätigung}

Entfällt.

\section{Zusatzinformation}

Inkubationszeit ca. 9 Monate bis 20 Jahre.

\section{Über die zuständige Landesbehörde an das RKI zu übermittelnder Fall}

\section{A. Klinisch diagnostizierte Erkrankung}

Entfällt.

B. Klinisch-epidemiologisch bestätigte Erkrankung

Entfällt.

C. Klinisch-labordiagnostisch bestätigte Erkrankung

Klinisches Bild einer Lepra und labordiagnostischer Nachweis.

D. Labordiagnostisch nachgewiesene Infektion bei nicht erfülltem klinischen Bild

Labordiagnostischer Nachweis bei bekanntem klinischen Bild, das die Kriterien für eine Lepra nicht erfüllt. Hierunter fallen auch asymptomatische Infektionen.

\section{E. Labordiagnostisch nachgewiesene Infektion bei unbekanntem klinischen Bild}

Labordiagnostischer Nachweis bei fehlenden Angaben zum klinischen Bild (nicht ermittelbar oder nicht erhoben).

\section{Referenzdefinition}

In Veröffentlichungen des Robert Koch-Instituts, die nicht nach Falldefinitionskategorien differenzieren (z.B. wöchentliche „Aktuelle Statistik meldepflichtiger Infektionskrankheiten“ im Epidemiologischen Bulletin), werden nur Erkrankungen der Kategorie $\mathbf{C}$ gezählt.

\section{Gesetzliche Grundlage}

\section{Meldepflicht}

Dem Gesundheitsamt wird gemäß \7 Abs. I Nr. 3I IfSG der direkte oder indirekte Nachweis von Mycobacterium leprae, soweit er auf eine akute Infektion hinweist, namentlich gemeldet. Darüber hinaus stellt das Gesundheitsamt gemäß $\int 25$ Abs. I IfSG ggf. eigene Ermittlungen an.

\section{Übermittlung}

Das Gesundheitsamt übermittelt gemäß \II Abs. I IfSG an die zuständige Landesbehörde nur Erkrankungs- oder Todesfälle und Erregernachweise, die der Falldefinition gemäß $\ 4$ Abs. 2 Nr. 2 Buchst. a IfSG entsprechen. 


\section{M.-tuberculosis-Komplex außer BCG (Tuberkulose)}

ICDıо: Ai5.- Tuberkulose der Atmungsorgane, bakteriologisch oder histologisch gesichert,

AI6.- Tuberkulose der Atmungsorgane, weder bakteriologisch noch histologisch gesichert,

Ar7.- Tuberkulose des Nervensystems,

Aı8.- Tuberkulose sonstiger Organe,

Aı9.- Miliartuberkulose,

P37.0 Angeborene Tuberkulose

\section{Vorbemerkung}

Diese Übermittlungskategorie umfasst außer BCG alle zum M.-tuberculosis-Komplex gehörigen Spezies, d.h. z.Zt. Mycobacterium tuberculosis, M. bovis, M. africanum, M. microti, M. canetti.

\section{Klinisches Bild}

Klinisches Bild einer Tuberkulose, definiert als eines der beiden folgenden Kriterien:

- der behandelnde Arzt stellt eine Indikation zur Durchführung einer vollständigen AntituberkulotikaTherapie,

- nach dem Tod werden Befunde bekannt, die zu Lebzeiten eine ärztliche Indikation zur Durchführung einer vollständigen Antituberkulotika-Therapie ergeben hätten.

\section{Labordiagnostischer Nachweis}

Positiver Befund mit mindestens einer der beiden folgenden Methoden:

[direkter Erregernachweis:]

- kulturelle Isolierung von M.-tuberculosis-Komplex,

- mikroskopischer, färberischer Nachweis säurefester Stäbchen, bestätigt durch

- Nukleinsäure-Nachweis (z.B. PCR) nur in Material des gleichen Organsystems.

\section{Zusatzinformationen}

- Magensaft gilt als verschlucktes respiratorisches Material.

- Die kulturelle Erregerisolierung und die Resistenzbestimmung sind in jedem Fall anzustreben.

- Der alleinige Nachweis säurefester Stäbchen oder der alleinige Nukleinsäure-Nachweis gelten nicht als labordiagnostischer Nachweis.

\section{Epidemiologische Bestätigung}

Epidemiologische Bestätigung, definiert als mindestens einer der beiden folgenden Nachweise unter Berücksichtigung der Inkubationszeit:

- Epidemiologischer Zusammenhang mit einer labordiagnostisch nachgewiesenen Infektion beim Menschen durch

- Mensch-zu-Mensch-Übertragung ODER

- gemeinsame Expositionsquelle (z.B. >Tierkontakt, \Lebensmittel).

- $\rightarrow$ Kontakt mit einem labordiagnostisch nachgewiesen infizierten Tier oder seinen Ausscheidungen, oder Verzehr seiner Produkte (z.B. Rohmilch).

Inkubationszeit ca. 6 Wochen bis mehrere Jahrzehnte. Bei Fällen mit vermutlich mehrjährigen Inkubationszeiten ist die epidemiologische Bestätigung allerdings in der Regel unsicher und sollte nur bei Vorliegen gewichtiger Hinweise (z.B. DNS-Fingerabdruck) postuliert werden. 


\section{Über die zuständige Landesbehörde an das RKI zu übermittelnder Fall}

\section{A. Klinisch diagnostizierte Erkrankung}

Klinisches Bild einer Tuberkulose, ohne labordiagnostischen Nachweis und ohne epidemiologische Bestätigung.

\section{B. Klinisch-epidemiologisch bestätigte Erkrankung}

Klinisches Bild einer Tuberkulose, ohne labordiagnostischen Nachweis, aber mit epidemiologischer Bestätigung.

\section{Klinisch-labordiagnostisch bestätigte Erkrankung}

Klinisches Bild einer Tuberkulose und labordiagnostischer Nachweis.

\section{Labordiagnostisch nachgewiesene Infektion bei nicht erfülltem klinischen Bild}

Labordiagnostischer Nachweis bei bekanntem klinischen Bild, das die Kriterien für Tuberkulose nicht erfüllt. Hierunter fallen auch asymptomatische Infektionen.

\section{E. Labordiagnostisch nachgewiesene Infektion bei unbekanntem klinischen Bild}

Labordiagnostischer Nachweis bei fehlenden Angaben zum klinischen Bild (nicht ermittelbar oder nicht erhoben).

\section{Zusatzinformationen}

- Ubiquitäre Mykobakterien und BCG gelten nicht als Erreger der Tuberkulose. Die von ihnen verursachten Krankheiten werden als Mykobakteriose bzw. BCG-Erkrankung bezeichnet. Bei alleinigem Nachweis dieser Erreger wird eine 'klinisch diagnostizierte Erkrankung' übermittelt, wenn der behandelnde Arzt eine Indikation zur Weiterführung einer vollständigen Antituberkulotika-Therapie stellt. Der Fall ist zu löschen, wenn aufgrund eines dieser Befunde die Indikation zur Weiterführung einer vollständigen Antituberkulotika-Therapie entfällt.

- Unter einer BCG-Behandlung (z.B. Therapie eines Blasenkarzinoms) oder bei einer BCG-Impfkomplikation muss daher eine weitere Typendifferenzierung innerhalb des M.-tuberculosis-Komplexes erfolgen.

- Eine Tuberkulinkonversion ohne tuberkulosetypischen Organbefund oder das Vorhandensein narbiger Residuen nach früherer Erkrankung an Tuberkulose gelten nicht als Erkrankung an Tuberkulose, auch wenn eine Chemoprävention durchgeführt wird.

\section{Referenzdefinition}

In Veröffentlichungen des Robert Koch-Instituts, die nicht nach Falldefinitionskategorien differenzieren (z.B. wöchentliche „Aktuelle Statistik meldepflichtiger Infektionskrankheiten“ im Epidemiologischen Bulletin), werden nur Erkrankungen der Kategorien A, B und C gezählt.

\section{Gesetzliche Grundlage}

\section{Meldepflicht}

Dem Gesundheitsamt wird gemäß $\ 6$ Abs. I Nr. I a.E. IfSG die Erkrankung und der Tod an einer behandlungsbedürftigen Tuberkulose, auch wenn ein bakteriologischer Nachweis nicht vorliegt, sowie gemäß $\llbracket 7$ Abs. I Nr. 32 IfSG der direkte Erregernachweis von Mycobacterium tuberculosis/africanum und M. bovis, sowie nachfolgend das Ergebnis der Resistenzbestimmung und vorab auch der Nachweis säurefester Stäbchen im Sputum, namentlich gemeldet. Darüber hinaus stellt das Gesundheitsamt gemäß 『25 Abs. I IfSG ggf. eigene Ermittlungen an.

\section{Übermittlung}

Das Gesundheitsamt übermittelt gemäß 『 II Abs. I IfSG an die zuständige Landesbehörde nur Erkrankungs- oder Todesfälle und Erregernachweise, die der Falldefinition gemäß $\ 4$ Abs. 2 Nr. 2 Buchst. a IfSG entsprechen. 


\section{Neisseria meningitidis (invasive Meningokokken-Erkrankung)}

ICDıо: A39.- Meningokokkeninfektion,

A39.0 Meningokokkenmeningitis,

A39.I Waterhouse-Friderichsen-Syndrom (Hämorrhagische Entzündung der Nebenniere durch Meningokokken, Meningokokkensepsis mit Nebennierenblutung),

A39.2 Akute Meningokokkensepsis,

(nicht A39.3 Chronische Meningokokkensepsis)

A39.4 Meningokokkensepsis, nicht näher bezeichnet (Meningokokken-Bakteriämie o.n.A.),

A39.5 Herzkrankheit durch Meningokokken (Endokarditis, Karditis o.n.A., Myokarditis, Perikarditis durch Meningokokken),

A39.8 Sonstige Meningokokkeninfektionen (Arthritis nach Meningokokkeninfektion, Arthritis, Enzephalitis, Konjunktivitis, retrobulbäre Neuritis durch Meningokokken),

A39.9 Meningokokkeninfektion, nicht näher bezeichnet (Krankheit durch Meningokokken o.n.A.)

\section{Klinisches Bild}

Klinisches Bild einer invasiven Meningokokken-Erkrankung, definiert als mindestens eines der fünf folgenden Kriterien:

- $\rightarrow$ Fieber,

- meningeale Zeichen (z.B. Nackensteifigkeit, Kopfschmerzen, veränderte Bewusstseinslage),

- Hautveränderungen (z.B. makulopapulöses Exanthem, punktförmige (Petechien) oder flächige (Ekchymosen) Einblutungen der Haut und Schleimhäute),

- Hirndruckzeichen (z.B. aufgetriebene Fontanelle, Erbrechen),

- Zeichen des Kreislaufversagens.

Das klinische Bild kann zusätzlich die folgende Form annehmen:

- Klinisches Bild einer Purpura fulminans (inkl. Waterhouse-Friderichsen-Syndrom), definiert als Vorliegen der beiden folgenden Kriterien:

- septisches Krankheitsbild,

- rasch fortschreitende Einblutungen der Haut und Schleimhäute.

ICDıO: A39.I Waterhouse-Friderichsen-Syndrom (Hämorrhagische Entzündung der Nebenniere durch Meningokokken, Meningokokkensepsis mit Nebennierenblutung)

\section{Zusatzinformationen}

- Vor allem bei Kleinkindern können die klinischen Zeichen der Meningitis zunächst auf Erbrechen und Fieber beschränkt sein.

- Das klinische Bild eines Waterhouse-Friderichsen-Syndroms wird typischerweise durch N. meningitidis, gelegentlich jedoch auch durch andere Erreger, z.B. Pneumokokken, Haemophilus influenzae oder Staphylokokken, verursacht.

- Bei impfpräventablen Krankheiten sollten stets Angaben zur Impfanamnese (Anzahl der vorangegangenen Impfungen, Art und Datum der letzten Impfung) erhoben (z.B. Impfbuchkontrolle) und übermittelt werden. 


\section{Labordiagnostischer Nachweis}

Positiver Befund mit mindestens einer der vier folgenden Methoden:

[direkter Erregernachweis nur in Blut, Liquor, hämorrhagischen Hautinfiltraten oder anderen >normalerweise sterilen klinischen Materialien:]

- Erregerisolierung (kulturell),

- mikroskopischer Nachweis von gram-negativen Diplokokken,

- Nukleinsäure-Nachweis (z.B. PCR),

- Antigennachweis des Kapselpolysaccharids (z.B. Latexagglutinationstest), auch als Schnelltest bezeichnet, nur im Liquor.

\section{Zusatzinformationen}

- Das Ergebnis der Serogruppenbestimmung sowie einer weitergehenden Feintypisierung sollte übermittelt werden. Nur die Serogruppen A, C, WI35 und Y sind impfpräventabel.

- Bei antibiotisch anbehandelten Patienten ist der Nukleinsäure-Nachweis mittels PCR möglich.

\section{Epidemiologische Bestätigung}

Epidemiologische Bestätigung, definiert als folgender Nachweis unter Berücksichtigung der Inkubationszeit:

- Epidemiologischer Zusammenhang mit einer labordiagnostisch nachgewiesenen Infektion beim Menschen durch

- Mensch-zu-Mensch-Übertragung.

Inkubationszeit ca. 2-Io Tage.

\section{Über die zuständige Landesbehörde an das RKI zu übermittelnder Fall}

\section{A. Klinisch diagnostizierte Erkrankung \\ Entfällt.}

B. Klinisch-epidemiologisch bestätigte Erkrankung

Klinisches Bild einer invasiven Meningokokken-Erkrankung, ohne labordiagnostischen Nachweis, aber mit epidemiologischer Bestätigung.

C. Klinisch-labordiagnostisch bestätigte Erkrankung

Klinisches Bild einer invasiven Meningokokken-Erkrankung und labordiagnostischer Nachweis.

D. Labordiagnostisch nachgewiesene Infektion bei nicht erfülltem klinischen Bild

Labordiagnostischer Nachweis bei bekanntem klinischen Bild, das die Kriterien für eine invasive Meningokokken-Erkrankung nicht erfüllt.

\section{E. Labordiagnostisch nachgewiesene Infektion bei unbekanntem klinischen Bild}

Labordiagnostischer Nachweis bei fehlenden Angaben zum klinischen Bild (nicht ermittelbar oder nicht erhoben). 


\section{Referenzdefinition}

In Veröffentlichungen des Robert Koch-Instituts, die nicht nach Falldefinitionskategorien differenzieren (z.B. wöchentliche „Aktuelle Statistik meldepflichtiger Infektionskrankheiten“ im Epidemiologischen Bulletin), werden nur Erkrankungen der Kategorien $\mathbf{B}$ und $\mathbf{C}$ gezählt.

\section{Gesetzliche Grundlage}

\section{Meldepflicht}

Dem Gesundheitsamt wird gemäß \6 Abs. I Nr. I Buchst. i IfSG der Krankheitsverdacht, die Erkrankung sowie der Tod an Meningokokken-Meningitis oder -Sepsis, sowie gemäß $\ 7$ Abs. I Nr. 33 IfSG nur der direkte Nachweis von Neisseria meningitidis, aus Liquor, Blut, hämorrhagischen Hautinfiltraten oder anderen normalerweise sterilen Substraten, soweit er auf eine akute Infektion hinweist, namentlich gemeldet. Darüber hinaus stellt das Gesundheitsamt gemäß $\int 25$ Abs. I IfSG ggf. eigene Ermittlungen an.

\section{Übermittlung}

Das Gesundheitsamt übermittelt gemäß 『II Abs. I IfSG an die zuständige Landesbehörde nur Erkrankungs- oder Todesfälle und Erregernachweise, die der Falldefinition gemäß \4 Abs. 2 Nr. 2 Buchst. a IfSG entsprechen. 


\section{Norovirus (Norovirus-Gastroenteritis)}

ICDıo: Ao8.I Akute Gastroenteritis durch Norwalk-Agens [Norwalk-Virus]

\section{Klinisches Bild}

Klinisches Bild einer akuten Norovirus-Gastroenteritis, definiert als mindestens eines der beiden folgenden Kriterien:

- Erbrechen,

- Durchfall.

\section{Labordiagnostischer Nachweis}

Positiver Befund mit mindestens einer der drei folgenden Methoden:

[direkter Erregernachweis:]

- Nukleinsäure-Nachweis (z.B. PCR),

- Antigennachweis (z.B. ELISA) nur im Stuhl,

- Elektronenmikroskopie.

\section{Epidemiologische Bestätigung}

Epidemiologische Bestätigung, definiert als mindestens einer der beiden folgenden Nachweise unter Berücksichtigung der Inkubationszeit:

- Epidemiologischer Zusammenhang mit einer labordiagnostisch nachgewiesenen Infektion beim Menschen durch

- Mensch-zu-Mensch-Übertragung ODER

- gemeinsame Expositionsquelle (z.B. - Lebensmittel).

- Verzehr eines Lebensmittels (inkl. Trinkwasser), in dessen Resten Norovirus labordiagnostisch nachgewiesen wurde.

Inkubationszeit ca. Io-50 Stunden. 


\section{Über die zuständige Landesbehörde an das RKI zu übermittelnder Fall}

\section{A. Klinisch diagnostizierte Erkrankung}

Entfällt.

\section{B. Klinisch-epidemiologisch bestätigte Erkrankung}

Klinisches Bild einer akuten Norovirus-Gastroenteritis, ohne labordiagnostischen Nachweis, aber mit epidemiologischer Bestätigung.

\section{Klinisch-labordiagnostisch bestätigte Erkrankung}

Klinisches Bild einer akuten Norovirus-Gastroenteritis und labordiagnostischer Nachweis.

D. Labordiagnostisch nachgewiesene Infektion bei nicht erfülltem klinischen Bild

Labordiagnostischer Nachweis bei bekanntem klinischen Bild, das die Kriterien für eine akute Norovirus-Gastroenteritis nicht erfüllt. Hierunter fallen auch asymptomatische Infektionen.

\section{E. Labordiagnostisch nachgewiesene Infektion bei unbekanntem klinischen Bild}

Labordiagnostischer Nachweis bei fehlenden Angaben zum klinischen Bild (nicht ermittelbar oder nicht erhoben).

\section{Referenzdefinition}

In Veröffentlichungen des Robert Koch-Instituts, die nicht nach Falldefinitionskategorien differenzieren (z.B. wöchentliche „Aktuelle Statistik meldepflichtiger Infektionskrankheiten“ im Epidemiologischen Bulletin), werden nur Erkrankungen der Kategorien $\mathbf{B}$ und $\mathbf{C}$ gezählt.

\section{Gesetzliche Grundlage}

\section{Meldepflicht}

Dem Gesundheitsamt wird gemäß $\ 7$ Abs. I Nr. 34 IfSG nur der direkte Nachweis von Norwalk-ähnlichem Virus (jetzt: Norovirus), soweit er auf eine akute Infektion hinweist, namentlich gemeldet. Darüber hinaus stellt das Gesundheitsamt gemäß \25 Abs. I IfSG ggf. eigene Ermittlungen an.

\section{Weitergehende Meldepflicht}

Dem Gesundheitsamt wird gemäß \ 6 Abs. I Nr. 2 IfSG ggf. auch der Verdacht auf und die Erkrankung an einer akuten infektiösen Gastroenteritis ohne labordiagnostischen Nachweis und ohne epidemiologische Bestätigung gemeldet.

\section{Übermittlung}

Das Gesundheitsamt übermittelt gemäß 『 II Abs. I IfSG an die zuständige Landesbehörde nur Erkrankungs- oder Todesfälle und Erregernachweise, die der Falldefinition gemäß $\ 4$ Abs. 2 Nr. 2 Buchst. a IfSG entsprechen. 


\section{Poliovirus (Poliomyelitis)}

ICDıo: A8o.- Akute Poliomyelitis [Spinale Kinderlähmung],

A80.0 Akute paralytische Poliomyelitis durch Impfvirus,

A80.I Akute paralytische Poliomyelitis durch importiertes Wildvirus,

A80.2 Akute paralytische Poliomyelitis durch einheimisches Wildvirus,

A80.3 Sonstige und nicht näher bezeichnete akute paralytische Poliomyelitis,

A80.4 Akute nichtparalytische Poliomyelitis,

A80.9 Akute Poliomyelitis, nicht näher bezeichnet

\section{Klinisches Bild}

Klinisches Bild einer akuten Poliomyelitis, definiert als Vorliegen aller drei folgenden Kriterien:

- akut eintretende schlaffe Lähmung einer oder mehrerer Extremitäten,

- verminderte oder fehlende Sehnenreflexe in den betroffenen Extremitäten,

- keine sensorischen oder kognitiven Defizite.

\section{Zusatzinformation}

Bei impfpräventablen Krankheiten sollten stets Angaben zur Impfanamnese (Anzahl der vorangegangenen Impfungen, Art und Datum der letzten Impfung) erhoben (z.B. Impfbuchkontrolle) und übermittelt werden.

\section{Labordiagnostischer Nachweis}

Positiver Befund mit mindestens einer der drei folgenden Methoden:

[direkter Erregernachweis:]

- Virusisolierung UND serologische Typisierung,

- -Nukleinsäure-Nachweis (z.B. PCR),

[indirekter (serologischer) Nachweis:]

- -deutliche Änderung zwischen zwei Proben beim Antikörpernachweis (z.B. NT).

\section{Zusatzinformation}

Die Bewertung von Antikörpernachweisen setzt die Kenntnis eines eventuellen zeitlichen Zusammenhangs mit einer Polioimpfung voraus. Das Ergebnis der intratypischen Differenzierung nach Wildvirus

ICDıo: A8o.I Akute paralytische Poliomyelitis durch importiertes Wildvirus,

A80.2 Akute paralytische Poliomyelitis durch einheimisches Wildvirus

oder Impfvirus (Vakzine-assoziierte Poliomyelitis, VAP)

ICDıо: A80.o Akute paralytische Poliomyelitis durch Impfvirus

sollte übermittelt werden.

\section{Epidemiologische Bestätigung}

Epidemiologische Bestätigung, definiert als folgender Nachweis unter Berücksichtigung der Inkubationszeit:

- Epidemiologischer Zusammenhang mit einer labordiagnostisch nachgewiesenen Infektion beim Menschen durch

- Mensch-zu-Mensch-Übertragung.

Inkubationszeit ca. 3-35 Tage. 


\section{Über die zuständige Landesbehörde an das RKI zu übermittelnder Fall}

\section{A. Klinisch diagnostizierte Erkrankung}

Klinisches Bild einer akuten Poliomyelitis, ohne labordiagnostischen Nachweis und ohne epidemiologische Bestätigung, und mindestens eines der drei folgenden Kriterien:

- Fortbestand der Parese (Lähmung) länger als 6o Tage nach Auftreten der Symptome,

- Tod des Erkrankten bei bis dahin fortbestehender Parese,

- weiterer Krankheitsverlauf bei bis dahin fortbestehender Parese nicht bekannt.

\section{B. Klinisch-epidemiologisch bestätigte Erkrankung}

Klinisches Bild einer akuten Poliomyelitis, ohne labordiagnostischen Nachweis, aber mit epidemiologischer Bestätigung.

\section{Klinisch-labordiagnostisch bestätigte Erkrankung}

Klinisches Bild einer akuten Poliomyelitis und labordiagnostischer Nachweis.

\section{Labordiagnostisch nachgewiesene Infektion bei nicht erfülltem klinischen Bild}

Labordiagnostischer Nachweis bei bekanntem klinischen Bild, das die Kriterien für eine akute Poliomyelitis nicht erfüllt. Hierunter fallen auch asymptomatische Infektionen.

\section{E. Labordiagnostisch nachgewiesene Infektion bei unbekanntem klinischen Bild}

Labordiagnostischer Nachweis bei fehlenden Angaben zum klinischen Bild (nicht ermittelbar oder nicht erhoben).

\section{Referenzdefinition}

In Veröffentlichungen des Robert Koch-Instituts, die nicht nach Falldefinitionskategorien differenzieren (z.B. wöchentliche „Aktuelle Statistik meldepflichtiger Infektionskrankheiten“ im Epidemiologischen Bulletin), werden nur Erkrankungen der Kategorien A, B und C gezählt.

\section{Gesetzliche Grundlage}

\section{Meldepflicht}

Dem Gesundheitsamt wird gemäß \6 Abs. I Nr. I Buchst. k IfSG der Krankheitsverdacht, die Erkrankung sowie der Tod an Poliomyelitis (als Verdacht gilt jede akute schlaffe Lähmung, außer wenn traumatisch bedingt), sowie gemäß $\llbracket 7$ Abs. I Nr. 35 IfSG der direkte oder indirekte Nachweis von Poliovirus, soweit er auf eine akute Infektion hinweist, namentlich gemeldet. Darüber hinaus stellt das Gesundheitsamt gemäß \25 Abs. I IfSG ggf. eigene Ermittlungen an.

\section{Übermittlung}

Das Gesundheitsamt übermittelt gemäß 』II Abs. I IfSG an die zuständige Landesbehörde nur Erkrankungs- oder Todesfälle und Erregernachweise, die der Falldefinition gemäß $\ 4$ Abs. 2 Nr. 2 Buchst. a IfSG entsprechen.

Zusätzlich ist gemäß 』I2 Abs. I IfSG das Auftreten von Poliomyelitis vom Gesundheitsamt unverzüglich über die zuständige oberste Landesgesundheitsbehörde und von dieser unverzüglich dem RKI zu übermitteln. Der Begriff 'Auftreten' schließt neben der Infektion/Erkrankung und dem Tod auch Verdachtsfälle ohne labordiagnostischen Nachweis und ohne epidemiologische Bestätigung ein. 


\section{Rabiesvirus, Lyssa-Virus (Tollwut)}

ICDio: A82.- Tollwut [Rabies], A82.0 Wildtier-Tollwut, A82.I Haustier-Tollwut, A82.9 Tollwut, nicht näher bezeichnet

\section{Klinisches Bild}

Klinisches Bild der Tollwut, definiert als mindestens zwei der sieben folgenden Kriterien:

- Schmerzen oder Parästhesien (Empfindungsstörungen) im Körperteil der Bissstelle,

- Erregtheit mit Spasmen der Schluckmuskulatur,

- Lähmungen,

- Delirien,

- Krämpfe,

- Angstzustände,

- Hydrophobie (Wasserscheu).

\section{Zusatzinformation}

Bei impfpräventablen Krankheiten sollten stets Angaben zur Impfanamnese (Anzahl der vorangegangenen Impfungen, Art und Datum der letzten Impfung) erhoben (z.B. Impfbuchkontrolle) und übermittelt werden.

\section{Labordiagnostischer Nachweis:}

Positiver Befund mit mindestens einer der drei folgenden Methoden:

[direkter Erregernachweis:]

- Virusisolierung,

- Nukleinsäure-Nachweis (z.B. PCR),

- Antigennachweis (z.B. IFT).

\section{Zusatzinformation}

Der direkte Erregernachweis zu Lebzeiten gelingt nur in etwa der Hälfte der Fälle. Ein negativer Befund schließt eine Tollwut-Infektion keineswegs aus.

\section{Epidemiologische Bestätigung}

Epidemiologische Bestätigung, definiert als mindestens einer der beiden folgenden Nachweise unter Berücksichtigung der Inkubationszeit:

- Kontakt mit einem labordiagnostisch nachgewiesen infizierten Tier oder seinen Ausscheidungen.

- Epidemiologischer Zusammenhang mit einer labordiagnostisch nachgewiesenen Infektion beim Menschen durch

- gemeinsame Expositionsquelle (z.B. $>$ Tierkontakt).

Inkubationszeit wenige Tage bis 8 Wochen, selten bis zu 7 Jahren. 


\section{Über die zuständige Landesbehörde an das RKI zu übermittelnder Fall}

\section{A. Klinisch diagnostizierte Erkrankung}

Entfällt.

\section{B. Klinisch-epidemiologisch bestätigte Erkrankung}

Klinisches Bild der Tollwut, ohne labordiagnostischen Nachweis, aber mit epidemiologischer Bestätigung.

\section{Klinisch-labordiagnostisch bestätigte Erkrankung}

Klinisches Bild der Tollwut und labordiagnostischer Nachweis.

D. Labordiagnostisch nachgewiesene Infektion bei nicht erfülltem klinischen Bild

Labordiagnostischer Nachweis bei bekanntem klinischen Bild, das die Kriterien für Tollwut nicht erfüllt.

\section{E. Labordiagnostisch nachgewiesene Infektion bei unbekanntem klinischen Bild}

Labordiagnostischer Nachweis bei fehlenden Angaben zum klinischen Bild (nicht ermittelbar oder nicht erhoben).

\section{Referenzdefinition}

In Veröffentlichungen des Robert Koch-Instituts, die nicht nach Falldefinitionskategorien differenzieren (z.B. wöchentliche „Aktuelle Statistik meldepflichtiger Infektionskrankheiten“ im Epidemiologischen Bulletin), werden nur Erkrankungen der Kategorien $\mathbf{B}$ und $\mathbf{C}$ gezählt.

\section{Gesetzliche Grundlage}

\section{Meldepflicht}

Dem Gesundheitsamt wird gemäß \6 Abs. I Nr. I Buchst. m IfSG der Krankheitsverdacht, die Erkrankung sowie der Tod an Tollwut, sowie gemäß $\ 7$ Abs. I Nr. 36 IfSG der direkte oder indirekte Nachweis von Rabiesvirus, soweit er auf eine akute Infektion hinweist, namentlich gemeldet. Darüber hinaus stellt das Gesundheitsamt gemäß $\int 25$ Abs. I IfSG ggf. eigene Ermittlungen an.

\section{Übermittlung}

Das Gesundheitsamt übermittelt gemäß 』 II Abs. I IfSG an die zuständige Landesbehörde nur Erkrankungs- oder Todesfälle und Erregernachweise, die der Falldefinition gemäß $\int 4$ Abs. 2 Nr. 2 Buchst. a IfSG entsprechen.

\section{Weitergehende Meldepflicht}

Vom Gesundheitsamt wird gemäß \6 Abs. I Nr. 4 IfSG auch die Verletzung eines Menschen durch ein tollwutkrankes, -verdächtiges oder -ansteckungsverdächtiges Tier sowie die Berührung eines solchen Tieres oder Tierkörpers erfasst. Diese sind jedoch nicht übermittlungspflichtig.

ICDio: Z20.3 Kontakt mit und Exposition gegenüber Tollwut 


\section{Rickettsia prowazekii (Fleckfieber)}

syn. Typhus exanthematicus

ICDıo: A75.o Epidemisches Fleckfieber durch Rickettsia prowazekii (Epidemisches Läusefleckfieber, Klassisches Fleckfieber)

\section{Klinisches Bild}

Klinisches Bild eines akuten Fleckfiebers, definiert als

- Fieber.

\section{Labordiagnostischer Nachweis}

Positiver Befund mit mindestens einer der fünf folgenden Methoden:

[direkter Erregernachweis:]

- Nukleinsäure-Nachweis (z.B. PCR),

- Antigennachweis mittels IFT nur in Gewebeproben (z.B. Milz, Lunge),

[indirekter (serologischer) Nachweis:]

- IgM-Antikörpernachweis (z.B. ELISA),

- $>$ deutliche Änderung zwischen zwei Proben beim IgG-Antikörpernachweis (z.B. ELISA, IFT),

- deutliche Änderung zwischen zwei Proben beim Antikörpernachweis mittels KBR.

\section{Epidemiologische Bestätigung}

Epidemiologische Bestätigung, definiert als folgender Nachweis unter Berücksichtigung der Inkubationszeit:

- Epidemiologischer Zusammenhang mit einer labordiagnostisch nachgewiesenen Infektion beim Menschen durch

- gemeinsame Expositionsquelle (z.B. Kleiderläuse).

Inkubationszeit ca. I-2 Wochen. 


\section{Über die zuständige Landesbehörde an das RKI zu übermittelnder Fall}

\section{A. Klinisch diagnostizierte Erkrankung}

Entfällt.

\section{B. Klinisch-epidemiologisch bestätigte Erkrankung}

Klinisches Bild eines akuten Fleckfiebers, ohne labordiagnostischen Nachweis, aber mit epidemiologischer Bestätigung.

\section{Klinisch-labordiagnostisch bestätigte Erkrankung}

Klinisches Bild eines akuten Fleckfiebers und labordiagnostischer Nachweis.

D. Labordiagnostisch nachgewiesene Infektion bei nicht erfülltem klinischen Bild

Labordiagnostischer Nachweis bei bekanntem klinischen Bild, das die Kriterien für ein akutes Fleckfieber nicht erfüllt. Hierunter fallen auch asymptomatische Infektionen.

\section{E. Labordiagnostisch nachgewiesene Infektion bei unbekanntem klinischen Bild}

Labordiagnostischer Nachweis bei fehlenden Angaben zum klinischen Bild (nicht ermittelbar oder nicht erhoben).

\section{Referenzdefinition}

In Veröffentlichungen des Robert Koch-Instituts, die nicht nach Falldefinitionskategorien differenzieren (z.B. wöchentliche „Aktuelle Statistik meldepflichtiger Infektionskrankheiten“ im Epidemiologischen Bulletin), werden nur Erkrankungen der Kategorien B und C gezählt.

\section{Gesetzliche Grundlage}

\section{Meldepflicht}

Dem Gesundheitsamt wird gemäß $\ 7$ Abs. I Nr. 37 IfSG der direkte oder indirekte Nachweis von Rickettsia prowazekii, soweit er auf eine akute Infektion hinweist, namentlich gemeldet. Darüber hinaus stellt das Gesundheitsamt gemäß $『 25$ Abs. I IfSG ggf. eigene Ermittlungen an.

\section{Übermittlung}

Das Gesundheitsamt übermittelt gemäß \ II Abs. I IfSG an die zuständige Landesbehörde nur Erkrankungs- oder Todesfälle und Erregernachweise, die der Falldefinition gemäß \4 Abs. 2 Nr. 2 Buchst. a IfSG entsprechen.

Zusätzlich ist gemäß \I2 Abs. I IfSG das Auftreten von Fleckfieber vom Gesundheitsamt unverzüglich an die zuständige oberste Landesgesundheitsbehörde und von dieser unverzüglich dem RKI zu übermitteln. Der Begriff 'Auftreten' schließt neben der Infektion/Erkrankung und dem Tod auch Verdachtsfälle ohne labordiagnostischen Nachweis und ohne epidemiologische Bestätigung ein. 


\section{Rotavirus (Rotavirus-Erkrankung)}

ICDıо: Ao8.o Enteritis durch Rotaviren

\section{Klinisches Bild}

Klinisches Bild einer Rotavirus-Erkrankung, definiert als mindestens eines der beiden folgenden Kriterien:

- Durchfall,

- Erbrechen.

\section{Zusatzinformation}

Bei impfpräventablen Krankheiten sollten stets Angaben zur Impfanamnese (Anzahl der vorangegangenen Impfungen, Art und Datum der letzten Impfung) erhoben (z.B. Impfbuchkontrolle) und übermittelt werden.

\section{Labordiagnostischer Nachweis}

Positiver Befund mit mindestens einer der drei folgenden Methoden:

[direkter Erregernachweis nur im Stuhl:]

- Antigennachweis (z.B. ELISA, einschließlich Schnelltest),

- -Nukleinsäure-Nachweis (z.B. PCR),

- Elektronenmikroskopie.

\section{Epidemiologische Bestätigung}

Epidemiologische Bestätigung, definiert als folgender Nachweis unter Berücksichtigung der Inkubationszeit:

- Epidemiologischer Zusammenhang mit einer labordiagnostisch nachgewiesenen Infektion beim Menschen durch

- Mensch-zu-Mensch-Übertragung.

Inkubationszeit ca. 24-72 Stunden. 


\section{Über die zuständige Landesbehörde an das RKI zu übermittelnder Fall}

\section{A. Klinisch diagnostizierte Erkrankung}

Entfällt.

\section{B. Klinisch-epidemiologisch bestätigte Erkrankung}

Klinisches Bild einer Rotavirus-Erkrankung, ohne labordiagnostischen Nachweis, aber mit epidemiologischer Bestätigung.

\section{Klinisch-labordiagnostisch bestätigte Erkrankung}

Klinisches Bild einer Rotavirus-Erkrankung und labordiagnostischer Nachweis.

D. Labordiagnostisch nachgewiesene Infektion bei nicht erfülltem klinischen Bild

Labordiagnostischer Nachweis bei bekanntem klinischen Bild, das die Kriterien für eine RotavirusErkrankung nicht erfüllt. Hierunter fallen auch asymptomatische Infektionen.

\section{E. Labordiagnostisch nachgewiesene Infektion bei unbekanntem klinischen Bild}

Labordiagnostischer Nachweis bei fehlenden Angaben zum klinischen Bild (nicht ermittelbar oder nicht erhoben).

\section{Referenzdefinition}

In Veröffentlichungen des Robert Koch-Instituts, die nicht nach Falldefinitionskategorien differenzieren (z.B. wöchentliche „Aktuelle Statistik meldepflichtiger Infektionskrankheiten“ im Epidemiologischen Bulletin), werden nur Erkrankungen der Kategorien $\mathbf{B}$ und $\mathbf{C}$ gezählt.

\section{Gesetzliche Grundlage}

\section{Meldepflicht}

Dem Gesundheitsamt wird gemäß $₫ 7$ Abs. I Nr. 38 IfSG der direkte oder indirekte Nachweis von Rotavirus, soweit er auf eine akute Infektion hinweist, namentlich gemeldet. Darüber hinaus stellt das Gesundheitsamt gemäß

『25 Abs. I IfSG ggf. eigene Ermittlungen an.

\section{Weitergehende Meldepflicht}

Dem Gesundheitsamt wird gemäß \6 Abs. I Nr. 2 IfSG ggf. auch der Verdacht auf und die Erkrankung an einer akuten infektiösen Gastroenteritis ohne labordiagnostischen Nachweis und ohne epidemiologische Bestätigung gemeldet.

\section{Übermittlung}

Das Gesundheitsamt übermittelt gemäß 『II Abs. I IfSG an die zuständige Landesbehörde nur Erkrankungs- oder Todesfälle und Erregernachweise, die der Falldefinition gemäß $\ 4$ Abs. 2 Nr. 2 Buchst. a IfSG entsprechen. 


\section{Salmonella Paratyphi A, B oder C (Paratyphus)}

ICDio: AoI.I Paratyphus A,

Aor.2 Paratyphus B,

Aor.3 Paratyphus C,

Aor.4 Paratyphus, nicht näher bezeichnet (Infektion durch Salmonella Paratyphi o.n.A.)

\section{Klinisches Bild}

Klinisches Bild eines Paratyphus, definiert als mindestens eines der beiden folgenden Kriterien:

- Fieber ODER

- mindestens zwei der drei folgenden Kriterien:

- Durchfall, Obstipation (Verstopfung) ODER krampfartige Bauchschmerzen,

- Husten,

- Kopfschmerzen.

\section{Labordiagnostischer Nachweis}

Positiver Befund mit der folgenden Methode:

[direkter Erregernachweis:]

- Erregerisolierung (kulturell).

\section{Zusatzinformationen}

- Das Ergebnis der Bestimmung des Serovars und ggf. des Lysotyps sollte übermittelt werden.

- Das enteritische Pathovar von $S$. Paratyphi B (früher $S$. Java) sollte in der Kategorie „Salmonellose“ übermittelt werden, da es anders als das systemische Pathovar von $S$. Paratyphi B in der Regel nicht das klinische Bild eines Paratyphus hervorruft.

Unterscheidungsmerkmale:

S. Paratyphi B enteritisches Pathovar: Tartrat positiv, SopE negativ, avrA positiv

$S$. Paratyphi B systemisches Pathovar: Tartrat negativ, SopE positiv, avrA negativ

(Bei uneindeutigen Ergebnissen ist die Wertigkeit des Virulenzgen-Nachweises (SopE, avrA) als höher einzustufen als die Tartratreaktion.)

\section{Epidemiologische Bestätigung}

Epidemiologische Bestätigung, definiert als mindestens einer der beiden folgenden Nachweise unter Berücksichtigung der Inkubationszeit:

- Epidemiologischer Zusammenhang mit einer labordiagnostisch nachgewiesenen Infektion beim Menschen durch

- Mensch-zu-Mensch-Übertragung ODER

- gemeinsame Expositionsquelle (z.B. -Lebensmittel).

- Verzehr eines Lebensmittels (inkl. Trinkwasser), in dessen Resten Salmonella Paratyphi labordiagnostisch nachgewiesen wurde.

Inkubationszeit ca. I-Io Tage. 


\section{Über die zuständige Landesbehörde an das RKI zu übermittelnder Fall}

\section{A. Klinisch diagnostizierte Erkrankung}

Entfällt.

\section{B. Klinisch-epidemiologisch bestätigte Erkrankung}

Klinisches Bild eines Paratyphus, ohne labordiagnostischen Nachweis, aber mit epidemiologischer Bestätigung.

\section{Klinisch-labordiagnostisch bestätigte Erkrankung}

Klinisches Bild eines Paratyphus und labordiagnostischer Nachweis.

D. Labordiagnostisch nachgewiesene Infektion bei nicht erfülltem klinischen Bild

Labordiagnostischer Nachweis bei bekanntem klinischen Bild, das die Kriterien für Paratyphus nicht erfüllt. Hierunter fallen auch asymptomatische Infektionen.

\section{E. Labordiagnostisch nachgewiesene Infektion bei unbekanntem klinischen Bild}

Labordiagnostischer Nachweis bei fehlenden Angaben zum klinischen Bild (nicht ermittelbar oder nicht erhoben).

\section{Referenzdefinition}

In Veröffentlichungen des Robert Koch-Instituts, die nicht nach Falldefinitionskategorien differenzieren (z.B. wöchentliche „Aktuelle Statistik meldepflichtiger Infektionskrankheiten“ im Epidemiologischen Bulletin), werden nur Erkrankungen der Kategorien $\mathbf{B}$ und $\mathbf{C}$ gezählt.

\section{Gesetzliche Grundlage}

\section{Meldepflicht}

Dem Gesundheitsamt werden gemäß \6 Abs. I Nr. I Buchst. n IfSG der Krankheitsverdacht, die Erkrankung sowie der Tod an Paratyphus, sowie gemäß \7 Abs. I Nr. 39 IfSG alle direkten Nachweise von Salmonella Paratyphi namentlich gemeldet. Darüber hinaus stellt das Gesundheitsamt gemäß $\$ 25$ Abs. I IfSG ggf. eigene Ermittlungen an.

\section{Übermittlung}

Das Gesundheitsamt übermittelt gemäß 『 II Abs. I IfSG an die zuständige Landesbehörde nur Erkrankungs- oder Todesfälle und Erregernachweise, die der Falldefinition gemäß $\int 4$ Abs. 2 Nr. 2 Buchst. a IfSG entsprechen. 


\section{Salmonella Typhi (Typhus abdominalis)}

ICDıо: Aoı.o Typhus abdominalis (Infektion durch Salmonella Typhi, Typhoides Fieber)

\section{Klinisches Bild}

Klinisches Bild eines Typhus, definiert als mindestens eines der beiden folgenden Kriterien:

- Fieber ODER

- mindestens zwei der drei folgenden Kriterien:

- Durchfall, Obstipation (Verstopfung) ODER krampfartige Bauchschmerzen,

- Husten,

- Kopfschmerzen.

\section{Zusatzinformation}

Bei impfpräventablen Krankheiten sollten stets Angaben zur Impfanamnese (Anzahl der vorangegangenen Impfungen, Art und Datum der letzten Impfung) erhoben (z.B. Impfbuchkontrolle) und übermittelt werden.

\section{Labordiagnostischer Nachweis}

Positiver Befund mit der folgenden Methode:

[direkter Erregernachweis:]

- Erregerisolierung (kulturell).

\section{Zusatzinformation}

Das Ergebnis der Lysotypbestimmung sollte übermittelt werden.

\section{Epidemiologische Bestätigung}

Epidemiologische Bestätigung, definiert als mindestens einer der beiden folgenden Nachweise unter Berücksichtigung der Inkubationszeit:

- Epidemiologischer Zusammenhang mit einer labordiagnostisch nachgewiesenen Infektion beim Menschen durch

- Mensch-zu-Mensch-Übertragung ODER

- gemeinsame Expositionsquelle (z.B. DLebensmittel).

- Verzehr eines Lebensmittels (inkl. Trinkwasser), in dessen Resten Salmonella Typhi labordiagnostisch nachgewiesen wurde.

Inkubationszeit ca. 3-60 Tage, gewöhnlich 8-I4 Tage. 


\section{Über die zuständige Landesbehörde an das RKI zu übermittelnder Fall}

\section{A. Klinisch diagnostizierte Erkrankung}

Entfällt.

\section{B. Klinisch-epidemiologisch bestätigte Erkrankung}

Klinisches Bild eines Typhus, ohne labordiagnostischen Nachweis, aber mit epidemiologischer Bestätigung.

\section{Klinisch-labordiagnostisch bestätigte Erkrankung}

Klinisches Bild eines Typhus und labordiagnostischer Nachweis.

D. Labordiagnostisch nachgewiesene Infektion bei nicht erfülltem klinischen Bild

Labordiagnostischer Nachweis bei bekanntem klinischen Bild, das die Kriterien für Typhus nicht erfüllt. Hierunter fallen auch asymptomatische Infektionen.

\section{E. Labordiagnostisch nachgewiesene Infektion bei unbekanntem klinischen Bild}

Labordiagnostischer Nachweis bei fehlenden Angaben zum klinischen Bild (nicht ermittelbar oder nicht erhoben).

\section{Referenzdefinition}

In Veröffentlichungen des Robert Koch-Instituts, die nicht nach Falldefinitionskategorien differenzieren (z.B. wöchentliche „Aktuelle Statistik meldepflichtiger Infektionskrankheiten“ im Epidemiologischen Bulletin), werden nur Erkrankungen der Kategorien $\mathbf{B}$ und $\mathbf{C}$ gezählt.

\section{Gesetzliche Grundlage}

\section{Meldepflicht}

Dem Gesundheitsamt werden gemäß \ 6 Abs. I Nr. I Buchst. n IfSG der Krankheitsverdacht, die Erkrankung sowie der Tod an Typhus abdominalis, sowie gemäß $\int 7$ Abs. I Nr. 4 O IfSG alle direkten Nachweise von Salmonella Typhi namentlich gemeldet. Darüber hinaus stellt das Gesundheitsamt gemäß $\int 25$ Abs. I IfSG ggf. eigene Ermittlungen an.

\section{Übermittlung}

Das Gesundheitsamt übermittelt gemäß \II Abs. I IfSG an die zuständige Landesbehörde nur Erkrankungs- oder Todesfälle und Erregernachweise, die der Falldefinition gemäß \4 Abs. 2 Nr. 2 Buchst. a IfSG entsprechen. 


\section{Salmonella spp., außer S. Typhi oder S. Paratyphi (Salmonellose)}

ICDıо: Ao2.- Sonstige Salmonelleninfektionen, inkl.: Infektion oder Lebensmittelvergiftung durch Salmonellen außer durch Salmonella Typhi und Salmonella Paratyphi,

Ao2.o Salmonellenenteritis (Enteritis infectiosa durch Salmonellen),

Ao2.I Salmonellensepsis,

A02.2 Lokalisierte Salmonelleninfektionen (Arthritis, Meningitis, Osteomyelitis, Pneumonie, tubulointerstitielle Nierenkrankheit durch Salmonellen),

Ao2.8 Sonstige näher bezeichnete Salmonelleninfektionen,

A02.9 Salmonelleninfektion, nicht näher bezeichnet

\section{Ausschlusskriterien}

- Infektion mit Salmonella Typhi oder Salmonella Paratyphi (außer enteritischem Pathovar von $S$. Paratyphi B; früher $S$. Java).

\section{Klinisches Bild}

Klinisches Bild einer akuten Salmonellose, definiert als mindestens eines der vier folgenden Kriterien:

- Durchfall,

- krampfartige Bauchschmerzen,

- Erbrechen,

- $\rightarrow$ Fieber.

\section{Zusatzinformation}

Salmonellen können auch generalisierte (Sepsis) und lokalisierte Infektionen außerhalb des Darmtrakts (z.B. Arthritis, Endokarditis, Pyelonephritis) verursachen. Diese sollen - im Falle einer akuten Infektion ebenfalls übermittelt werden. Eine ebenfalls mögliche reaktive Arthritis ist nicht melde- und übermittlungspflichtig.

ICDio: Ao2.I Salmonellensepsis,

A02.2 Lokalisierte Salmonelleninfektionen (Arthritis, Meningitis, Osteomyelitis, Pneumonie, tubulointerstitielle Nierenkrankheit durch Salmonellen),

Ao2.8 Sonstige näher bezeichnete Salmonelleninfektionen

\section{Labordiagnostischer Nachweis}

Positiver Befund mit der folgenden Methode:

[direkter Erregernachweis:]

- Erregerisolierung (kulturell).

\section{Zusatzinformationen}

- Das Ergebnis der Bestimmung des Serovars und ggf. des Lysotyps sollte übermittelt werden.

- Zur Einordnung der früheren $S$. Java (jetzt enteritisches Pathovar von $S$. Paratyphi B) als Salmonellose siehe Falldefinition „Paratyphus“. 


\title{
Epidemiologische Bestätigung
}

Epidemiologische Bestätigung, definiert als mindestens einer der drei folgenden Nachweise unter Berücksichtigung der Inkubationszeit:

- Epidemiologischer Zusammenhang mit einer labordiagnostisch nachgewiesenen Infektion beim Menschen durch

- Mensch-zu-Mensch-Übertragung ODER

- gemeinsame Expositionsquelle (z.B. $>$ Tierkontakt, $>$ Lebensmittel).

- Verzehr eines Lebensmittels (inkl. Trinkwasser), in dessen Resten Salmonella spp. labordiagnostisch nachgewiesen wurde.

- $>$ Kontakt mit einem labordiagnostisch nachgewiesen infizierten Tier (z.B. Geflügel) oder seinen Ausscheidungen, oder Verzehr seiner Produkte (z.B. Eier).

Inkubationszeit ca. 6-72 Stunden.

\section{Über die zuständige Landesbehörde an das RKI zu übermittelnder Fall (unter Berücksichtigung der Ausschlusskriterien)}

\author{
A. Klinisch diagnostizierte Erkrankung \\ Entfällt.
}

\section{B. Klinisch-epidemiologisch bestätigte Erkrankung}

Klinisches Bild einer akuten Salmonellose, ohne labordiagnostischen Nachweis, aber mit epidemiologischer Bestätigung.

C. Klinisch-labordiagnostisch bestätigte Erkrankung

Klinisches Bild einer akuten Salmonellose und labordiagnostischer Nachweis.

D. Labordiagnostisch nachgewiesene Infektion bei nicht erfülltem klinischen Bild

Labordiagnostischer Nachweis bei bekanntem klinischen Bild, das die Kriterien für eine akute Salmonellose nicht erfüllt. Hierunter fallen auch asymptomatische Infektionen.

E. Labordiagnostisch nachgewiesene Infektion bei unbekanntem klinischen Bild

Labordiagnostischer Nachweis bei fehlenden Angaben zum klinischen Bild (nicht ermittelbar oder nicht erhoben).

\section{Referenzdefinition}

In Veröffentlichungen des Robert Koch-Instituts, die nicht nach Falldefinitionskategorien differenzieren (z.B. wöchentliche „Aktuelle Statistik meldepflichtiger Infektionskrankheiten“ im Epidemiologischen Bulletin), werden nur Erkrankungen der Kategorien $\mathbf{B}$ und $\mathbf{C}$ gezählt. 


\section{Gesetzliche Grundlage}

\section{Meldepflicht}

Dem Gesundheitsamt wird gemäß $\int 7$ Abs. I Nr. 4I IfSG der direkte oder indirekte Nachweis von sonstigen Salmonella Serovaren (d.h. außer $S$. Typhi oder $S$. Paratyphi), soweit er auf eine akute Infektion hinweist, namentlich gemeldet. Darüber hinaus stellt das Gesundheitsamt gemäß \25 Abs. I IfSG ggf. eigene Ermittlungen an.

\section{Weitergehende Meldepflicht}

Dem Gesundheitsamt wird gemäß \6 Abs. I Nr. 2 IfSG ggf. auch der Verdacht auf und die Erkrankung an einer akuten infektiösen Gastroenteritis ohne labordiagnostischen Nachweis und ohne epidemiologische Bestätigung gemeldet.

\section{Übermittlung}

Das Gesundheitsamt übermittelt gemäß 『 II Abs. I IfSG an die zuständige Landesbehörde nur Erkrankungs- oder Todesfälle und Erregernachweise, die der Falldefinition gemäß $₫ 4$ Abs. 2 Nr. 2 Buchst. a IfSG entsprechen. 


\section{Shigella spp. (Shigellose)}

ICDıo: Ao3.- Shigellose [Bakterielle Ruhr], Ao3.0 Shigellose durch Shigella dysenteriae (Shigellose durch Shigellen der Gruppe A [Shiga-Kruse-Ruhr]), Ao3.I Shigellose durch Shigella flexneri (Shigellose durch Shigellen der Gruppe B),

Ao3.2 Shigellose durch Shigella boydii (Shigellose durch Shigellen der Gruppe C),

Ao3.3 Shigellose durch Shigella sonnei (Shigellose durch Shigellen der Gruppe D),

Ao3.8 Sonstige Shigellosen,

Ao3.9 Shigellose, nicht näher bezeichnet (Bakterielle Ruhr [Bakterielle Dysenterie] o.n.A.)

\section{Ausschlusskriterien}

- Klinisches Bild eines HUS (siehe Falldefinition des enteropathischen HUS).

\section{Klinisches Bild}

Klinisches Bild einer akuten Shigellose, definiert als mindestens eines der vier folgenden Kriterien:

- Durchfall,

- krampfartige Bauchschmerzen,

- Erbrechen,

- Fieber.

\section{Labordiagnostischer Nachweis}

Positiver Befund mit der folgenden Methode:

[direkter Erregernachweis:]

- Erregerisolierung (kulturell) nur aus Stuhl.

\section{Zusatzinformation}

Das Ergebnis der Spezies-Bestimmung (S. sonnei, S. flexneri, S. boydii, S. dysenteriae) sollte übermittelt werden.

\section{Epidemiologische Bestätigung}

Epidemiologische Bestätigung, definiert als mindestens einer der beiden folgenden Nachweise unter Berücksichtigung der Inkubationszeit:

- Epidemiologischer Zusammenhang mit einer labordiagnostisch nachgewiesenen Infektion beim Menschen durch

- Mensch-zu-Mensch-Übertragung ODER

- gemeinsame Expositionsquelle (z.B. DLebensmittel).

- Verzehr eines Lebensmittels (inkl. Trinkwasser), in dessen Resten Shigella spp. labordiagnostisch nachgewiesen wurde.

Inkubationszeit ca. 12-96 Stunden. 


\title{
Über die zuständige Landesbehörde an das RKI zu übermittelnder Fall (unter Berücksichtigung der Ausschlusskriterien)
}

\author{
A. Klinisch diagnostizierte Erkrankung \\ Entfällt.
}

\section{B. Klinisch-epidemiologisch bestätigte Erkrankung}

Klinisches Bild einer akuten Shigellose, ohne labordiagnostischen Nachweis, aber mit epidemiologischer Bestätigung.

\section{Klinisch-labordiagnostisch bestätigte Erkrankung}

Klinisches Bild einer akuten Shigellose und labordiagnostischer Nachweis.

D. Labordiagnostisch nachgewiesene Infektion bei nicht erfülltem klinischen Bild

Labordiagnostischer Nachweis bei bekanntem klinischen Bild, das die Kriterien für eine akute Shigellose nicht erfüllt. Hierunter fallen auch asymptomatische Infektionen.

\section{E. Labordiagnostisch nachgewiesene Infektion bei unbekanntem klinischen Bild}

Labordiagnostischer Nachweis bei fehlenden Angaben zum klinischen Bild (nicht ermittelbar oder nicht erhoben).

\section{Referenzdefinition}

In Veröffentlichungen des Robert Koch-Instituts, die nicht nach Falldefinitionskategorien differenzieren (z.B. wöchentliche „Aktuelle Statistik meldepflichtiger Infektionskrankheiten“ im Epidemiologischen Bulletin), werden nur Erkrankungen der Kategorien B und C gezählt.

\section{Gesetzliche Grundlage}

\section{Meldepflicht}

Dem Gesundheitsamt wird gemäß $\ 7$ Abs. I Nr. 42 IfSG der direkte oder indirekte Nachweis von Shigella sp., soweit er auf eine akute Infektion hinweist, namentlich gemeldet. Darüber hinaus stellt das Gesundheitsamt gemäß $\llbracket 25$ Abs. I IfSG ggf. eigene Ermittlungen an.

\section{Weitergehende Meldepflicht}

Dem Gesundheitsamt wird gemäß \6 Abs. I Nr. 2 IfSG ggf. auch der Verdacht auf und die Erkrankung an einer akuten infektiösen Gastroenteritis ohne labordiagnostischen Nachweis und ohne epidemiologische Bestätigung gemeldet.

\section{Übermittlung}

Das Gesundheitsamt übermittelt gemäß 』II Abs. I IfSG an die zuständige Landesbehörde nur Erkrankungs- oder Todesfälle und Erregernachweise, die der Falldefinition gemäß $\int 4$ Abs. 2 Nr. 2 Buchst. a IfSG entsprechen. 


\section{Trichinella spiralis (Trichinellose)}

syn. Trichinose

ICDıo: B75 Trichinellose (Infektion durch Trichinella-Arten, Trichinose)

\section{Klinisches Bild}

Klinisches Bild einer akuten Trichinellose, definiert als mindestens zwei der fünf folgenden Kriterien:

- Eosinophilie,

- Durchfall,

- Fieber,

- Muskelschmerzen,

- periorbitales Ödem (Schwellung um die Augenhöhle).

\section{Labordiagnostischer Nachweis}

Positiver Befund mit mindestens einer der beiden folgenden Methoden:

[direkter Erregernachweis:]

- Mikroskopischer Nachweis von Trichinella-Larven nur in einer Muskelbiopsie,

[indirekter (serologischer) Nachweis:]

- IgM- ODER IgG-Antikörpernachweis ( deutliche Änderung zwischen zwei Proben oDER einmaliger -deutlich erhöhter Wert, z.B. ELISA, IFT).

\section{Epidemiologische Bestätigung}

Epidemiologische Bestätigung, definiert als mindestens einer der beiden folgenden Nachweise unter Berücksichtigung der Inkubationszeit:

- Epidemiologischer Zusammenhang mit einer labordiagnostisch nachgewiesenen Infektion beim Menschen durch

- gemeinsame Expositionsquelle (z.B. Verzehr potentiell kontaminierter Lebensmittel).

- Verzehr eines Lebensmittels, in dessen Resten Trichinella spiralis labordiagnostisch nachgewiesen wurde.

Inkubationszeit ca. 5-45 Tage. 


\section{Über die zuständige Landesbehörde an das RKI zu übermittelnder Fall}

\section{A. Klinisch diagnostizierte Erkrankung}

Entfällt.

\section{B. Klinisch-epidemiologisch bestätigte Erkrankung}

Klinisches Bild einer akuten Trichinellose, ohne labordiagnostischen Nachweis, aber mit epidemiologischer Bestätigung.

\section{Klinisch-labordiagnostisch bestätigte Erkrankung}

Klinisches Bild einer akuten Trichinellose und labordiagnostischer Nachweis.

D. Labordiagnostisch nachgewiesene Infektion bei nicht erfülltem klinischen Bild

Labordiagnostischer Nachweis bei bekanntem klinischen Bild, das die Kriterien für eine akute Trichinellose nicht erfüllt. Hierunter fallen auch asymptomatische Infektionen.

\section{E. Labordiagnostisch nachgewiesene Infektion bei unbekanntem klinischen Bild}

Labordiagnostischer Nachweis bei fehlenden Angaben zum klinischen Bild (nicht ermittelbar oder nicht erhoben).

\section{Referenzdefinition}

In Veröffentlichungen des Robert Koch-Instituts, die nicht nach Falldefinitionskategorien differenzieren (z.B. wöchentliche „Aktuelle Statistik meldepflichtiger Infektionskrankheiten“ im Epidemiologischen Bulletin), werden nur Erkrankungen der Kategorien $\mathbf{B}$ und $\mathbf{C}$ gezählt.

\section{Gesetzliche Grundlage}

\section{Meldepflicht}

Dem Gesundheitsamt wird gemäß $\ 7$ Abs. I Nr. 43 IfSG der direkte oder indirekte Nachweis von Trichinella spiralis, soweit er auf eine akute Infektion hinweist, namentlich gemeldet. Darüber hinaus stellt das Gesundheitsamt gemäß \25 Abs. I IfSG ggf. eigene Ermittlungen an.

\section{Weitergehende Meldepflicht}

Dem Gesundheitsamt wird gemäß \6 Abs. I Nr. 2 IfSG ggf. auch der Verdacht auf und die Erkrankung an einer akuten infektiösen Gastroenteritis ohne labordiagnostischen Nachweis und ohne epidemiologische Bestätigung gemeldet.

\section{Übermittlung}

Das Gesundheitsamt übermittelt gemäß 』II Abs. I IfSG an die zuständige Landesbehörde nur Erkrankungs- oder Todesfälle und Erregernachweise, die der Falldefinition gemäß $\ 4$ Abs. 2 Nr. 2 Buchst. a IfSG entsprechen. 


\section{Vibrio cholerae (Cholera)}

ICDio: Aoo.- Cholera,

Aoo.o Cholera durch Vibrio cholerae O:I, Biovar cholerae (Klassische Cholera),

Aoo.I Cholera durch Vibrio cholerae O:I, Biovar El Tor (El-Tor-Cholera),

Aoo.9 Cholera, nicht näher bezeichnet

\section{Klinisches Bild}

Klinisches Bild einer Cholera, definiert als mindestens eines der beiden folgenden Kriterien:

- Durchfall,

- Erbrechen.

\section{Zusatzinformation}

Bei impfpräventablen Krankheiten sollten stets Angaben zur Impfanamnese (Anzahl der vorangegangenen Impfungen, Art und Datum der letzten Impfung) erhoben (z.B. Impfbuchkontrolle) und übermittelt werden.

\section{Labordiagnostischer Nachweis}

Positiver Befund bei allen drei folgenden Untersuchungsschritten:

[direkter Erregernachweis:]

- Erregerisolierung (kulturell) UND

- Nachweis des OI- oder OI39-Antigens (z.B. Objektträgeragglutination) nur im Isolat UND

[Toxinnachweis:]

- Nachweis des Cholera-Enterotoxins (z.B. ELISA) bzw. Nukleinsäure-Nachweis (z.B. PCR) des Cholera-Enterotoxin-Gens nur im Isolat.

\section{Zusatzinformation}

Die Bewertung von labordiagnostischen Nachweisen setzt die Kenntnis eines eventuellen zeitlichen Zusammenhangs mit einer Cholera-Lebendimpfung voraus.

\section{Epidemiologische Bestätigung}

Epidemiologische Bestätigung, definiert als mindestens einer der drei folgenden Nachweise unter Berücksichtigung der Inkubationszeit:

- Epidemiologischer Zusammenhang mit einer labordiagnostisch nachgewiesenen Infektion beim Menschen durch

- Mensch-zu-Mensch-Übertragung ODER

- gemeinsame Expositionsquelle (z.B. \Badegewässer, $>$ Lebensmittel).

- Baden in einem labordiagnostisch nachgewiesen kontaminierten Gewässer.

- Verzehr eines Lebensmittels (inkl. Trinkwasser), in dessen Resten $V$. cholerae labordiagnostisch nachgewiesen wurde.

Inkubationszeit wenige Stunden bis ca. 5 Tage. 


\section{Über die zuständige Landesbehörde an das RKI zu übermittelnder Fall}

\section{A. Klinisch diagnostizierte Erkrankung}

Entfällt.

\section{B. Klinisch-epidemiologisch bestätigte Erkrankung}

Klinisches Bild einer Cholera, ohne labordiagnostischen Nachweis, aber mit epidemiologischer Bestätigung.

\section{Klinisch-labordiagnostisch bestätigte Erkrankung}

Klinisches Bild einer Cholera und labordiagnostischer Nachweis.

D. Labordiagnostisch nachgewiesene Infektion bei nicht erfülltem klinischen Bild

Labordiagnostischer Nachweis bei bekanntem klinischen Bild, das die Kriterien für Cholera nicht erfüllt. Hierunter fallen auch asymptomatische Infektionen.

\section{E. Labordiagnostisch nachgewiesene Infektion bei unbekanntem klinischen Bild}

Labordiagnostischer Nachweis bei fehlenden Angaben zum klinischen Bild (nicht ermittelbar oder nicht erhoben).

\section{Referenzdefinition}

In Veröffentlichungen des Robert Koch-Instituts, die nicht nach Falldefinitionskategorien differenzieren (z.B. wöchentliche „Aktuelle Statistik meldepflichtiger Infektionskrankheiten“ im Epidemiologischen Bulletin), werden nur Erkrankungen der Kategorien $\mathbf{B}$ und $\mathbf{C}$ gezählt.

\section{Gesetzliche Grundlage}

\section{Meldepflicht}

Dem Gesundheitsamt wird gemäß \6 Abs. I Nr. I Buchst. b IfSG der Krankheitsverdacht, die Erkrankung sowie der Tod an Cholera, sowie gemäß $\ 7$ Abs. I Nr. 44 IfSG der direkte oder indirekte Nachweis von Vibrio cholerae OI und Or39, soweit er auf eine akute Infektion hinweist, namentlich gemeldet. Darüber hinaus stellt das Gesundheitsamt gemäß 『25 Abs. I IfSG ggf. eigene Ermittlungen an.

\section{Übermittlung}

Das Gesundheitsamt übermittelt gemäß 』II Abs. I IfSG an die zuständige Landesbehörde nur Erkrankungs- oder Todesfälle und Erregernachweise, die der Falldefinition gemäß \4 Abs. 2 Nr. 2 Buchst. a IfSG entsprechen.

Zusätzlich ist gemäß \I2 Abs. I IfSG das Auftreten von Cholera vom Gesundheitsamt unverzüglich über die zuständige oberste Landesgesundheitsbehörde und von dieser unverzüglich dem RKI zu übermitteln. Der Begriff 'Auftreten' schließt neben der Infektion/Erkrankung und dem Tod auch Verdachtsfälle ohne labordiagnostischen Nachweis und ohne epidemiologische Bestätigung ein. 


\section{Yersinia enterocolitica, darmpathogen (Yersiniose)}

ICDıo: Ao4.6 Enteritis durch Yersinia enterocolitica

\section{Klinisches Bild}

Klinisches Bild einer akuten Yersiniose, definiert als mindestens eines der fünf folgenden Kriterien:

- Durchfall,

- krampfartige Bauchschmerzen (Pseudoappendizitis),

- Tenesmen (schmerzhafter Stuhldrang),

- Erbrechen,

- Fieber.

\section{Zusatzinformation}

In der Folge kommt es oft zu extraintestinalen Reaktionen (z.B. Erythema nodosum, Arthritis), die aber keine Kriterien für eine akute Yersiniose sind. Diese sind nicht melde- und übermittlungspflichtig.

ICDıо: A28.2 Extraintestinale Yersiniose

\section{Labordiagnostischer Nachweis}

Positiver Befund mit der folgenden Methode:

[direkter Erregernachweis:]

- Erregerisolierung (kulturell).

\section{Zusatzinformationen}

- Das Ergebnis der Bestimmung humanpathogener Serotypen und Pathogenitätsfaktoren sollte übermittelt werden.

- Neben Y. enterocolitica gibt es auch andere darmpathogene Arten der Gattung Yersinia wie z.B. $Y$. pseudotuberculosis, die nach den gesetzlichen Bestimmungen nicht meldepflichtig sind.

\section{Epidemiologische Bestätigung}

Epidemiologische Bestätigung, definiert als mindestens einer der drei folgenden Nachweise unter Berücksichtigung der Inkubationszeit:

- Epidemiologischer Zusammenhang mit einer labordiagnostisch nachgewiesenen Infektion beim Menschen durch

- Mensch-zu-Mensch-Übertragung ODER

- gemeinsame Expositionsquelle (z.B. $\triangleright$ Tierkontakt, $\triangleright$ Lebensmittel).

- Kontakt mit einem labordiagnostisch nachgewiesen infizierten Tier oder seinen Ausscheidungen.

- Verzehr eines Lebensmittels (inkl. Trinkwasser), in dessen Resten $Y$. enterocolitica labordiagnostisch nachgewiesen wurde.

Inkubationszeit ca. 3-Io Tage. 


\section{Über die zuständige Landesbehörde an das RKI zu übermittelnder Fall}

\section{A. Klinisch diagnostizierte Erkrankung}

Entfällt.

\section{B. Klinisch-epidemiologisch bestätigte Erkrankung}

Klinisches Bild einer akuten Yersiniose, ohne labordiagnostischen Nachweis, aber mit epidemiologischer Bestätigung.

\section{Klinisch-labordiagnostisch bestätigte Erkrankung}

Klinisches Bild einer akuten Yersiniose und labordiagnostischer Nachweis.

D. Labordiagnostisch nachgewiesene Infektion bei nicht erfülltem klinischen Bild

Labordiagnostischer Nachweis bei bekanntem klinischen Bild, das die Kriterien für eine akute Yersiniose nicht erfüllt. Hierunter fallen auch asymptomatische Infektionen.

\section{E. Labordiagnostisch nachgewiesene Infektion bei unbekanntem klinischen Bild}

Labordiagnostischer Nachweis bei fehlenden Angaben zum klinischen Bild (nicht ermittelbar oder nicht erhoben).

\section{Referenzdefinition}

In Veröffentlichungen des Robert Koch-Instituts, die nicht nach Falldefinitionskategorien differenzieren (z.B. wöchentliche „Aktuelle Statistik meldepflichtiger Infektionskrankheiten“ im Epidemiologischen Bulletin), werden nur Erkrankungen der Kategorien $\mathbf{B}$ und $\mathbf{C}$ gezählt.

\section{Gesetzliche Grundlage}

\section{Meldepflicht}

Dem Gesundheitsamt wird gemäß $\ 7$ Abs. I Nr. 45 IfSG der direkte oder indirekte Nachweis von darmpathogener Yersinia enterocolitica, soweit er auf eine akute Infektion hinweist, namentlich gemeldet. Darüber hinaus stellt das Gesundheitsamt gemäß 『25 Abs. I IfSG ggf. eigene Ermittlungen an.

\section{Weitergehende Meldepflicht}

Dem Gesundheitsamt wird gemäß \6 Abs. I Nr. 2 IfSG ggf. auch der Verdacht auf und die Erkrankung an einer akuten infektiösen Gastroenteritis ohne labordiagnostischen Nachweis und ohne epidemiologische Bestätigung gemeldet.

\section{Übermittlung}

Das Gesundheitsamt übermittelt gemäß 『 II Abs. I IfSG an die zuständige Landesbehörde nur Erkrankungs- oder Todesfälle und Erregernachweise, die der Falldefinition gemäß $\ 4$ Abs. 2 Nr. 2 Buchst. a IfSG entsprechen. 


\section{Yersinia pestis (Pest)}

ICDıо: A2o.- Pest, inkl.: Infektion durch Yersinia pestis,

A20.0 Bubonenpest,

A20.I Hautpest,

A20.2 Lungenpest,

A20.3 Pestmeningitis,

A20.7 Pestsepsis,

A20.8 Sonstige Formen der Pest (abortive Pest, asymptomatische Pest, Pestis minor),

A20.9 Pest, nicht näher bezeichnet

\section{Klinisches Bild}

Klinisches Bild der Pest, definiert als mindestens eines der vier folgenden Kriterien:

- $\rightarrow$ Fieber,

- Lymphknotenschwellung,

- Rachenentzündung (Pharyngitis),

- Husten.

Das klinische Bild kann zusätzlich eine der vier folgenden Formen annehmen:

- Beulenpest,

ICDio: A20.0 Bubonenpest

- Lungenpest,

ICDio: A20.2 Lungenpest

- Pestsepsis,

ICDio: A20.7 Pestsepsis

- Pestmeningitis.

ICDio: A20.3 Pestmeningitis

\section{Labordiagnostischer Nachweis}

Positiver Befund mit mindestens einer der vier folgenden Methoden:

\section{[direkter Erregernachweis:]}

- Erregerisolierung (kulturell),

- Nukleinsäure-Nachweis (z.B. PCR) der Gene cafI (FI-Kapselantigen) oDER pla (Plasminaktivator),

- Nachweis des FI-Kapselantigens mittels Fluoreszenzmikroskopie,

[indirekter (serologischer) Nachweis:]

- \deutliche Änderung zwischen zwei Proben beim Anti-FI-IgG-Antikörpernachweis (z.B. ELISA). 


\title{
Epidemiologische Bestätigung
}

Epidemiologische Bestätigung, definiert als mindestens einer der beiden folgenden Nachweise unter Berücksichtigung der Inkubationszeit:

- Epidemiologischer Zusammenhang mit einer labordiagnostisch nachgewiesenen Infektion beim Menschen durch

- Mensch-zu-Mensch-Übertragung ODER

- gemeinsame Expositionsquelle (z.B. potentiell infizierte Tiere (z.B. Flöhe), Tätigkeit in einem Labor, in dem mit $Y$. pestis gearbeitet wurde).

- - Kontakt mit einem labordiagnostisch nachgewiesen infizierten Tier oder seinen Ausscheidungen. Inkubationszeit ca. I-7 Tage.

\section{Über die zuständige Landesbehörde an das RKI zu übermittelnder Fall}

\author{
A. Klinisch diagnostizierte Erkrankung \\ Entfällt.
}

B. Klinisch-epidemiologisch bestätigte Erkrankung

Klinisches Bild der Pest, ohne labordiagnostischen Nachweis, aber mit epidemiologischer Bestätigung.

C. Klinisch-labordiagnostisch bestätigte Erkrankung

Klinisches Bild der Pest und labordiagnostischer Nachweis.

D. Labordiagnostisch nachgewiesene Infektion bei nicht erfülltem klinischen Bild

Labordiagnostischer Nachweis bei bekanntem klinischen Bild, das die Kriterien für Pest nicht erfüllt. Hierunter fallen auch asymptomatische Infektionen.

\section{E. Labordiagnostisch nachgewiesene Infektion bei unbekanntem klinischen Bild}

Labordiagnostischer Nachweis bei fehlenden Angaben zum klinischen Bild (nicht ermittelbar oder nicht erhoben).

\section{Referenzdefinition}

In Veröffentlichungen des Robert Koch-Instituts, die nicht nach Falldefinitionskategorien differenzieren (z.B. wöchentliche „Aktuelle Statistik meldepflichtiger Infektionskrankheiten“ im Epidemiologischen Bulletin), werden nur Erkrankungen der Kategorien $\mathbf{B}$ und $\mathbf{C}$ gezählt.

\section{Gesetzliche Grundlage}

\section{Meldepflicht}

Dem Gesundheitsamt wird gemäß $₫ 6$ Abs. I Nr. I Buchst. 1 IfSG der Krankheitsverdacht, die Erkrankung sowie der Tod an Pest, sowie gemäß $\ 7$ Abs. I Nr. 46 IfSG der direkte oder indirekte Nachweis von Yersinia pestis, soweit er auf eine akute Infektion hinweist, namentlich gemeldet. Darüber hinaus stellt das Gesundheitsamt gemäß $\int 25$ Abs. I IfSG ggf. eigene Ermittlungen an.

\section{Übermittlung}

Das Gesundheitsamt übermittelt gemäß \II Abs. I IfSG an die zuständige Landesbehörde nur Erkrankungs- oder Todesfälle und Erregernachweise, die der Falldefinition gemäß $\mathbb{4} 4$ Abs. 2 Nr. 2 Buchst. a IfSG entsprechen.

Zusätzlich ist gemäß 』I2 Abs. I IfSG das Auftreten von Pest vom Gesundheitsamt unverzüglich an die zuständige oberste Landesgesundheitsbehörde und von dieser unverzüglich dem RKI zu übermitteln. Der Begriff 'Auftreten' schließt neben der Infektion/Erkrankung und dem Tod auch Verdachtsfälle ohne labordiagnostischen Nachweis und ohne epidemiologische Bestätigung ein. 


\section{$51 \quad$ Andere Erreger hämorrhagischer Fieber (virale hämorrhagische Fieber)}

ICDıо: A92.- Sonstige durch Moskitos [Stechmücken] übertragene Viruskrankheiten,

A92.0 Chikungunya-Viruskrankheit ((Hämorrhagisches) Chikungunya-Fieber),

A92.4 Rifttalfieber (Rift-Valley-Fieber),

A96.- Hämorrhagisches Fieber durch Arenaviren,

A96.0 Hämorrhagisches Fieber durch Junín-Viren (Argentinisches hämorrhagisches Fieber),

A96.I Hämorrhagisches Fieber durch Machupo-Viren (Bolivianisches hämorrhagisches Fieber)

A96.8 Sonstiges hämorrhagisches Fieber durch Arenaviren,

A96.9 Hämorrhagisches Fieber durch Arenaviren, nicht näher bezeichnet,

A98.0 Hämorrhagisches Krim-Kongo-Fieber (Zentralasiatisches hämorrhagisches Fieber),

A98.I Hämorrhagisches Omsk-Fieber,

A98.2 Kyasanur-Wald-Krankheit

A98.8 Sonstige näher bezeichnete hämorrhagische Viruskrankheiten,

A99 Nicht näher bezeichnete hämorrhagische Viruskrankheit

\section{Vorbemerkung}

Virale hämorrhagische Fieber können als akut fieberhaftes Krankheitsbild auch ohne Zeichen einer

-hämorrhagischen Verlaufsform auftreten. Der Anteil der Fälle mit hämorrhagischem Verlauf variiert je nach Erreger.

\section{Ausschlusskriterien}

- Nachweis eines spezifisch übermittlungspflichtigen Erregers eines hämorrhagischen Fiebers (Denguevirus, Ebolavirus, Gelbfiebervirus, Hantavirus, Lassavirus, Marburgvirus).

\section{Klinisches Bild}

Klinisches Bild eines akuten viralen hämorrhagischen Fiebers, definiert als mindestens eines der beiden folgenden Kriterien:

- Fieber,

- hämorrhagischer Verlauf.

\section{Labordiagnostischer Nachweis}

Positiver Befund mit mindestens einer der vier folgenden Methoden:

[direkter Erregernachweis eines Virus, das ein virales hämorrhagisches Fieber auslösen kann:]

- Virusisolierung,

- Nukleinsäure-Nachweis (z.B. PCR),

[indirekter (serologischer) Nachweis eines Virus, das ein virales hämorrhagisches Fieber auslösen kann:]

- IgM-Antikörpernachweis (z.B. IFT, ELISA),

- \deutliche Änderung zwischen zwei Proben beim IgG-Antikörpernachweis (z.B. IFT, ELISA).

\section{Epidemiologische Bestätigung}

Entfällt.

\section{Zusatzinformation}

Inkubationszeit ca. I-I2 Tage bei Krim-Kongo-Fieber, ca. 3-I2 Tage bei Rifttal-Fieber, ca. 7-I6 Tage bei südamerikanischen hämorrhagischen Fiebern, ca. 3-8 Tage bei OHF/KFD. 


\title{
Über die zuständige Landesbehörde an das RKI zu übermittelnder Fall (unter Berücksichtigung der Ausschlusskriterien)
}

\author{
A. Klinisch diagnostizierte Erkrankung \\ Entfällt.
}

B. Klinisch-epidemiologisch bestätigte Erkrankung

Entfällt.

C. Klinisch-labordiagnostisch bestätigte Erkrankung

Klinisches Bild eines akuten viralen hämorrhagischen Fiebers und labordiagnostischer Nachweis.

D. Labordiagnostisch nachgewiesene Infektion bei nicht erfülltem klinischen Bild

Labordiagnostischer Nachweis bei bekanntem klinischen Bild, das die Kriterien für ein akutes virales haemorrhagisches Fieber nicht erfüllt. Hierunter fallen auch asymptomatische Infektionen.

\section{E. Labordiagnostisch nachgewiesene Infektion bei unbekanntem klinischen Bild}

Labordiagnostischer Nachweis bei fehlenden Angaben zum klinischen Bild (nicht ermittelbar oder nicht erhoben).

\section{Referenzdefinition}

In Veröffentlichungen des Robert Koch-Instituts, die nicht nach Falldefinitionskategorien differenzieren (z.B. wöchentliche „Aktuelle Statistik meldepflichtiger Infektionskrankheiten“ im Epidemiologischen Bulletin), werden nur Erkrankungen der Kategorie C gezählt.

\section{Gesetzliche Grundlage}

\section{Meldepflicht}

Dem Gesundheitsamt wird gemäß \6 Abs. I Nr. I Buchst. g IfSG der Krankheitsverdacht, die Erkrankung sowie der Tod an viralem hämorrhagischen Fieber, sowie gemäß \7 Abs. I Nr. 47 IfSG der direkte oder indirekte Nachweis von anderen Erregern hämorrhagischer Fieber (d.h. außer den in $\ 7$ Abs. I IfSG namentlich benannten), soweit er auf eine akute Infektion hinweist, namentlich gemeldet. Darüber hinaus stellt das Gesundheitsamt gemäß

『25 Abs. I IfSG ggf. eigene Ermittlungen an.

\section{Übermittlung}

Das Gesundheitsamt übermittelt gemäß 『 II Abs. I IfSG an die zuständige Landesbehörde nur Erkrankungs- oder Todesfälle und Erregernachweise, die der Falldefinition gemäß $\int 4$ Abs. 2 Nr. 2 Buchst. a IfSG entsprechen.

Zusätzlich ist gemäß \I2 Abs. I IfSG das Auftreten von viralem hämorrhagischen Fieber vom Gesundheitsamt unverzüglich über die zuständige oberste Landesgesundheitsbehörde und von dieser unverzüglich dem RKI zu übermitteln. Der Begriff 'Auftreten' schließt neben der Infektion/Erkrankung und dem Tod auch Verdachtsfälle, definiert als fieberhafter hämorrhagischer Verlauf ohne labordiagnostischen Nachweis, ein. 


\section{Index}

A

Adenovirus I8

Adenovirus-Keratokonjunktivitis I8

Adenovirus-Konjunktivitis I8

anamnestische Angaben Io

Andes-Virus 64

Angina pseudomembranacea diphtherica 38

Anthrax 20

Arenaviren I34

ausführendes Labor II

Aussatz 98

Ausschlusskriterien Io

\section{B}

\section{Bacillus anthracis 20}

Badegewässer 7

Bakterielle Ruhr I24

Balkangrippe 40

Bang-Krankheit 24

BCG Ioo

Borrelia recurrentis 22

Botulismus 36

Brucella spp. 24

Brucellose 24

Bubonenpest I32

Buschgelbfieber 58

\section{C}

Campylobacter spp. 26

Campylobacter-Enteritis 26

Canicola-Fieber 88

Chikungunya-Viruskrankheit I34

Chlamydia psittaci 28

Chlamydia trachomatis 28

Chlamydophila pneumoniae 28

Chlamydophila psittaci 28

Cholera I28

CJK 30

Clostridium botulinum 36

Corynebacterium spp. 38

Coxiella burnetii 40

Creutzfeldt-Jakob-Krankheit 30

Cryptosporidium parvum 42

\section{D}

DAEC (diffus-adhärente E. colı) 50

Darmmilzbrand 20

Delta-Virus 72

Denguefieber 44

Dengue-Schock-Syndrom 44

Denguevirus 44

Diphtherie 38

direkter Nachweis II
Dobrava-Virus 64

Dschungelgelbfieber 58

Durchfall 5

\section{E}

E.-coli-Enteritis 50

EAggEC (enteroaggregative E. coli) 50

Ebolafieber 46

Ebolavirus 46

EHEC-Erkrankung 48

EIEC (enteroinvasive E. coll) 50

Elek-Test 38

EPEC (enteropathogene E. coll) 50 epidemiologische Bestätigung I2

Epidemische Nephropathie $6_{4}$

Erythema nodosum I30

Escherichia coli, enterohämorrhagisch 48

Escherichia coli, sonstige darmpathogene Stämme 50

ETEC (enterotoxische E. coll) 50

Evidenztypen Io

\section{$\mathbf{F}$}

Falldefinitionskategorien I3

fatale familiäre Insomnie 30

Fehlgeburt 7

Feindifferenzierung II

Feldfieber 88

Fieber 5

Fleckfieber II2

follikuläre Konjunktivitis I8

Francisella tularensis 52

Frühgeburt 7

Frühsommer-Meningoenzephalitis 56

FSME-Virus 56

\section{G}

Gelbfiebervirus 58

Gerstmann-Sträussler-ScheinkerSyndrom 30

Giardia lamblia 60

Giardiasis 60

Granulomatosis infantiseptica 90

Grippe 82

grippeähnliche Beschwerden 5

\section{$\mathrm{H}$}

Hadernkrankheit 20

Haemophilus influenzae 62

Hämolytisch-urämisches Syndrom 78

Hämorrhagie 5 hämorrhagische Verlaufsform 5

Hämorrhagisches Denguefieber 44

Hämorrhagisches Krim-Kongo-

Fieber I34

Hämorrhagisches Omsk-Fieber I34

Hantaan-Virus 64

Hantavirus 64

Hasenpest 52

Hautdiphtherie 38

Hautmilzbrand 20

Hautpest 132

HAV 66

HBV 68

HCV 70

HDV 72

Hepatitis-A-Virus 66

Hepatitis-B-Virus 68

Hepatitis-C-Virus 70

Hepatitis-D-Virus 72

Hepatitis-E-Virus 74

Herd I2

HEV 74

HFRS (Hämorrhagisches Fieber mit renalem Syndrom) 64

Hirschfliegenfieber 52

HPS (hantavirus pulmonary syndrome) 64

HUS 78

I

ICD Io Io

IfSG-Hotline I6

indirekter Nachweis II

Influenza 82

Influenzavirus 82

inkomplettes HUS 78

Inkubationszeit I2

Junín-Viren I34

\section{K}

Keratoconjunctivitis epidemica 18 Keratokonjunktivitis I8

Kinderlähmung Io8

klinisch diagnostizierte Erkrankung I3

klinisch-epidemiologisch bestätigte

Erkrankung I3

klinisches Bild Io

klinisch-labordiagnostisch bestätigte

Erkrankung I4

komplettes HUS 78

Konjunktivitis 18

Kontakt 6

Krim-Kongo-Fieber I34 
Kryptosporidiose 42

Kyasanur-Wald-Krankheit I34

$\mathbf{L}$

labordiagnostisch nachgewiesene Infektion I4, I5

labordiagnostischer Nachweis II

Lambliasis 60

Lassafieber 84

Lassavirus 84

Läusefleckfieber II2

Läuserückfallfieber 22

Lebendgeburt 7

Lebensmittel 7

Legionärskrankheit 86

Legionella spp. 86

Legionellose 86

Lepra 98

Leptospira interrogans 88

Leptospirose 88

Liquor/Serum-Index 56

Listeria monocytogenes 90

Listeriose 90

Lungenentzündung 6

Lungenmilzbrand 20

Lungenpest 132

Lyssa-Virus IIo

\section{M}

M.-tuberculosis-Komplex Ioo

Machupo-Viren I34

Maltafieber 24

Marburgfieber 94

Marburgvirus 94

Masern 96

Masernvirus 96

Meningokokken-Erkrankung IO2

Miliartuberkulose Ioo

Milzbrand 20

Mitteleuropäische Enzephalitis 56

Mittelmeerfieber 24

MOMPI-Gen 28

Morbilli 96

Morbus Bang 24

Morbus Weil 88

Moschkowitz 78

Mycobacterium leprae 98

Mycobacterium tuberculosis ioo

\section{N}

Nachweismethode II

Nasenrachendiphtherie 38

Neisseria meningitidis IO2

Nephropathia epidemica 64

Neugeborenenlisteriose 90

Nierenfunktionsstörung 6

Nierenversagen 6

Norovirus 106

Norwalk-Virus Io6

Nukleinsäure-Nachweis 6
O

Omsk-Fieber I34

Ornithose 28

\section{P}

Papageienkrankheit 28

Paratyphus II6

PCR 6

Pest $\mathrm{I} 32$

Poliomyelitis I08

Poliovirus 108

Psittakose 28

Pustula maligna 20

Puumala-Virus 64

\section{Q}

Q-Fieber 40

Query-Fieber 40

\section{R}

Rabiesvirus IIO

Rachendiphtherie 38

Referenzdefinition I5

Reiseanamnese I2

Rickettsia burnetii 40

Rickettsia prowazekii II2

Rifttalfieber I34

Rotavirus II4

Rückfallfieber 22

\section{S}

Salmonella Java II6, I20

Salmonella Paratyphi іг6

Salmonella spp. I20

Salmonella Typhi iı8

Salmonellose I20

Säuglingsbotulismus 36

Schlammfieber 88

Schweinebrucellose 24

Schwimmbadkonjunktivitis I8

Sensitivität Io

Seoul-Virus 64

septisches Krankheitsbild 6

Sequenzierung 6

Shiga-Kruse-Ruhr I24

Shigella spp. I24

Shigellose I24

Silvatisches Gelbfieber 58

Sin-Nombre-Virus 64

Spezifität Io

Spinale Kinderlähmung Io8

STEC-Erkrankung 48

steriles Material 6

Stuhlanreicherungskultur 50

Subakute spongioforme

Enzephalopathie 30

Sumpffieber 88

\section{T}

Thrombotisch-thrombozytopenische Purpura 78

Thrombozytopenie 5, 78

Tierkontakt 7

Tollwut IIo

Tonsillendiphtherie 38

Totgeburt 7

Tourniquet-Test 5

Trichinella spiralis 126

Trichinellose 126

Trichinose 126

TTP 78

Tuberkulose го०

Tularämie 52

Typhus abdominalis II8

Typhus exanthematicus II2

\section{U}

Übermittlungskategorie Io

Übertragungsweg I2

Untersuchungsmaterial II

\section{V}

Variante CJK 33

vCJK 33

Vibrio cholerae I28

virales hämorrhagisches Fieber 44 , $46,58,64,84,94$, I 34

Virushepatitis A 66

Virushepatitis B 68

Virushepatitis C 70

Virushepatitis D 72

Virushepatitis E 74

Virushepatitis Non A - E 76

\section{W}

Waterhouse-Friderichsen-Syndrom IO2

Weil-Krankheit 88

Wundbotulismus 36

\section{$Y$}

Yersinia enterocolitica 130

Yersinia pestis $\mathrm{I} 32$

Yersiniose 130

\section{Z}

Zentraleuropäische FrühsommerMeningoenzephalitis $5^{6}$ 